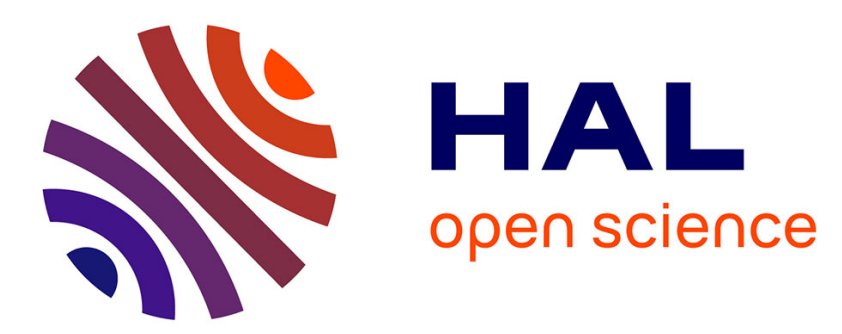

\title{
Geochemical Constraints on the Origin of the Moon and Preservation of Ancient Terrestrial Heterogeneities
}

\author{
Simon Lock, Katherine Bermingham, Rita Parai, Maud Boyet
}

\section{To cite this version:}

Simon Lock, Katherine Bermingham, Rita Parai, Maud Boyet. Geochemical Constraints on the Origin of the Moon and Preservation of Ancient Terrestrial Heterogeneities. Space Science Reviews, 2020, 216 (6), 10.1007/s11214-020-00729-z . hal-02955588

\author{
HAL Id: hal-02955588 \\ https://hal.uca.fr/hal-02955588
}

Submitted on 12 Nov 2020

HAL is a multi-disciplinary open access archive for the deposit and dissemination of scientific research documents, whether they are published or not. The documents may come from teaching and research institutions in France or abroad, or from public or private research centers.
L'archive ouverte pluridisciplinaire HAL, est destinée au dépôt et à la diffusion de documents scientifiques de niveau recherche, publiés ou non, émanant des établissements d'enseignement et de recherche français ou étrangers, des laboratoires publics ou privés. 


\title{
Geochemical constraints on the origin of the Moon and preservation of ancient terrestrial heterogeneities
}

\author{
Simon J. Lock ${ }^{\mathrm{a}, *}$, Katherine R. Bermingham ${ }^{\mathrm{b}, \mathrm{c}}$, Rita Parai $^{\mathrm{d}}$, Maud Boyet ${ }^{\mathrm{e}}$ \\ ${ }^{a}$ Division of Geological and Planetary Sciences, California Institute of Technology, Pasadena, CA 91125, USA. \\ ${ }^{b}$ Department of Earth and Planetary Sciences, Rutgers University, Piscataway, NJ 08854, USA \\ ${ }^{c}$ Department of Geology, University of Maryland,College Park, MD 20742, USA. \\ ${ }^{d}$ Department of Earth and Planetary Sciences, Washington University in St. Louis, Saint Louis, MO 63130, USA. \\ ${ }^{e}$ Université Clermont Auvergne, CNRS, IRD, OPGC, Laboratoire Magmas et Volcans, F-63000 Clermont-Ferrand, France.
}

\begin{abstract}
The Moon forming giant impact marks the end of the main stage of Earth's accretion and sets the stage for the subsequent evolution of our planet. The giant impact theory has been the accepted model of lunar origin for 40 years, but the parameters of the impact and the mechanisms that led to the formation of the Moon are still hotly debated. Here we review the principal geochemical observations that constrain the timing and parameters of the impact, the mechanisms of lunar formation, and the contemporaneous evolution of Earth. We discuss how chemical and isotopic studies on lunar, terrestrial and meteorite samples relate to physical models and how they can be used to differentiate between lunar origin models. In particular, we argue that the efficiency of mixing during the collision is a key test of giant impact models. A high degree of intra-impact mixing is required to explain the isotopic similarity between the Earth and Moon but, at the same time, the impact did not homogenize the whole terrestrial mantle, as isotopic signatures of pre-impact heterogeneity are preserved. We summarize the outlook for the field and highlight the key advances in both measurements and modeling needed to advance our understanding of lunar origin.
\end{abstract}

Key words: Earth, Moon, Impacts, Formation, Geochemistry, Isotopes

\section{Introduction}

The terminal event in the main stage of Earth's accretion is thought to be the Moon-forming giant impact (Hartmann and Davis, 1975; Cameron and Ward, 1976). A planetary body (often referred to as Theia) collided with the proto-Earth, injecting material into orbit from which the Moon formed. The giant impact melted and vaporized much of Earth and set the initial conditions for the subsequent evolution of our planet. The giant impact theory has been the accepted model of lunar origin for 40 years, yet the parameters of the impact and the mechanisms that led to the formation of the Moon are intensely debated (see reviews by Asphaug, 2014; Barr, 2016).

Lunar origin is one of the best characterized problems in terrestrial planetary formation as we have comparatively large quantities of samples from each body available for geochemical analysis, and a wealth of geophysical measurements and orbital observations. It is partly for these reasons, however, that the topic of lunar origin remains so controversial. Models that match the first order physical observations (such as the mass of the Moon and Earth) are potentially excluded by other lines of evidence from geochemical studies. Geochemical constraints and geodynam-

\footnotetext{
*Corresponding author: slock@caltech.edu
}

ical models must go hand in hand in the effort to elucidate the details of lunar formation.

Here, we provide an overview of the various permutations of the giant impact model and how the Moon is formed in each case. We then review the constraints on lunar origin and how they bear on the different models, focusing on evidence from geochemical measurements of lunar and terrestrial samples.

\section{Giant impact models for lunar origin}

Early models of the Moon-forming giant impacts were focused on reproducing physical constraints, e.g., the mass of the Moon. Cameron and Ward (1976) proposed that the Moon-forming giant impact set the angular momentum of the Earth-Moon system, which placed a very strong constraint on the parameters of the impact (e.g., the masses of the colliding bodies, impact velocity, impact angle). Numerical simulations have found that a narrow range of impacts, grazing impacts of roughly Mars-mass impactors near the mutual escape velocity ${ }^{1}$, can possibly inject suf-

\footnotetext{
${ }^{1}$ The mutual escape velocity is the minimum velocity required to overcome gravity and separate two bodies that are initially touching. Alternatively, the mutual escape velocity is the impact velocity of two bodies drawn together by gravity from infinite distance given zero initial relative velocity.
} 
ficient mass and angular momentum into orbit to form an iron-poor (see Section 4), lunar-mass Moon (Canup and Asphaug, 2001; Canup, 2004, 2008). The energy of the impact melts or vaporizes much of the colliding bodies and leaves the proto-Earth spinning with a roughly 5 hour period. This so-called canonical scenario has become the de-facto working model for lunar formation and has been the basis of our understanding of the outcome of giant impacts in the solar system.

A canonical Moon-forming impact injects material into orbit, forming a multiphase (i.e., a mixture of liquid and vapor) disk around the proto-Earth (Figure 1a). Condensed material (i.e., not vapor) that is injected beyond the Roche limit (the point beyond which large objects can survive without being torn apart by tidal forces ${ }^{2}$ ) accretes to form one or two large satellites on a timescale of order weeks (Ida et al., 1997; Kokubo et al., 2000). Further mass is then added to the proto-Moon over tens to hundreds of years by viscous spreading of material from the Roche-interior disk (Thompson and Stevenson, 1988; Salmon and Canup, 2012, 2014; Charnoz and Michaut, 2015; Ward, 2017). The numerical techniques used for giant impact simulations cannot resolve the complex physics and chemistry, or long timescales, of disk evolution (years to hundreds of years). Separate models are required to understand the formation of the Moon and to build scaling laws that can predict the mass of the satellite that would be formed by a disk of a given mass and angular momentum as determined by giant impact simulations. The complex structure and dynamics of the multiscale, multiphase, and multicomponent Roche-interior disk are difficult to model numerically and the processes that could drive viscous spreading, and their efficiency, are poorly understood. Furthermore, how the disk interacts with the proto-Earth has not been fully explored (Pahlevan and Stevenson, 2007; Desch and Taylor, 2013). Understanding the evolution of the Roche-interior disk is vital for predicting the efficiency of lunar accretion and the geochemistry of the Moon. For example, using scaling laws from lunar accretion models that attempt to include some of the complexities of the Roche-interior disk (Salmon and Canup, 2012, 2014), very few of the published canonical Moon-forming impacts would produce a lunar-mass Moon (see discussion in Lock et al., 2018). Determining how the Moon forms following an impact remains a major stumbling block for lunar origin studies.

Although the canonical impact has been the dominant focus for work on lunar formation, other potential impacts have been explored. Reufer et al. (2012) showed that a hit-and-run collision could leave the largest remnant with a circumplanetary disk. It has also been proposed that the Moon was formed by not one but multiple giant impacts, with each impact delivering a fraction of the lunar mass

\footnotetext{
${ }^{2}$ For the case of the post-impact Earth, the Roche limit is at a distance of about $2.9 R_{\text {Earth }}$ from the center of the body, where $R_{\text {Earth }}$ is the radius of the present-day Earth.
}

(Rufu et al., 2017). A modification of the canonical impact where the pre-impact proto-Earth is hot enough to have a molten upper mantle has also been suggested (Hosono et al., 2019). In each of these cases, it is assumed that the post-impact evolution is similar to that in the canonical case, with varying silicate-vapor fractions.

Recently, various mechanisms have been discovered that could transfer angular momentum from the Earth-Moon system to the Earth-Sun system during the early period of lunar tidal evolution (Ćuk and Stewart, 2012; Wisdom and Tian, 2015; Ćuk et al., 2016; Tian et al., 2017). There is significant uncertainty as to the amount of angular momentum that could have been transferred, in part due to the difficulties in calculating the evolving tidal parameters of the early Earth and Moon. Current models, however, suggest that the Earth-Moon system could have started with as much as twice its present-day angular momentum. The possibility that the angular momentum of the EarthMoon system has evolved since lunar formation has dramatically expanded the range of potential Moon-forming giant impacts and a number of different impact parameters have been explored (Canup, 2012; Ćuk and Stewart, 2012; Lock et al., 2018). It is expected that most planets will acquire significant angular momentum during accretion as a result of single or multiple giant impacts (Agnor et al., 1999; Kokubo and Genda, 2010; Rufu et al., 2017). In fact, studies that have attempted to track the angular momentum of terrestrial planets indicate that terminal impacts with angular momenta as low as the canonical impact would be rare (Kokubo and Genda, 2010). It should be noted that these models have neglected several significant processes (e.g., the formation and tidal evolution of moons) that could affect the angular momentum of planets during accretion and models that include these effects are required to confirm the angular momentum distribution of proto-planets. The canonical Moon-forming impact is also a relatively low energy impact and the range of potential impact parameters (e.g., the masses of the colliding bodies, impact velocity, impact angle) is very narrow. There is a much wider array of giant impacts that occur during accretion and the vast majority of accretionary impacts between embryo-sized bodies are of higher specific energy than the canonical scenario (see e.g., Quintana et al., 2016), resulting in hotter and more vaporized post-impact bodies (Lock and Stewart, 2017). Therefore, given the expected range of giant impacts that occur during accretion and the potential for the angular momentum of the Earth-Moon system to have been reduced during lunar tidal evolution, it is reasonable to expect that the terminal giant impact for Earth would be of higher angular momentum and energy than the canonical impact.

High-energy, high-angular momentum impacts provide new environments for lunar formation. In particular, it has been found that a range of such impacts produce a new class of planetary bodies called synestias (Lock and Stewart, 2017). Synestias are bodies that exceed the corotation limit (CoRoL). As the angular momentum of a corotating 


\section{a. Canonical lunar disk}

1. The substantially vaporized and extended post-impact Earth has no surface, smoothly transitioning from a liquid lower mantle to a vapor atmosphere

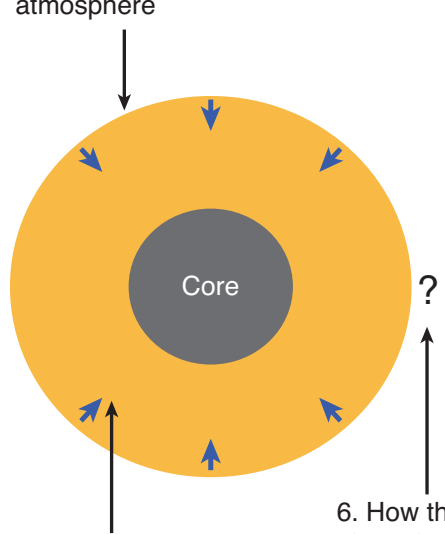

5. Droplets that fall into the planet are vaporized planet interact is uncertain

\section{Radiative cooling at the} photosphere causes the vapor to condense, driving a rain of silicate droplets

4. Condensates settle to the midplane, potentially forming a liquid layer or froth
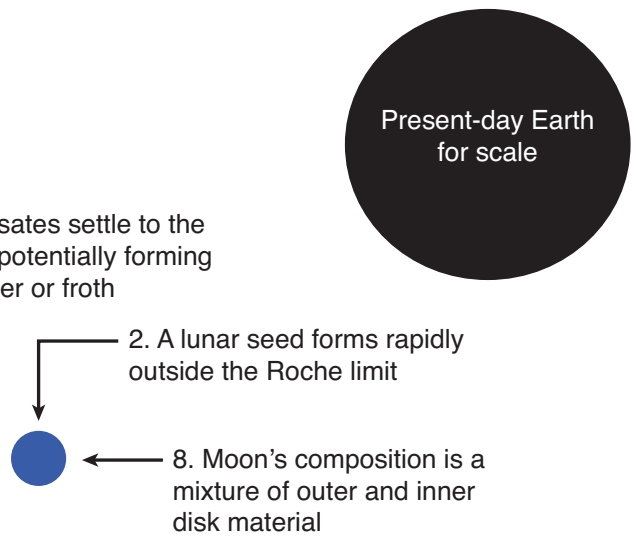

7b. Moonlets form at the Roche limit and are rapidly accreted by the lunar seed

\section{b. Terrestrial synestia} pushes mass beyond the Roche limit

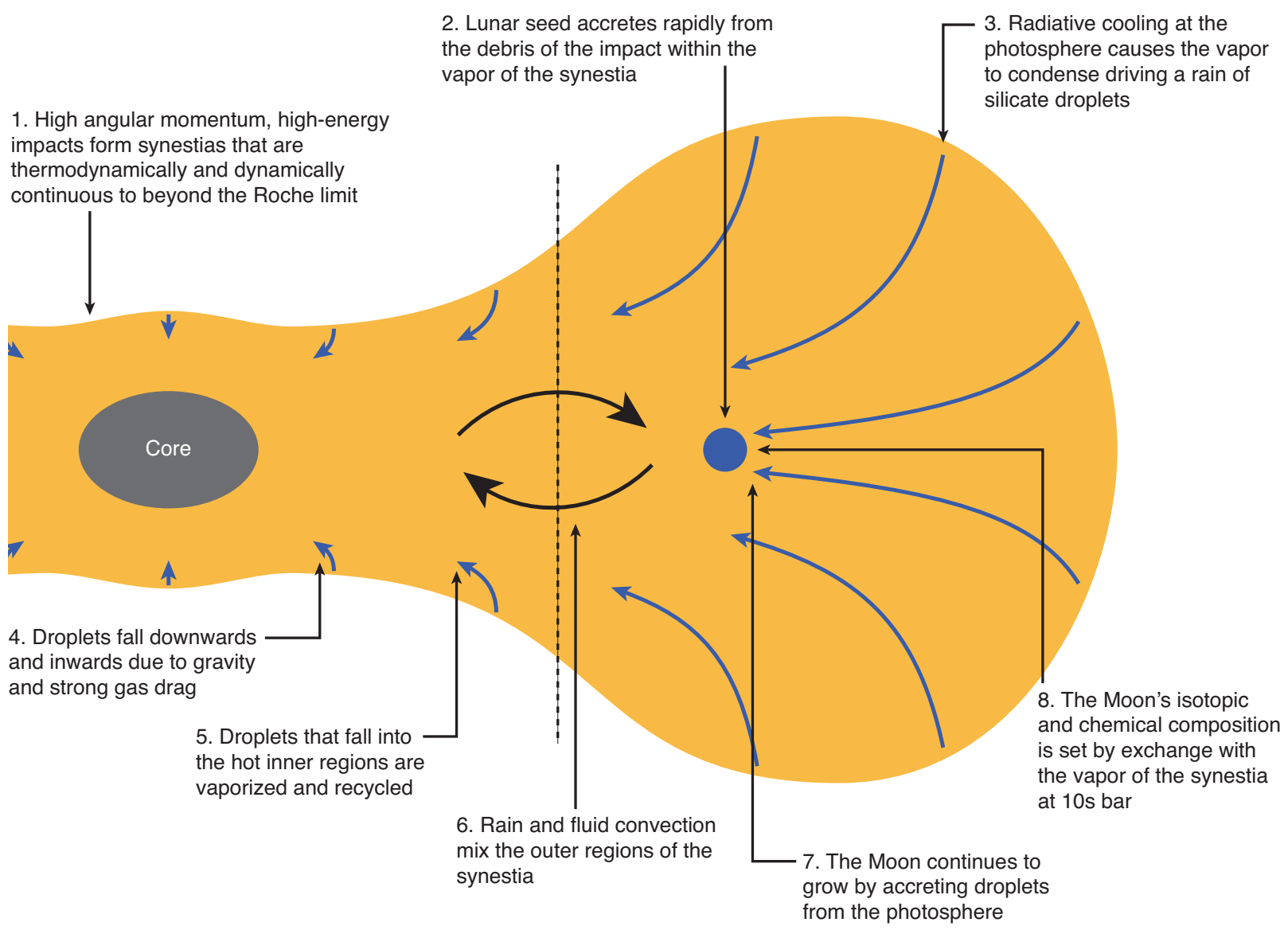

Figure 1: Schematic of the canonical (a) and synestia (b) Moon-formation models. Post-impact structures are shown roughly to scale as they would appear a few months after the impact with the depicted surface being the photosphere, the point at which the structure becomes optically thin. Colors are used to differentiate between: the metal core of the bodies (grey); the silicate portion of the bodies (yellow); and the existence and motions of condensates in the low-pressure regions of the structures (blue). Vertical dashed lines indicate the Roche limit, the point beyond which large objects can survive without being torn apart by tidal forces $\left(\sim 2.9 R_{\text {Earth }}\right)$. 
planet is increased, it rotates faster and becomes increasingly oblate. At a critical angular momentum the angular velocity at the equator is equal to that of a Keplerian orbit, i.e., the angular velocity at the equator is the same as a body in orbit. This point, at which the angular momentum is high enough that the angular velocity at the equator equals that of a circular Keplerian orbit, is the CoRoL. More generally, the CoRoL is a surface that depends on the properties of the body (e.g., thermal state, angular momentum, total mass, and compositional layering). Post-impact synestias are thermodynamically and dynamically continuous bodies with an inner corotating region transitioning to a significantly sub-Keplerian disk-like region further from the rotation axis. Post-impact synestias are typically many times larger than an equivalent condensed planet and form large biconcave disk-shaped structures. Synestias are predicted to be common during terrestrial planet formation and most final planets would have been transformed into a synestia at least once during their accretion (Lock and Stewart, 2017). Note that all previously proposed high-angular momentum impacts (Canup, 2012; Cuk and Stewart, 2012) produce synestias but this was not realized at the time.

A synestia is a distinct dynamical structure from a planet and condensate-dominated circumplanetary disk system, and, as a result, different processes dominate the early evolution of a synestia (Figure 1b). Recently, it was proposed that if a giant impact produced a sufficiently extended synestia the Moon would have formed inside it, surrounded by 10s bar of silicate vapor (Lock et al., 2018). A lunar seed, accreted from large debris injected into orbit during the impact, would have grown over years to tens of years by accreting silicate droplets raining from the photosphere, where radiative cooling leads to condensation of the vapor. The rain of droplets from the photosphere also acts to transport mass and angular momentum in the synestia as the droplets are dragged inwards by the gas, leading to mixing of the outer layers. Over time, as the vapor cools and condenses, the synestia shrinks to within the lunar orbit terminating lunar accretion. Although promising as a model for lunar origin, the formation of the Moon from a synestia is a very recent idea and many pieces of the scenario need to be explored in more depth.

The range of possible high-angular momentum giant impacts, and the corresponding range of post-impact states, are only beginning to be explored. There are many possible scenarios between the end member cases of the canonical disk and the highly extended synestias proposed by Lock et al. (2018) and future work is needed to explore this continuum of possibilities.

\section{Timing of Moon formation}

Various different approaches have been used to constrain the timing of the Moon-forming giant impact, resulting in ages that vary from $60 \mathrm{Myr}$ to $250 \mathrm{Myr}$ after the beginning of the solar system, defined as the time of the con- densation of the first solids (calcium aluminum inclusions) from the cooling nebular gas of the protoplanetary disk at $4567 \pm 0.16 \mathrm{Ma}$ (Connelly et al., 2012). Estimates of the timing of the Moon-forming giant impact are determined from dating lunar samples (Apollo samples and lunar meteorites), calculation of the timing of lunar magma ocean (LMO) crystallization, and numerical simulations. Time constraints on terrestrial events that post-date the last giant impact are derived from terrestrial samples (e.g. the oldest zircons derived from the early crust, samples that record the formation of different reservoirs during crystallization of the terrestrial magma ocean) and provide a limit on how late the Moon could have formed. It is important to note that none of the approaches to dating the Moon-forming giant impact directly dates the impact itself. Each method dates an event that occurred on Earth or the Moon which was tied to the impact, lunar formation, or differentiation of Earth and/or the Moon in some way. There is therefore always an additional uncertainty, on top of any intrinsic uncertainty in the approach, as to what event a given technique is dating and how the timing of that event relates to the timing of the giant impact.

All ages defined by lunar samples are interpreted based on the same assumed evolution after lunar formation. Mafic silicates crystallized from an initially extensively molten Moon and subsequently sank into the mantle to form the source regions of much later mare basalt magmatism (Warren, 1985). After some 70-80\% crystallization, plagioclase began to crystallize from what was by then a dense iron-rich differentiated magma, causing the plagioclase to float to form the ferroan anorthosite (FAN) suite (FAS) of the lunar highlands rocks (Dowty et al., 1974). The FAS, therefore, likely contains the oldest lunar rocks. Further crystallization resulted in a residual liquid strongly enriched in incompatible elements. This reservoir is the source of KREEP basalts. They were given the name KREEP based on their marked enrichment in potassium $(\mathrm{K})$, rare earth elements (REE) and phosphorus (P), among other incompatible elements (see e.g., Snyder et al., 1995). Studies of short- and long-lived systematics have helped refine the lunar chronology from the formation of the different source reservoirs to lunar magmatism. No method can directly provide the age of the Moon's formation but different systems can date events that are closely linked to the LMO stage. For example, the oldest ages measured for the lunar anorthosite crust are assumed to date the magma ocean crystallization if this process is relatively short. In general, this is a good assumption as models of the LMO agree that a stable plagioclase flotation crust formed in less than a million years. However, it should be noted that several processes could extend the cooling timescale for the LMO (tidal heating, formation of a thick lid, presence of an optically-thick atmosphere: Tian et al., 2017; Elkins-Tanton et al., 2011; Saxena et al., 2017) potentially resulting in the persistence of partially molten regions of the lunar mantle for several million years.

Below we summarize the different methods that have 


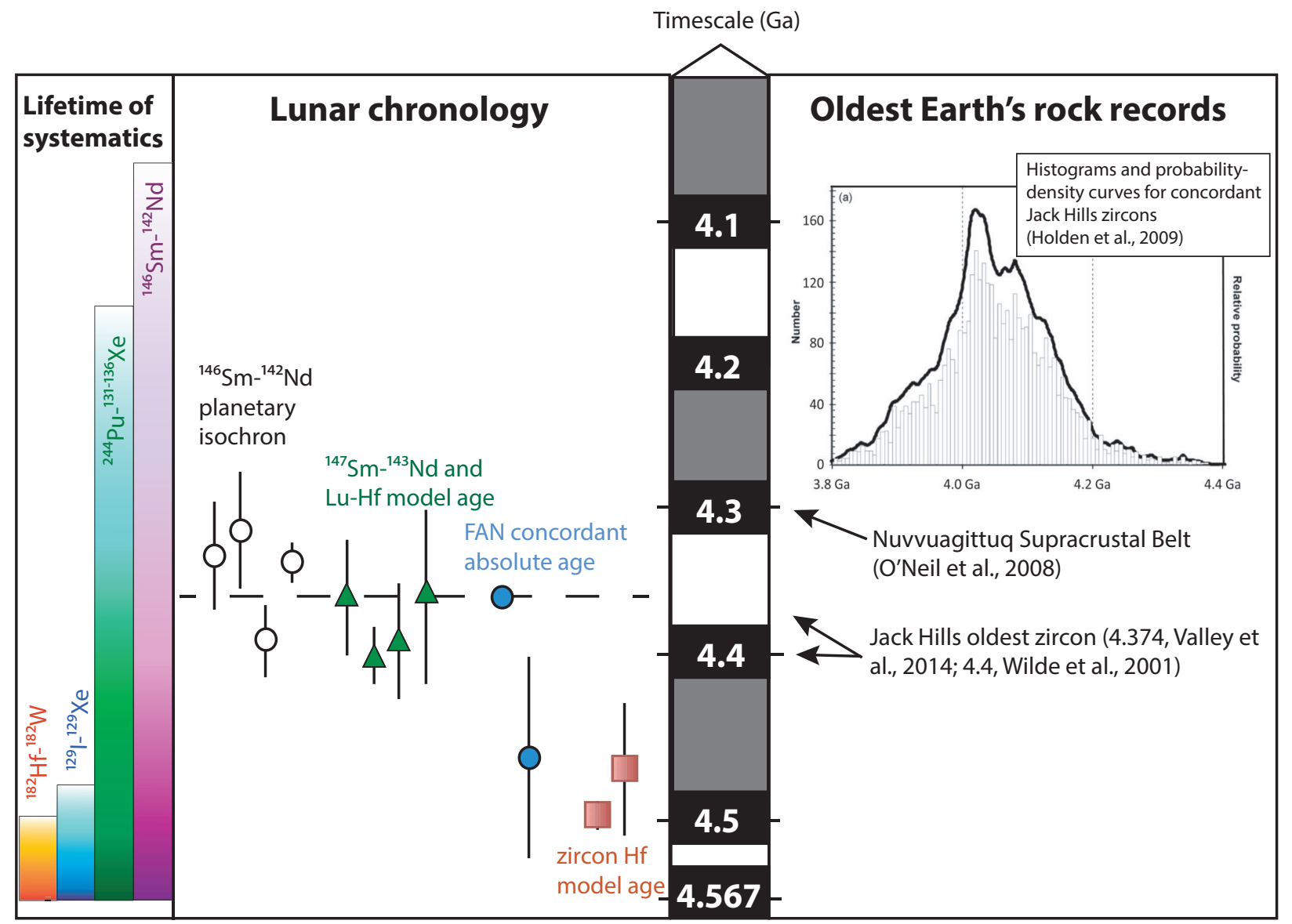

Figure 2: Age estimates for the crystallization of the lunar magma ocean compared to the oldest terrestrial records. References: ${ }^{146} \mathrm{Sm}-{ }^{142} \mathrm{Nd}$ planetary isochron (Nyquist et al., 1995; Boyet and Carlson, 2007; McLeod et al., 2014; Borg et al., 2019), ${ }^{147} \mathrm{Sm}-{ }^{143} \mathrm{Nd}$ and Lu-Hf model age on bulk-rocks (Lugmair and Carlson, 1978; Sprung et al., 2013; Gaffney and Borg, 2014), FAN absolute datations (Borg et al., 2011; Nyquist et al., 2010), zircon Hf model age (Taylor et al., 2009; Barboni et al., 2017). The dashed line represents the most concordant estimate for the age of a lunar sample and so our preferred estimate for the timing of the giant impact that formed the Moon. Interpreting these ages (crust crystallization, differentiation of the lunar interior) as those of the formation of the Moon requires a rapid crystallization of the lunar magma ocean (see Section 3 for more details). Radioactive parent isotopes for short-lived systematics are alive during five half lives (lifetimes shown on the left). 
been used to determine the age of the Moon and their results (Figure 2):

1. Absolute ages for FAS rocks: 100-200 Myr after the beginning of the solar system. Only two samples have produced concordant ages from multiple isotope dating techniques: sample 60025 dated at $4360 \pm 3 \mathrm{Ma}$ (Borg et al., 2011) and sample 67075 dated at $4470 \pm 70 \mathrm{Ma}$ (Nyquist et al., 2010). Concordant ages $(4304 \pm 12 \mathrm{Ma})$ from the ${ }^{147} \mathrm{Sm}-{ }^{143} \mathrm{Nd}$, ${ }^{146} \mathrm{Sm}-{ }^{142} \mathrm{Nd}$, Rb-Sr, and Ar-Ar isotopic systems were obtained on a lithic breccia from the noritic anorthosite 60016 (Marks et al., 2019). However, for this specific sample this age is not an age of crystallization because all these isotope systematics have different closure temperatures; rather it reflects the time of excavation of this sample from the crust by a large impact event (Marks et al., 2019). In contrast, Ar-Ar ages on FAN 60025 and 67075 are significantly younger and around 4.1 Ga (see Borg et al., 2011) showing later disturbances. The troctolite anorthosite 62237 recently measured by Sio et al. (2020) plot on the same internal Sm-Nd isochron as 60025 suggesting they formed contemporaneously.

2. U-Pb ages of lunar zircons: the oldest lunar zircon is estimated to have formed $151 \pm 6 \mathrm{Myr}$ after the beginning of the solar system. This zircon was located in the matrix of a clast-rich impact melt breccia (Nemchin et al., 2009). Nemchin et al. (2009) interpreted this age as the age of formation of the KREEP source as experiments show that zircon saturation is achieved only at the very end of LMO crystallization (Dickinson and Hess, 1982). The significance of zircon ages remains debated and could represent magmatic and/or impact activity on the Moon (Grange et al., 2013).

3. Model ages for the LMO crystallization (KREEP, mare basalts, Mg-suite crustal rocks): 130-200 Myr after the beginning of the solar system (Lugmair and Carlson, 1978; Sprung et al., 2013; Gaffney and Borg, 2014). Model ages determined using both Sm-Nd and Lu-Hf long-lived systematics give similar results. Here age refers to the formation of the different source reservoirs (i.e., the time at which fractionation of parent/daughter ratios occurred).

4. Planetary isochron age using short-lived ${ }^{146} \mathrm{Sm}_{-}{ }^{142} \mathrm{Nd}$ systematics: 180-230 Myr after the beginning of the solar system (Nyquist et al., 1995; Boyet and Carlson, 2007; Brandon et al., 2009; McLeod et al., 2014; Borg et al., 2019). Ages are calculated from the slope of the fossil isochron where the ${ }^{142} \mathrm{Nd} /{ }^{144} \mathrm{Nd}$ ratio of different samples is plotted against the parent/daughter ratio of their sources. Here assumptions are made for calculating the source parent/daughter ratio (e.g., one or several stage evolution, initial composition of the bulk Moon) which explains at least part of the dispersion in ages.
5. The absence of variation in ${ }^{182} \mathrm{~W} /{ }^{184} \mathrm{~W}$ recorded in the lunar samples measured to date precludes global differentiation of the Moon prior to 60-70 Myr after the beginning of the solar system (Touboul et al., 2015; Kruijer and Kleine, 2017) (c.f., Thiemens et al., 2019).

6. Hafnium isotopic analyses were performed on the same volumes of lunar zircon dated by high-precision $\mathrm{U}-\mathrm{Pb}$ geochronology and a model Lu-Hf differentiation age of $60 \mathrm{Myr}$ after the beginning of the solar system was obtained (Barboni et al., 2017). Several samples have elevated ${ }^{178} \mathrm{Hf} /{ }^{177} \mathrm{Hf}$ ratios showing that the Hf isotopic compositions (and hence the inferred ages) are strongly affected by capture of secondary neutrons produced during cosmic ray exposure. Although the robustness of the correction was raised, a sample not affected by this secondary effect gives an age of 60 Myr. Previous Lu-Hf data on lunar zircons dated the crystallization of the lunar magma ocean at $100 \mathrm{Ma}$ with an upper limit of $200 \mathrm{Ma}$ (Taylor et al., 2009).

7. Numerical simulations of planet formation that attempt to match the highly siderophile element $\left(\mathrm{HSE}^{3}\right)$ abundances in the terrestrial mantle: 95 \pm 32 Myr after the beginning of the solar system (Jacobson et al., 2014).

Recent isotope studies support a young Moon. Borg et al. (2019) showed that mare basalt sources and ferroan anorthosite suite cumulates define a linear array on a ${ }^{146} \mathrm{Sm} /{ }^{144} \mathrm{Nd}$ versus ${ }^{142} \mathrm{Nd} /{ }^{144} \mathrm{Nd}$ isochron plot demonstrating these materials were derived from a common reservoir at $4336_{-32}^{+31} \mathrm{Ma}$. This age is similar to the age obtained on the FAN 60025 (4360 \pm 3 Ma, Borg et al., 2011). The age derived for sample 60025 is the most robust age determined for lunar samples because three different chronometers $\left({ }^{146} \mathrm{Sm}-{ }^{142} \mathrm{Nd},{ }^{147} \mathrm{Sm}-{ }^{143} \mathrm{Nd},{ }^{207} \mathrm{~Pb}-{ }^{206} \mathrm{~Pb}\right)$ produce the same age within uncertainty. Isotope studies on highlands rocks enriched in magnesium, known as the Mg-suite and interpreted to be partial melts of cumulates in the lunar interior, also produce similar ages (Carlson et al., 2014). A lunar crust formed contemporaneously with different terrestrial mantle reservoirs suggests a rapid crystallization of the LMO, in agreement with numerical models (< 1 Myr, e.g., Elkins-Tanton et al., 2011). It has been proposed that the young ages of the lunar crust could be due to solidification of the LMO being prolonged by tidal heating (Elkins-Tanton et al., 2011), but if the Moon formed late, then a mechanism to prolong the solidification of the LMO is not required.

\footnotetext{
${ }^{3}$ HSEs are those elements that have a strong propensity to be in metals over silicates and so are overwhelmingly incorporated into Earth's core during accretion. Typically, HSEs are defined as elements that have metal-silicate partition coefficients ( $D$ values, concentration ratio of an element in liquid metal to liquid silicate) $>10,000$.
} 
The age of sample 60025 is also in agreement with ages proposed for the last magma ocean event on Earth estimated to be around 150-200 Myr after the beginning of the solar system from ${ }^{146,147} \mathrm{Sm}^{142,143} \mathrm{Nd}$ systematics measurements on Eoarchean samples (e.g., Rizo et al., 2011; Caro et al., 2017). A major melting event on Earth at this time is consistent with the presence of zircon formed in a terrestrial crust at $4.4 \mathrm{Ga}$ (Wilde et al., 2001; Valley et al., 2014) and the age of $4.3 \mathrm{Ga}$ estimated from the ${ }^{146} \mathrm{Sm}-{ }^{142} \mathrm{Nd}$ systematics for samples from the Nuvvuagittuq greenstone belt (northern Quebec, Canada) representing the oldest preserved crustal section on Earth (O'Neil et al., 2008). However, it may be challenging to reconcile outgassing of a late magma ocean with ${ }^{129} \mathrm{I}-{ }^{129} \mathrm{Xe}$ systematics in mid-ocean ridge basalts, which exhibit large excesses in ${ }^{129} \mathrm{Xe}$ that are intrinsic to the upper mantle and not derived from a deeper-seated mantle source (e.g., Mukhopadhyay and Parai, 2019; Parai et al., 2019). Mantle excesses in ${ }^{129} \mathrm{Xe}$ indicate that retention of Xe began within the lifetime of ${ }^{129} \mathrm{I}(<100$ Myr after CAIs: Porcelli et al., 2001; Mukhopadhyay and Parai, 2019). If the Moon-forming giant impact generated a terrestrial magma ocean after ${ }^{129}$ I was extinct, this implies that magma ocean outgassing after the Moon-forming giant impact was inefficient. The efficiency by which noble gases are degassed from a magma ocean is uncertain, and depends on the style of magma ocean solidification (fractional or batch crystallization) and the fraction of melt that is trapped as the mantle freezes which are both poorly understood (see e.g., Solomatov and Stevenson, 1993a,b,c; Miyazaki and Korenaga, 2019).

Geochronology on the Moon remains a challenging task due to the nature and limited number of samples available. Most lunar samples were collected during the Apollo missions, which landed predominantly in the mare basin areas where basalts are relatively young $(<3.9 \mathrm{Ga})$ in comparison to the average lunar crust, thereby potentially biasing the sample suite. FANs have been mostly sampled during the Apollo 16 mission and some samples are also available in the lunar meteorite collection. The question of whether samples taken from a small area of the lunar surface constrain the age of the crust persists since lunar highland meteorites and Luna mission anorthosites are more magnesium-rich than Apollo ferroan anorthosites (Gross et al., 2014). Lunar crustal rocks were not all formed during the crystallization of the LMO; some were likely generated via complex crustal processes later in time. Impacts on the lunar surface have also extensively shocked crustal rocks, which can disturb radiogenic isotope signatures. For example, Rb-Sr systematics in FANs are vulnerable to shock resetting that may yield young apparent ages (Norman et al., 2003). The large deficit in ${ }^{142} \mathrm{Nd}$ measured in FAN 62255 may indicate direct crystallization from the LMO 60-125 Myr after the beginning of the solar system (Boyce et al., 2015), but such measurements of ${ }^{142} \mathrm{Nd}$ in FANs with extremely low rare earth element abundances are challenging. Additional samples and further analyses are needed to better understand lunar chronology from the radiogenic isotope record.

\section{Bulk lunar elemental composition}

Estimates of the Moon's bulk composition (inclusive of the core, mantle, and crust) suggest that it is very similar to Earth's with two principal exceptions: the Moon has a much smaller metal core (Williams et al., 2014; Weber et al., 2011; Garcia et al., 2011); and the Moon is more depleted in volatile and moderately volatile elements (MVE; e.g., K, Na, Zn, and Cl: Ringwood and Kesson, 1977; Wanke et al., 1977; Morgan et al., 1978; Longhi, 2006; Albarède et al., 2015; Taylor, 2014; Hauri et al., 2015; Taylor and Wieczorek, 2014; Ni et al., 2019, see Figure 3). The similarity of the Earth and Moon in the major elements (excepting some siderophile elements, those that have a propensity to partition into metals, such as iron) suggests that the two bodies formed from material from a similar reservoir, consistent with the observed similarity in non-mass dependent isotopic composition (Section 6). The similarities and differences in composition between the two bodies can give us insight into the mechanisms of lunar formation.

It is estimated that the Moon has a metallic iron core that is only $\sim 2 \%$ of its mass (compared to $\sim 30 \%$ for Earth) which places a significant constraint on lunar origin models (Williams et al., 2014; Weber et al., 2011; Garcia et al., 2011). This constraint is met in the canonical giant impact model as, in a subset of collisions, only a small quantity of core material from the impactor is injected into orbit, creating an iron-depleted proto-lunar disk. The majority of the impactor's core material merges with the core of the target. The generation of iron-depleted disks has been used as a constraint in other lunar origin scenarios (Reufer et al., 2012; Rufu et al., 2017; Hosono et al., 2019). Lock et al. (2018) proposed an alternative explanation for the small lunar core in the context of the synestia model which may also be relevant in other lunar formation scenarios. They argued that since the bulk composition of Earth was set by the impact and that the Moon-forming region had a composition similar to that of the rest of the silicate portion of the post-impact body (as required by the isotopic constraints, see Section 6), the vapor in the outer regions of the synestia would have had close to bulk silicate Earth (BSE) composition. Using physical chemistry models, the authors showed that $\sim 2$ wt $\%$ metal could be precipitated from a cooling BSE liquid at low to modest pressures $\left(10^{-6}-10^{2}\right.$ bar $)$. The metal that now constitutes the core of the Moon could have been partially, or completely, sourced from metal that precipitated directly from silicate liquid in moonlets or the Moon itself, and injection of free metal into the disk may not be required. Note that some amount of metal from condensed material injected into orbit during the impact may also contribute to the mass of the lunar core in the synestia model. Further work on the combined thermal and chemical evolution of 


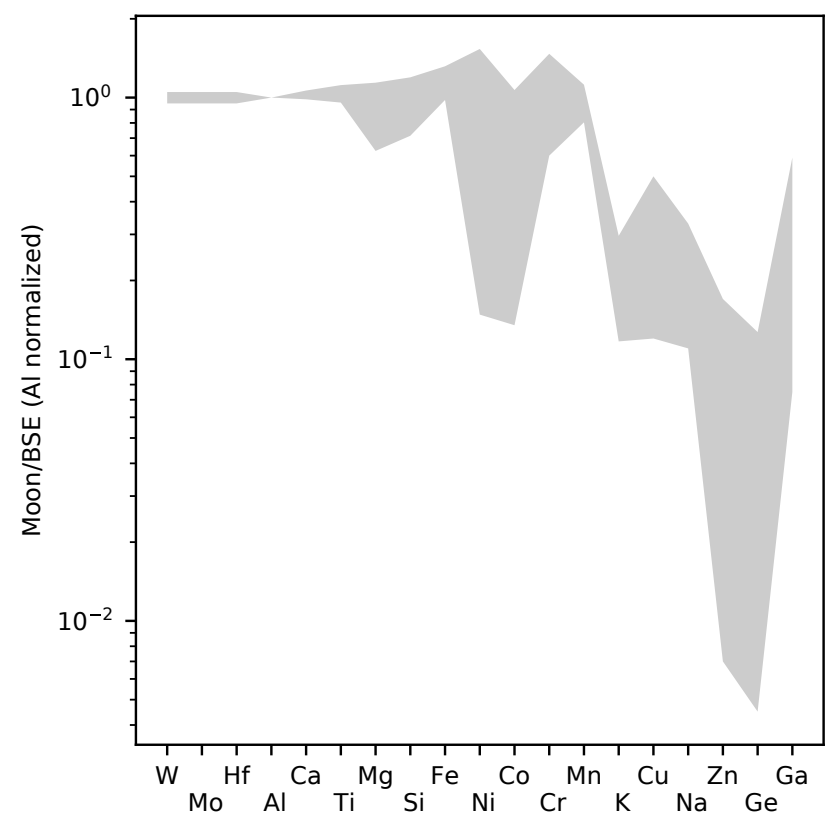

Figure 3: The lunar composition is depleted in moderately volatile elements (MVEs) relative to the bulk silicate Earth (BSE). The gray band is the range of published estimates for the bulk lunar composition, doubly normalized to the mole fraction of $\mathrm{Al}$ and the abundance of each element in the BSE (McDonough and Sun, 1995). The range shown is based on estimates and discussions provided by Ringwood and Kesson (1977); Wänke et al. (1977); Morgan et al. (1978); Ringwood (1979); Taylor (1982); Wänke and Dreibus (1982); Ringwood et al. (1987); Warren (2005); Longhi (2006); Taylor and McLennan (2009); Taylor (2014), and Hauri et al. (2015) (see discussion in Section S5.1 of Lock et al., 2018). the lunar disk and the Moon is required to explore the relative contributions to the lunar core from different potential mechanisms.

The MVE depletion of the Moon is a key chemical constraint on lunar origin models. In a series of studies (Ringwood and Kesson, 1977; Ringwood, 1986), Ringwood and colleagues argued that the lunar composition could be explained if the Moon was a partial condensate of vapor derived from Earth's mantle. Few studies have attempted to combine the dynamics, thermodynamics and chemistry of lunar origin, which is necessary to test the proposed models. Recently, Canup et al. (2015) used the canonical lunar disk models of Salmon and Canup (2012) and physical chemistry calculations to link the dynamics and thermodynamics of accretion from a canonical disk. They also suggested that the lunar volatile element depletion could be explained if the material that formed the observable Moon was a partial condensate of disk material. However, the model presented by Canup et al. (2015) does not quantitatively explain the magnitude, nor the pattern, of moderately volatile element depletion observed for the Moon.

Lock et al. (2018) combined physical and geochemical models to estimate the composition of the Moon formed from a terrestrial synestia and showed that such a scenario can reproduce both the pattern and magnitude of MVE depletion in the Moon. By simulating the evolution of a terrestrial synestia using a modified hydrodynamic code, they demonstrated that the pressure of silicate vapor surrounding the growing Moon could be on the order of $10 \mathrm{~s}$ bar. They then argued that the Moon would equilibrate with the gas around it in the structure at the pressure of the gas and a temperature set by the onset of vaporization of the major elements (particularly $\mathrm{Si}$ ). Using physical chemistry calculations, they showed that equilibration of a BSE chemical system at those pressures and temperatures could reproduce the bulk lunar composition. MVEs that were not incorporated into the Moon would remain in the vapor of the synestia. Over time, radiative cooling of the synestia would cause it to contract. Eventually the synestia contracted within the orbit of the Moon, cutting off exchange between the vapor of the synestia and the Moon, and leaving the Moon with its distinctive MVE depleted composition. The MVEs that remained in the vapor of the synestia would have been incorporated into the BSE. The result that the lunar composition can be explained by partial condensation of BSE material at $10 \mathrm{~s}$ bar and at temperatures tied to the onset of vaporization of the major elements may also place a constraint on the equilibration conditions of lunar material in other lunar origin models. However, the thermodynamic properties of MVEs at the high temperatures of post-impact bodies are not well known, and more experimental studies of silicate vaporization are needed to confirm this result.

Alternatively, it has been proposed that the MVE depletion of the Moon could be explained by evaporative loss from the Moon during the early stages of the LMO 
(Charnoz et al., 2019; Young and Tang, 2019). We will discuss this suggestion in the next section in connection with MVE isotopic fractionation.

Determining the bulk chemical (and isotopic) composition of the Moon is challenging due to the limited spatial coverage of samples and limited constraints on the composition of the core (Steenstra et al., 2016, 2017, 2020; Jing et al., 2014; Antonangeli et al., 2015). Furthermore, determining the composition of the lunar mantle from only crustal samples requires the use of petrological melting models and there are intrinsic degeneracies in the inferred source compositions. As a result, there is still significant variation in different estimates of lunar composition. Future missions that sample new locations and different lithologies, particularly sample return missions, are vital to further constrain the lunar composition.

\section{Moderately volatile element isotopic fractiona- tion}

Further insight on the mechanism of MVE depletion of the Moon relative to Earth is provided by isotopic studies. It has been found that lunar samples exhibit massdependent isotopic fractionation relative to Earth for various MVEs (K, Rb, Zn, Cl, Sn, Cr, Ga; Herzog et al., 2009; Sharp et al., 2010; Paniello et al., 2012; Boyce et al., 2015, 2018; Kato et al., 2015; Wang and Jacobsen, 2016; Day et al., 2017; Kato and Moynier, 2017; Pringle and Moynier, 2017; Dhaliwal et al., 2018; Sossi et al., 2018; Wang et al., 2019a,b; Stephant et al., 2019; Nie and Dauphas, 2019; Wimpenny et al., 2019, see Figure 4). Different elements show different directions and magnitudes of fractionation and there is considerable variability in the fractionation of different lunar samples for some elements. MVE isotopic fractionation has the potential to be a powerful tool to constrain the formation and later evolution of the Moon, but interpreting the observed fractionations is difficult as numerous processes can cause mass-dependent fractionation. Here we will restrict ourselves to the discussion of potential mechanisms for MVE isotopic fractionation during lunar formation or on the newly formed Moon. We will not discuss fractionation due to other processes, such as postemplacement alteration (e.g., Potts et al., 2018; Barnes et al., 2019), and those acting after the lunar magma ocean had largely solidified (e.g., Barnes et al., 2016), or during the ascent, eruption or emplacement of the melts that formed lunar rocks (e.g., Sharp et al., 2010).

MVE isotopic fractionation could arise during the formation of the Moon due to processes in the lunar disk or synestia. Wang and Jacobsen (2016) proposed that the observed isotopic fractionation in $\mathrm{K}$ could be produced by equilibrium exchange between liquid and vapor at moderate pressures (10s bar) consistent with the conditions expected for the formation of the Moon from a terrestrial synestia (Lock et al., 2018). However, at the high temperatures of liquid-vapor exchange in synestias and in the midplane of the canonical disk at the Roche-limit
(> 3500 K; Lock et al., 2018; Canup et al., 2015) the expected equilibrium isotopic fractionation is too small to explain the observations (Dauphas et al., 2018). To amplify the effect from equilibrium fractionation, it has been suggested, on the basis of the observed light isotopic composition of Sn, that the lunar material experienced repeated stages of equilibration and phase separation at somewhat lower temperatures ( $2500 \mathrm{~K}$; Wang et al., 2019a). Alternatively, a small degree of non-equilibrium fractionation during partial evaporation of MVEs could explain the observed heavy isotopic signature of many MVEs (Nie and Dauphas, 2019), but may be in disagreement with light isotopic signatures such as those observed for Sn (Wang et al., 2019a). Assessing the feasibility of each of these arguments and understanding the implications of MVE isotopic fractionations for lunar origin is challenging. Different parcels of lunar material follow varying pressuretemperature-composition-time paths before (and after) being incorporated into the Moon and likely go through multiple steps of vaporization and condensation. Thus, the lunar MVE isotopic composition may reflect the weighted average of the varying signatures from material that experienced different histories. Current models of Moon formation do not track the thermodynamic paths of lunar material to the level of detail needed to access the resulting isotopic fractionation.

The newly-formed Moon would be substantially molten and it has been suggested that the loss of silicate vapor from the surface of the LMO could fractionate MVEs both elementally and isotopically (Paniello et al., 2012; Boyce et al., 2015; Kato et al., 2015; Day et al., 2017; Kato and Moynier, 2017; Sossi et al., 2018; Stephant et al., 2019; Charnoz et al., 2019; Young and Tang, 2019). Recently, Charnoz et al. (2019) and Young and Tang (2019) have attempted to model this process and found that it is possible to lose significant amounts of MVEs from the Moon by evaporative loss, producing mass-dependent isotopic fractionations. However, these models assume that the loss from the Moon is in steady state, which is not necessarily the case given the surface of the Moon is far out of equilibrium with its surroundings. Processes that may prove important, such as radiative transfer and condensation of the expanding vapor, have also been neglected.

Understanding MVE fractionation between Earth and the Moon is a new and rapidly developing frontier in lunar formation studies, but more work, particularly studies measuring multiple different elements in the same samples, is required to untangle the contributions of different processes to the isotopic fractionation (e.g., Nie and Dauphas, 2019). In order to use these observations to place constraints on the origin and evolution of the Moon, coupled chemical, thermal and dynamical models will be required to quantify the isotopic fractionation due to different processes. Models that can couple the elemental depletion and isotopic fractionation of MVEs could prove particularly powerful determinants of lunar origin and evolution. For such models, there is a need for improved experimen- 


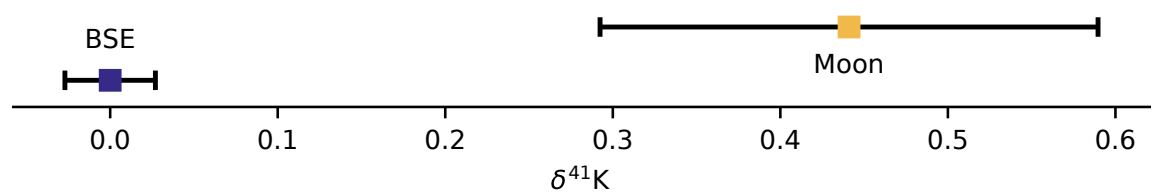

Wang \& Jacobsen (2016)

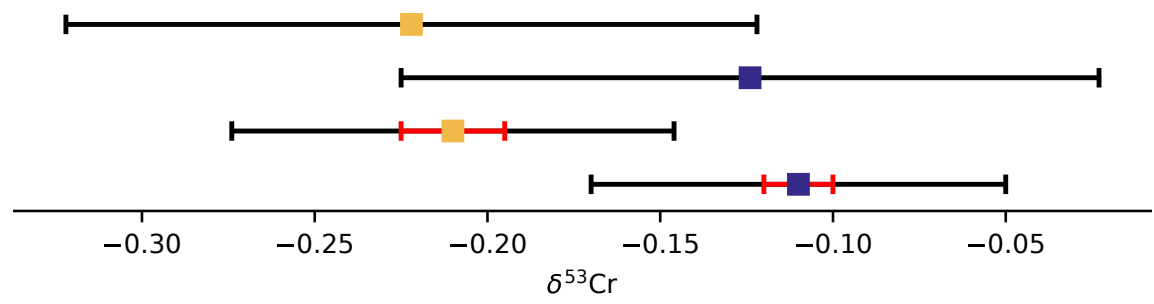

Moon: Bonnand et al. (2016)

BSE: Schoenberg et al. (2008)

Sossi et al. (2018)

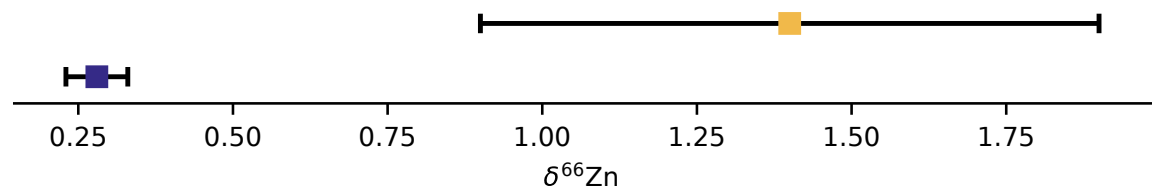

Moon: Kato et al. (2015)

BSE: Chen et al. (2013)

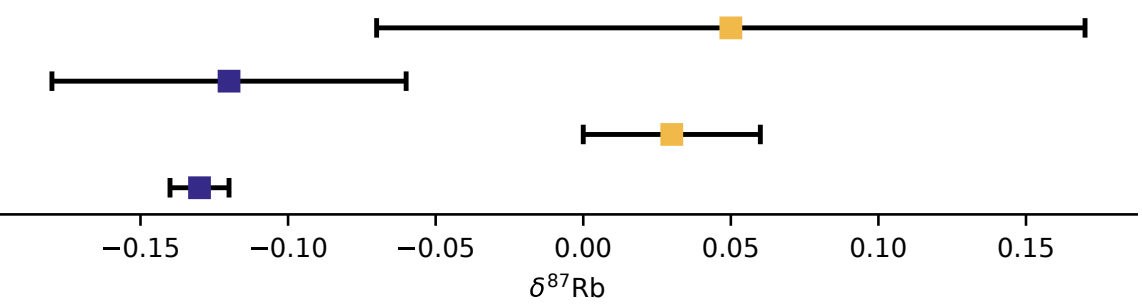

Pringle \& Moynier (2017)

Nie \& Dauphas (2019)

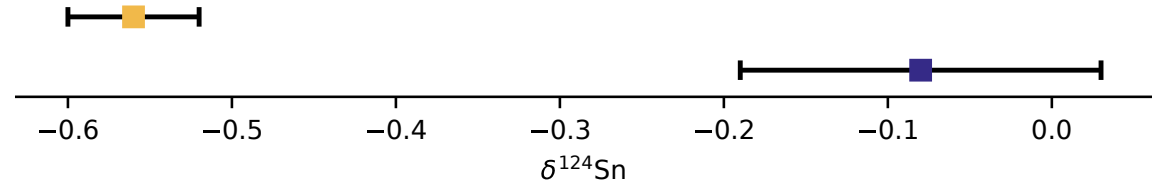

Moon: Wang et al. (2019)

BSE: Wang et al. (2018)

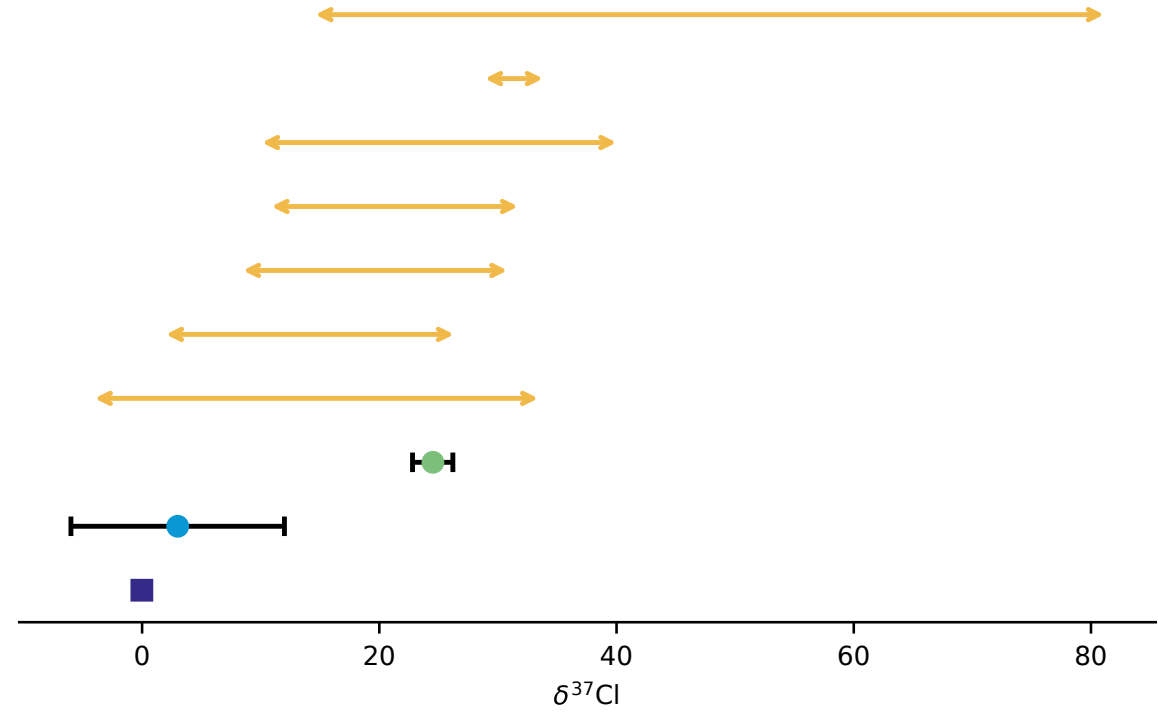

Impact rocks

Highland crust

High-Al basalts

Very high-K basalts

KREEP/KREEP-rich basalts

High-Ti basalts

Low-Ti basalts

urKREEP source: Boyce et al. (2018)

Mare source: Boyce et al. (2018)

Earth mantle: Sharp et al. (2013)

Figure 4: Caption on next page. 


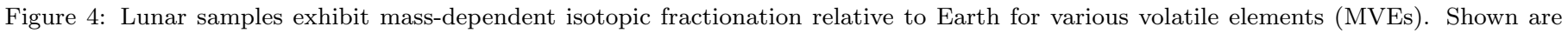

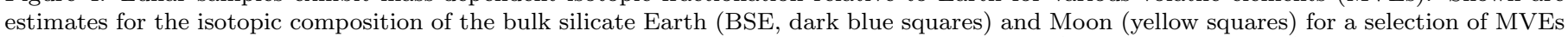

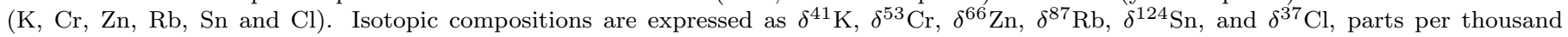

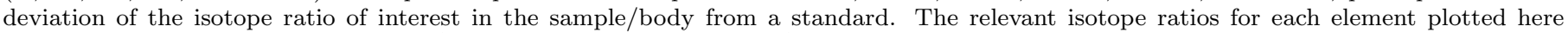

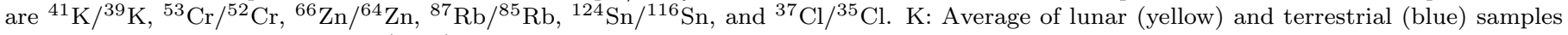

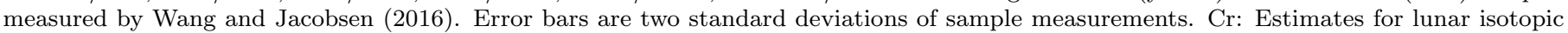

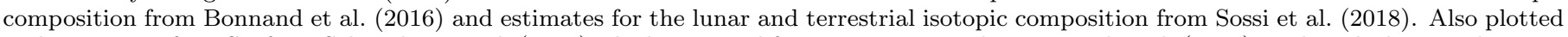

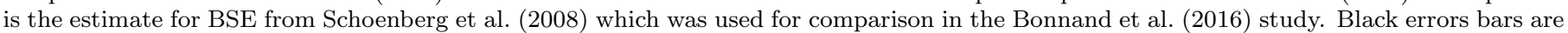

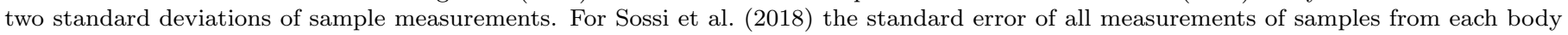

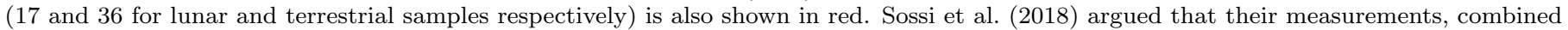

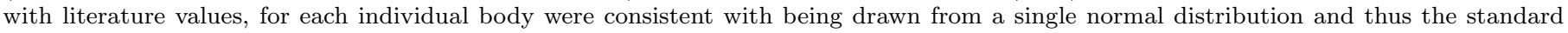

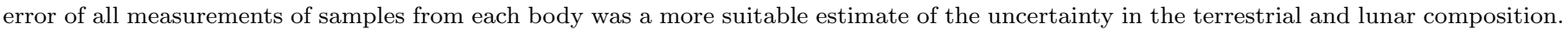

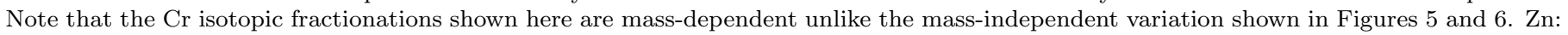

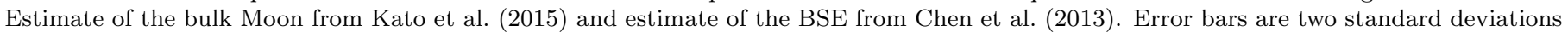

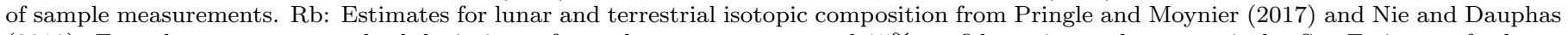

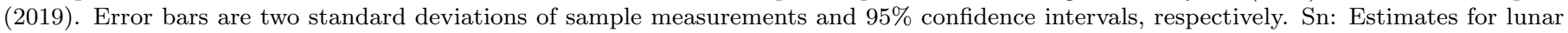

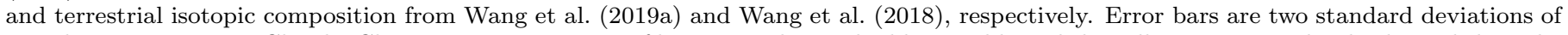

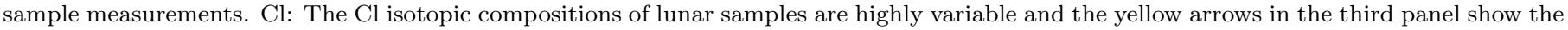

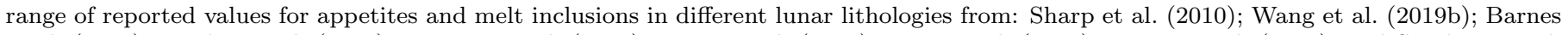

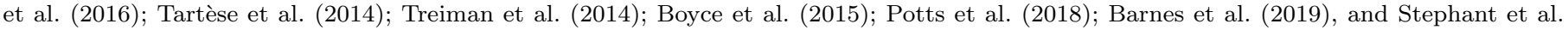

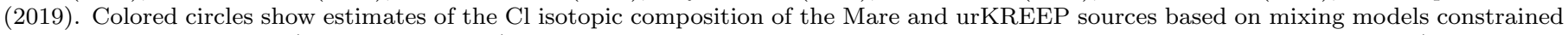

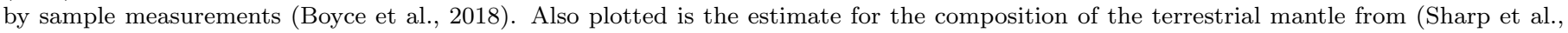
2013).

tal constraints on the behavior of MVEs at the very high temperatures expected during lunar formation and magma ocean evolution, a regime that is exceedingly difficult to reach in a lab setting (Sossi et al., 2019).

\section{Similarity in lunar and terrestrial non-mass de- pendent isotope ratios}

Increasingly precise isotopic measurements of terrestrial and lunar samples have shown that Earth and the Moon share very similar non-mass dependent stable isotope ratios for a range of elements including $\mathrm{Cr}, \mathrm{O}, \mathrm{Si}$, and $\mathrm{Ti}$ (e.g., Lugmair and Shukolyukov, 1998; Wiechert et al., 2001; Armytage et al., 2012; Zhang et al., 2012; Young et al., 2016; Greenwood et al., 2018, see Figures 5 and 6). Significant non-mass dependent variation in the isotope ratios of these elements are observed among other planetary bodies (Clayton and Mayeda, 1996; Yin et al., 2002; Trinquier et al., 2007; Zhang et al., 2012). Such isotopic signatures are thought to reflect the provenance of material that formed different bodies (i.e., the region in the protoplanetary disk from which material was derived). Given the non-mass dependent variation of stable isotope ratios observed among planetary materials, the impactor Theia is generally expected to have had non-mass dependent stable isotopic signatures distinct from the proto-Earth.

Refractory radiogenic isotope variations (e.g., ${ }^{182} \mathrm{~W}$ ) are also a type of non-mass dependent isotope variation and ${ }^{182} \mathrm{~W}$ isotope signatures were likely substantially different on Theia and the proto-Earth. Radioactive decay of lithophile ${ }^{182} \mathrm{Hf}$ generates radiogenic moderately siderophile ${ }^{182} \mathrm{~W}$ (half-life of $8.9 \mathrm{Myr}$, Vockenhuber et al., 2004), such that ${ }^{182} \mathrm{~W}$ isotopic ratios are sensitive to the conditions and timing of metal-silicate partitioning associated with core formation on each of the colliding bodies. A difference in ${ }^{182} \mathrm{~W}$ isotopic composition in Theia and the
proto-Earth is therefore anticipated, as it is improbable that the two bodies had independent differentiation histories that produced identical ${ }^{182} \mathrm{~W}$ isotope compositions through the stochastic process of planet formation (Kleine et al., 2009; Kruijer et al., 2015; Touboul et al., 2015; Kruijer and Kleine, 2017). However, as for the stable isotopes, the Earth and Moon likely had similar ${ }^{182} \mathrm{~W}$ isotope compositions immediately following Moon formation (Kruijer et al., 2015; Touboul et al., 2015). Recent W isotopic studies measured a small ${ }^{182} \mathrm{~W}$ excess of $\sim 25 \mathrm{ppm}$ (parts per million) in lunar rocks relative to modern terrestrial samples (Touboul et al., 2015; Kruijer et al., 2015; Kruijer and Kleine, 2017). Earth and the Moon have accreted different amounts of material since the Moon-forming impact which has slightly changed their respective ${ }^{182} \mathrm{~W}$ isotopic compositions and the observed ${ }^{182} \mathrm{~W}$ excess in lunar rocks is consistent with estimates of the disproportionate late accretion to the Earth and Moon. Although alternatives have been proposed (e.g., Thiemens et al., 2019), the most parsimonious conclusion is therefore that Earth and the Moon started with similar ${ }^{182} \mathrm{~W}$ isotope compositions.

Numerical simulations of giant impacts predict that the canonical lunar disk is derived primarily from the impactor, and in this case the Moon would be expected to acquire the distinct isotopic signature of the impactor (Canup and Asphaug, 2001; Canup, 2004, 2008). Such a scenario would likely result in measurable refractory nucleosynthetic and radiogenic isotopic differences between Earth and the Moon (Pahlevan and Stevenson, 2007; Melosh, 2014; Young et al., 2016; Kruijer and Kleine, 2017), which have not been observed. Note that if the impactor and target had significantly different bulk mantle compositions, an elemental compositional difference between Earth and the Moon would also be expected. In particular, if the impactor and target had substantially different core formation histories (as would likely be the case 

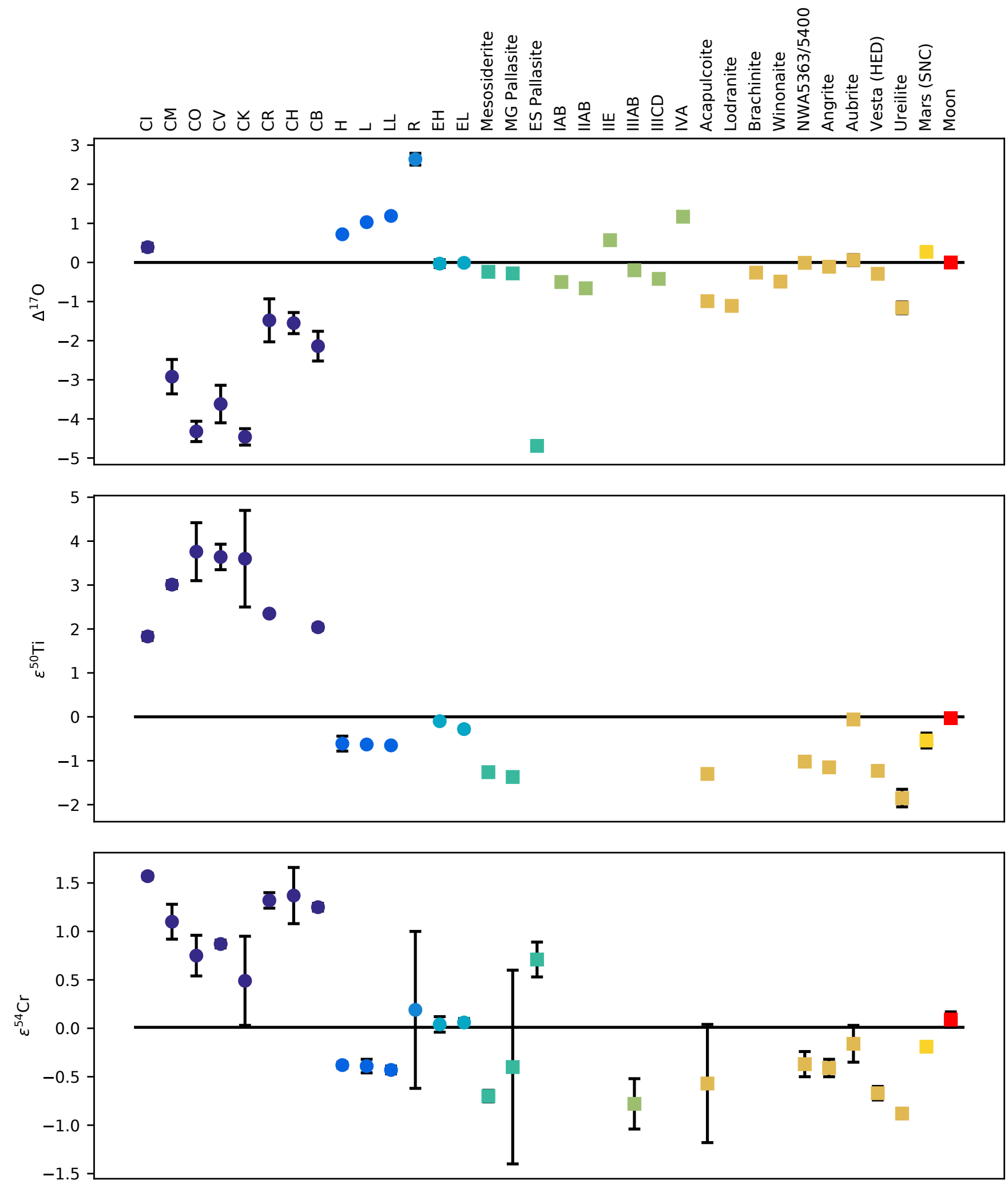

Figure 5: Caption on next page. 


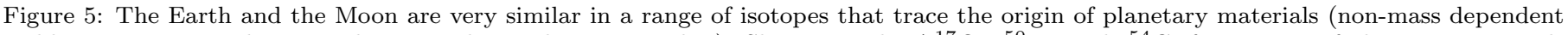

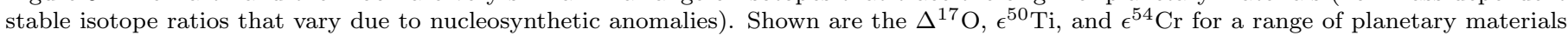

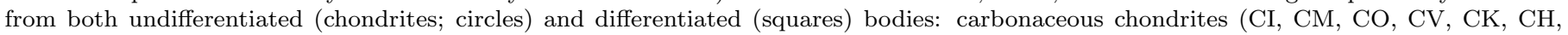

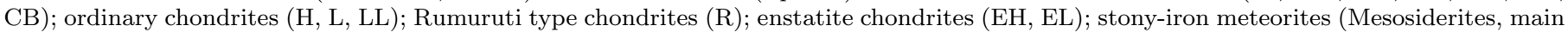

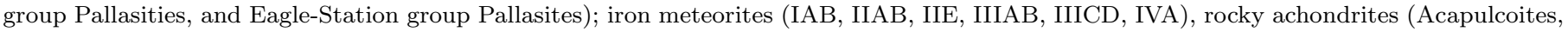

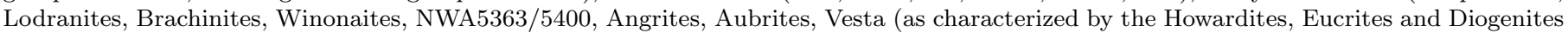

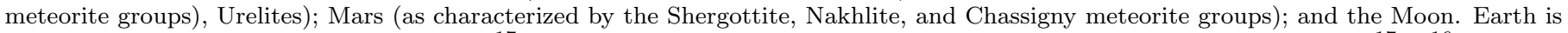

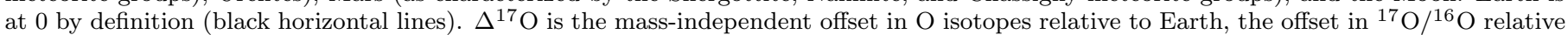

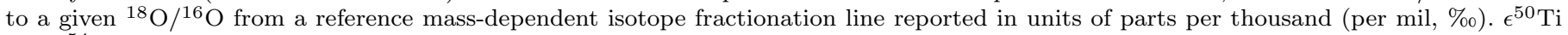

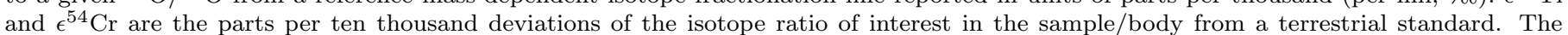

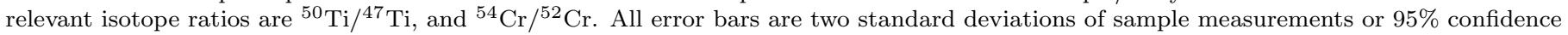

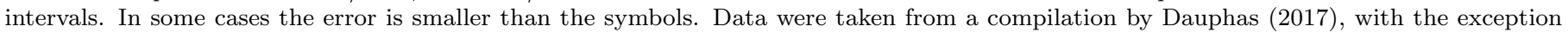
that the lunar value for $\epsilon^{54} \mathrm{Cr}$ was taken from Mougel et al. (2018). Original data sources are given in Appendix A1.

in most proposed scenarios, not just the canonical model) then their mantles would have had different abundances of moderately siderophile elements (MSEs, e.g., V, Cr, Mn). However, the BSE and the Moon have very similar MSE concentrations and it has been argued that it would be hard to reconcile this fact with a scenario in which lunar material was largely sourced from the impactor (Seifert and Ringwood, 1988; Drake et al., 1989), although the strength of this argument is dependent on the core formation histories of the impacting bodies, the mass and nature of late veneer etc. The contradiction between the geochemical observations of similarity and dynamical expectations of difference is often referred to as the 'lunar isotopic crisis.'

Three classes of solutions to the crisis of unexpected isotopic similarity have been proposed. First, the impactor and proto-Earth could have formed from the same source material (i.e., they formed from material derived from the same region in the disk) and thus shared nearly identical nucleosynthetic isotopic signatures (Jacobsen et al., 2013; Dauphas et al., 2014; Dauphas, 2017). This suggestion has a basis in the observation that some meteorite groups (e.g., enstatite chondrites) have non-mass dependent stable isotope compositions not dissimilar to that of Earth (e.g., Dauphas et al., 2014; Dauphas, 2017; Boyet et al., 2018). If the impactor and target accreted the majority of their mass from a common reservoir with a specific mix of nucleosynthetic components, the Earth and Moon would inherit similar non-mass dependent stable isotopic signatures. This explanation for the isotopic similarity between Earth and the Moon, however, relies upon coincidence to explain the inferred similarity of the ${ }^{182} \mathrm{~W}$ isotopic compositions of the Earth and Moon before late accretion (Dauphas et al., 2014; Touboul et al., 2015; Kruijer and Kleine, 2017) and could be difficult to reconcile with the similar MSE concentrations in the BSE and the Moon (see discussion in Sossi and Moynier, 2017). Nevertheless, the possibility of a more homogeneous inner solar system relaxes the isotopic constraint on models of Moon-formation, as a given scenario need only produce similar ${ }^{182} \mathrm{~W}$ compositions in the Earth and Moon.

Alternatively, the Moon may have been constructed from material injected into orbit by many smaller impacts (Rufu et al., 2017). Such a process would be a natural outcome of the many impacts Earth experienced during its formation and the Moon would then be a mixture of the compositions of each impactor. However, to reproduce the isotopic similarity between Earth and the Moon it is likely that 10 s of such impacts are required, and the satellite from each previous impact must survive and merge with the newly formed moon (Rufu et al., 2017; Rufu and Aharonson, 2019; Citron et al., 2018). The likelihood of such a combination of events being able to form our Moon is still being worked out but is potentially quite low.

In the third class of solution, extensive mixing of impactor and target material during the impact or postimpact mixing between different reservoirs could mitigate initial isotopic heterogeneities. The requirement is that there ends up being a similar mass fraction of impactor material in the region of the post-impact body from which the Moon forms (i.e., the disk) as there is in the post-impact body as a whole. Due to the large shearing flows during giant impacts, there is potential for substantial mixing (Nakajima and Stevenson, 2015). However, the shear is highly heterogeneous in the colliding bodies and mixing is inhibited by thermal buoyancy of highly shocked compared to weakly shocked material (Carter et al., 2020). The degree of mixing is likely underestimated in current giant impact models due to the lack of thermal equilibration between parcels of mass in Lagrangian methods and the fact the resolution is too low to capture small-scale instabilities (c.f. Deng et al., 2019). Nevertheless, as the canonical impact is a grazing impact, opportunity for mixing of impactor and target material is limited and the lunar disk will mostly be derived from Theia. Pahlevan and Stevenson (2007) suggested that exchange of material between the planet and the disk could erase isotopic heterogeneity between the two reservoirs. However, the extent of mixing required to explain the observations, especially the isotopic similarity for the most refractory elements, is likely to be unfeasible due to the large dynamical and thermodynamic boundary between the planet and the disk (Melosh, 2014; Lock and Stewart, 2017).

In most high energy and/or high angular momentum impacts there is greater opportunity for mixing between impactor and target during the impact. The higher energy of the impact causes the colliding bodies to be more substantially disrupted than in the canonical impact and 

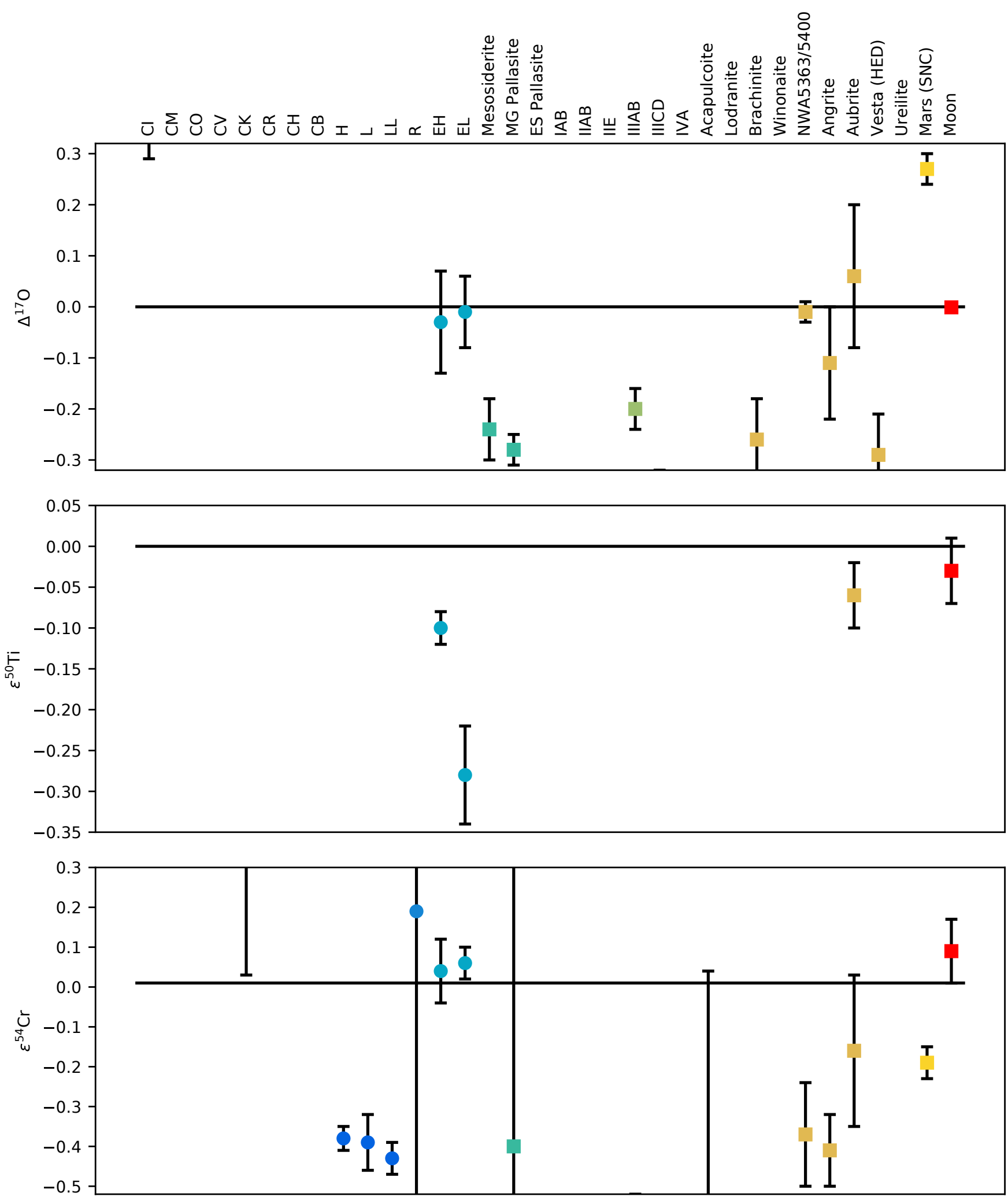

Figure 6: The Earth and the Moon are very similar in a range of isotopes that trace the origin of planetary materials (non-mass dependent stable isotope ratios called nucleosynthetic anomalies). As Figure 5 except showing a restricted range of isotopic compositions, focused on those values close to that of the Earth and Moon. 
the greater torques lead to increased shear. The ratio of impactor to target material in the Moon-forming regions of the post-impact structure (synestia or otherwise) is, therefore, typically more similar to the bulk planet than in the canonical model (Canup, 2012; Ćuk and Stewart, 2012; Lock et al., 2018). It has been found that in a limited range of scenarios the mixing is thorough enough in current giant impact simulations to produce an isotopic similarity between Earth and the Moon by impact processes alone (Canup, 2012; Ćuk and Stewart, 2012), but the probability of such specific impact parameters is thought to be low. Lock et al. (2018) argued that silicate rain and thermal convection in post-impact synestias could mix a large mass fraction (10\%) of the post-impact structure, diluting any isotopic heterogeneity after the impact and increasing the range of impacts that could produce an isotopically similar Earth and Moon.

However, there are considerable barriers to mixing within all post-impact bodies. Firstly, post-impact bodies are highly thermally stratified. Figure 7 shows the thermal structure of post-impact bodies formed by a canonical impact (Figure 7c) and a high-energy, high-angular momentum impact that resulted in a synestia (Figure $7 \mathrm{f}$ ). Specific entropy is a useful variable with which to access the thermal stratification of a structure made of a single material, as it gives an indication of the thermal state of a parcel of material without a dependency on pressure (unlike temperature). A parcel of higher entropy will always be more buoyant than one of lower entropy if they are of the same composition. The outer regions of post-impact bodies (beyond $\sim 10 \times 10^{6} \mathrm{~m}$ in the examples in Figure 7 ), from where most lunar material is sourced, are typically near-isentropic and there is only a weak thermal barrier to mixing in the outer regions (Nakajima and Stevenson, 2014; Lock and Stewart, 2017; Lock et al., 2018). However, the strong increase in entropy with radius (and pressure) in both post-impact bodies between $\sim 5 \times 10^{6} \mathrm{~m}$ and $\sim 10 \times 10^{6} \mathrm{~m}$ suppresses any mixing between the outer regions and the cooler interior of the post-impact body. Mixing of material from the lower mantle to the outer regions is unfeasible without significant cooling of the outer regions or large-scale instability. Secondly, postimpact bodies are rapidly rotating (Figure 7a, d) and there is a significant angular momentum gradient with radius (Figure $7 \mathrm{~b}, \mathrm{e}$ ). For a parcel of mass to move outwards in the structure it must gain angular momentum either from shear in the vapor or from drag by infalling condensates. The rapid rotation and angular momentum gradient create a significant barrier to radial mixing and mass exchange perpendicular to the rotation axis in the postimpact body (Pahlevan and Stevenson, 2007). Convection parallel to the rotation axis is less inhibited by rapid rotation, and in the isentropic outer regions vertical mixing is rapid (on timescales of order weeks), driven by cooling of the vapor at the photosphere (Pahlevan and Stevenson, 2007; Lock et al., 2018). The effect of rapid rotation on limiting radial mass transport has been demonstrated in simulations of convection in giant planets (Kaspi et al., 2009), rapidly-rotating magma oceans (Maas and Hansen, 2019), and protoplanetary disks (Shariff, 2009). As a result of the substantial barriers to mixing, post-impact mixing is likely only able to homogenize a fraction of the postimpact body. Lock et al. (2018) argued that, in the case of a synestia, radial transport of silicate rain droplets due to gas drag would be able to overcome the angular momentum barrier and mix regions of the body with specific entropies above the critical point (up to $50 \%$ of the body, but typically less). However, even if such large fractions of the post-impact body mixed, a considerable amount of intra-impact mixing is still required if the impactor and target had substantially different isotopic compositions.

To demonstrate the difficulty in producing an Earth and Moon with similar stable isotope compositions, even with significant post-impact mixing, we can use a simple calculation (see Appendix A2 for full details). For our model, we will use the similarity between Earth and the Moon in O isotopes as our principle constraint (Young et al., 2016; Greenwood et al., 2018). There is a large amount of nonmass dependent $\mathrm{O}$ isotope variability between solar system bodies (Figures 5 and 6 ), and it is typically assumed that the bodies that collided to form the Moon would have had somewhat different $\mathrm{O}$ isotope compositions. Non-mass dependent variation in $\mathrm{O}$ isotopes is typically quantified in terms of $\Delta^{17} \mathrm{O}$, the offset in ${ }^{17} \mathrm{O} /{ }^{16} \mathrm{O}$ relative to a given ${ }^{18} \mathrm{O} /{ }^{16} \mathrm{O}$ ratio from the mass-dependent isotope fractionation line defined by terrestrial rocks (commonly known as the terrestrial fractionation line, TFL), and are reported in units of parts per million (ppm) or parts per thousand (per mil, \%o). Oxygen is a primary constituent of mantle rocks and only thought to be in relatively low concentrations in planetary cores, making it a good tracer of the bulk silicate material from the impactor and target. Also, as the concentrations of $\mathrm{O}$ in impactor and target mantles would have been very similar, mixing between the impactor and the target is linear in isotope space. Using $\mathrm{O}$ as a primary constraint avoids the complications that affect modeling of minor elements (e.g., W), such as extreme concentration contrasts between different chemical reservoirs and a strong dependence on the previous accretion histories of the impacting bodies.

In our model, we divide the post-impact body into two regions: an outer region from which the Moon inherits its composition (e.g., the lunar disk or outer synestia) and an inner region which remains isolated from the outer region during the formation of the Moon (Figure 8). Both regions are made up of a mixture of impactor and target material. After the Moon forms, either the lunar disk collapses back to Earth or the synestia cools and contracts, and the remnants of the outer Moon-forming region and the inner region are combined. The material from the remnant outer and inner regions is then assumed to mix to produce the present-day observable mantle. Note that the Moon-forming region in this model is not descriptive of the physical position of the region, or the role it plays in form- 

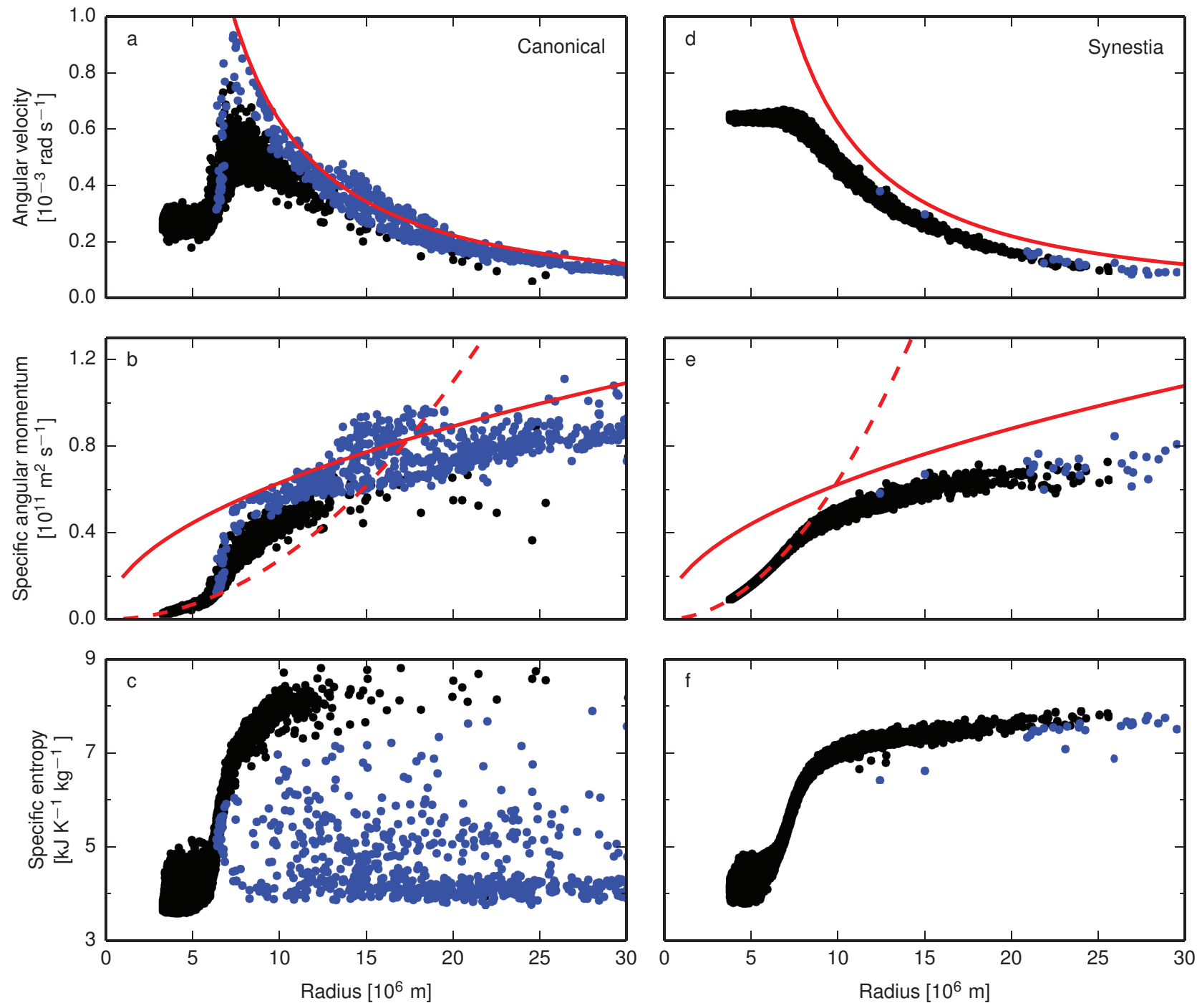

Figure 7: There are significant thermal and rotational barriers to mixing in post-impact bodies. Shown are the post-impact bodies formed in smoothed-particle hydrodynamics (SPH) impact simulations for example canonical and terrestrial synestia Moon-forming impact scenarios (one in each column). Dots represent silicate SPH particles in the midplane of each post-impact structure 48 hrs after first contact. Solid red lines denote the angular velocity or specific angular momentum of a circular Keplerian orbit around a point mass. Dashed red line indicates the specific angular momentum of material corotating with the inner region. The black particles are either at pressures above the critical point $(25.5 \mathrm{kbar})$ or are pure vapor, and the blue particles are mixtures of liquid and vapor. The super-Keplerian particles in a and $\mathrm{b}$ are the remnants of a disrupting moonlet. Modified from Lock and Stewart (2017). 
ing the Moon - it is simply the fraction of the body from which the Moon inherits its composition. We can calculate the fraction of the body that must participate in mixing after the impact (i.e., the mass of the outer, Moon-forming region from which the Moon inherits its composition) to explain the isotopic similarity of the Earth and Moon for a given isotopic difference between the impactor and target and a given degree of intra-impact mixing. We parameterized the degree of intra-impact mixing by the difference in the mass fraction of the two regions that derives from the impactor, i.e., how well impactor material is dispersed through the body during the impact.

Figure 9 shows the results of our mixing calculation. The lines mark the silicate mass fraction of the postimpact body that must be mixed to reproduce an Earth and Moon with similar $\mathrm{O}$ isotope compositions given an initial difference in the mass fraction of impactor in the Moon-forming and isolated reservoirs. These two variables are indicators of the degree of intra-impact ( $\mathrm{x}$-axis) and post-impact mixing (y-axis). The lower the efficiency of mixing during the impact (higher values on the x-axis) the larger the mass fraction of the post-impact body that must be mixed after the impact (y-axis) to explain the isotopic similarity between Earth and the Moon. Different colored lines indicate the results for different $\Delta^{17} \mathrm{O}$ offsets between the impactor and target for an Earth-Moon difference of -1 ppm (solid lines, as determined by Young et al., 2016) and $-6 \mathrm{ppm}$ (dashed lines, the most extreme value within 2 standard error from Young et al., 2016). For reference, the difference between Earth and Mars today is 0.3\%o (Franchi et al., 1999), and the average difference between Earth and enstatite chondrites calculated by Dauphas (2017) is $0.01 \%$ (Figures 5 and 6 ). Note that the most recent measurements of oxygen isotopes are in the same range as that of the Young et al. (2016) determination, with a reported difference of $-3 \pm 3 \mathrm{ppm}$ between terrestrial and lunar samples, and hence a maximum offset within 2 standard error of $-6 \mathrm{ppm}$ (Greenwood et al., 2018). Greenwood et al. (2018) attributed the inferred difference between the Earth and Moon to differential accretion of water from the late veneer, requiring the post-impact difference between the two bodies to be even smaller. To explain the given offset between Earth and the Moon, the combined degree of intra- and post-impact mixing must be such that it lies on the colored line in each case. The greater the $\Delta^{17} \mathrm{O}$ offsets between the impactor and target, or the smaller the isotopic difference between the present-day Earth and Moon, the more intra- or post-impact mixing that is required.

The red crosses in Figure 9 show the results of canonical impacts reported by Canup $(2004,2008)$ assuming the Moon is sourced from a perfect mixture of the material implanted in the disk (which is sourced largely from the impactor) with no-post impact exchange between the planet and disk (c.f., Pahlevan and Stevenson, 2007). Black and grey points show synestias from the simulations of Lock et al. (2018) and Lock and Stewart (2019). We followed the arguments of Lock et al. (2018) to determine the fraction of the outer regions of the synestia that could be mixed by silicate rain (y-axis) and determined the corresponding difference in impactor fraction between the mixed outer regions and the unmixed inner regions (x-axis). All of these impacts are high-angular momentum and so experience significantly more mixing than in the canonical case, but the gray dots are those simulations in the styles of Ćuk and Stewart (2012) and Canup (2012) that are explicitly designed to maximize mixing. Note, again, that intra-impact mixing is likely underestimated in current numerical simulations and so the $\mathrm{x}$-axis values for impact simulations should be viewed as a weak upper limit.

If the impactor and target were isotopically dissimilar (e.g., the $\Delta^{17} \mathrm{O}$ difference was similar to that between Earth and Mars today, 0.3\%o; Franchi et al., 1999), the only way to produce isotopic similarity is to extremely efficiently mix impactor and target material during the impact or to mix almost the entire body afterwards. Even if the isotopic difference between the impactor and target are small (e.g., similar to the average for enstatite chondrites calculated by Dauphas, 2017, 0.01\%) a significant amount of intra- or post-impact mixing is required unless the true isotope difference between the Earth and Moon today is at the extremes allowed by the uncertainties in observations. Nevertheless, post-impact mixing may still be important for homogenizing smaller-scale isotopic heterogeneities in the Moon-forming region. Given the difficulties in mixing the majority of the post-impact body (see discussion above), it is inescapable that either the impactor and target were nearly identical in $\mathrm{O}$ isotopes or extensive intra-impact mixing is required.

Compared to that provided by $\mathrm{O}$ isotopes, the constraint offered by ${ }^{182} \mathrm{~W}$ is harder to quantify. Predicting the ${ }^{182} \mathrm{~W}$ isotopic composition of the Earth and Moon from a given model is difficult due to the uncertainties in the disproportionate late accretion onto the two bodies, the effects of core formation on both the Earth and Moon, and the dependence of the pre-impact history of the colliding bodies on the concentrations of $\mathrm{W}$ and isotopic differences. Tungsten is also a trace element for which concentrations can vary significantly between different reservoirs, leading to highly non-linear mixing. Note that the range in likely impactor ${ }^{182} \mathrm{~W}$ compositions is larger than for O (Kruijer et al., 2015; Touboul et al., 2015; Kruijer and Kleine, 2017; Kleine and Walker, 2017; Young et al., 2016). The similarity of the Earth and Moon in ${ }^{182} \mathrm{~W}$ isotopic compositions before the addition of late veneer therefore places a weaker constraint on mixing than $\mathrm{O}$, but likely still requires a significant degree of intra-impact mixing or a coincidentally similar composition impactor. Hence, although post-impact mixing can aid in producing an Earth and Moon with similar stable isotopic compositions, a significant degree of intra-impact mixing and/or a somewhat isotopically similar impactor and target is probably also required.

Note that satisfying the constraint of isotopic similarity by intra-impact mixing of impactor and target material 


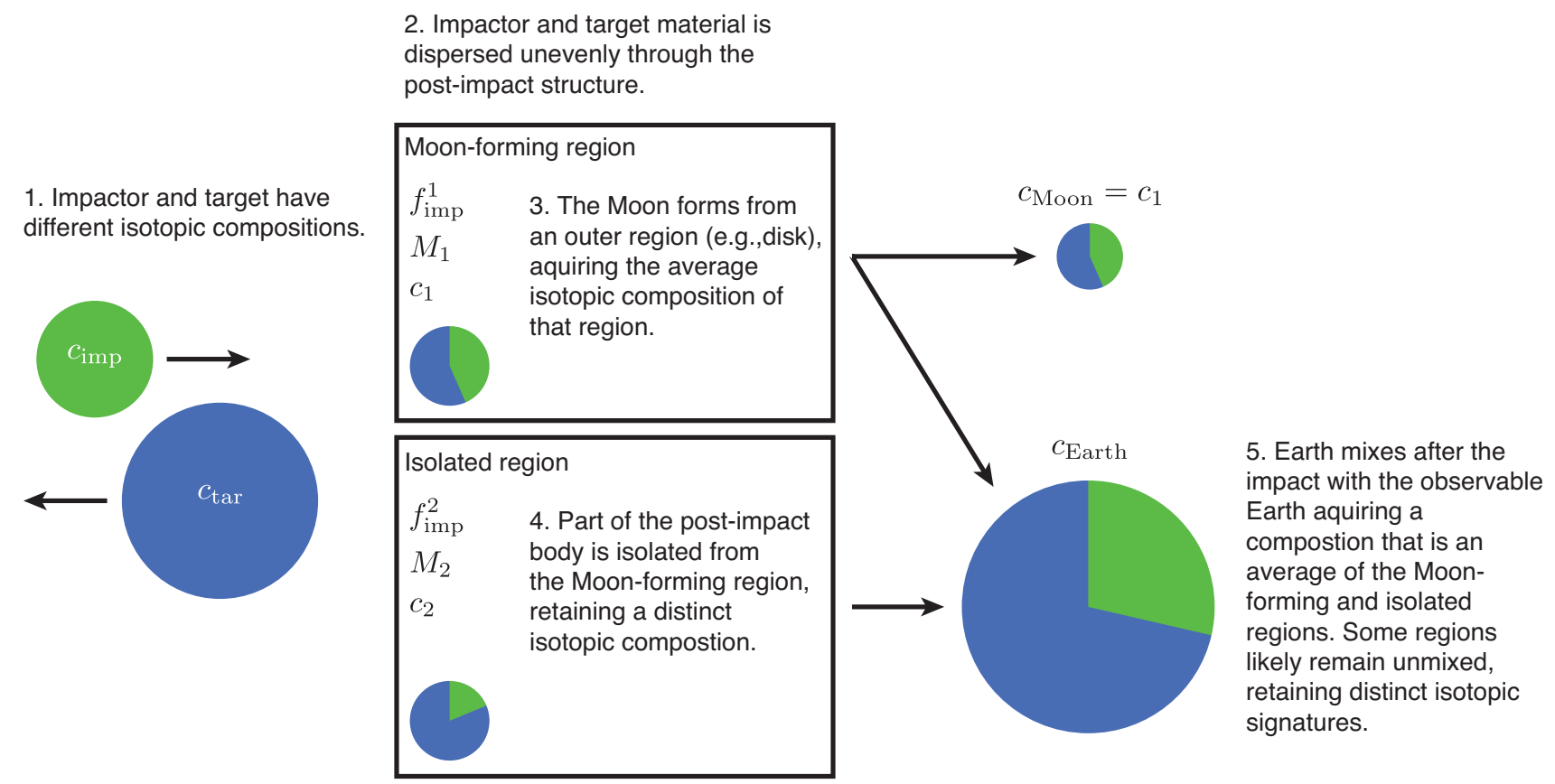

Figure 8: Schematic of mixing model. For details see Section 6 and Appendix A2.

does not strictly require homogenization of a significant fraction of the mantle. As long as the Moon-forming region was made up of a similar mass-fraction of impactor and target material as the rest of the body (assuming that the material injected into the Moon-forming region was representative of the bulk silicate composition of both bodies), the material outside the Moon-forming region could have remained poorly mixed with significant heterogeneity. This is in contrast to the case where the constraint of isotopic similarity was satisfied by post-impact mixing, in which a large fraction of the post-impact Earth must have been homogenized to produce a Moon-forming region representative of the composition of the whole body. However, the distribution of impactor and target material produced by an impact is not independent of the degree of internal homogenization of the post-impact structure. Impacts that lead to similar impactor mass fractions in the outer and inner regions of the post-impact body are typically high-energy and high-angular momentum. Such impacts have the potential to homogenize large regions of the body due to the significant shear during the impact (Nakajima and Stevenson, 2015), although the efficiency is uncertain (see above). Also, if the impacting bodies had significant internal isotopic heterogeneity, then it is unlikely that a representative sample of the silicate of each impacting body would have been injected into the Moon-forming region without homogenization of a significant fraction of the post-impact body. Regardless, it is important to bear in mind the important distinction between mixing of impactor and target material between the Moon-forming and interior regions of the post-impact body, and the internal homogenization of each region.

Current giant impact simulations suggest that there are a range of high angular momentum giant impacts that could produce synestias that are sufficiently well mixed to meet the constraint of isotopic similarity (Lock et al., 2018). These include the originally proposed scenarios of Canup (2012) and Ćuk and Stewart (2012) but also a number of intermediate scenarios (e.g., 0.3 and 0.75 , or 0.4 and 0.65 Earth-mass bodies colliding). Extensive intra-impact mixing is more likely in many high-angular momentum impacts than in the canonical grazing impact (whether of note they produce synestias), making them better candidates for lunar origin. However, accurately quantifying mixing, and therefore the range of possible Moon-forming giant impacts, remains a significant challenge. Significant developments in the codes used for giant impact studies are required to accurately capture the mixing processes during impacts. It may be the case that the required methods and resolution to accurately quantify mixing are computationally unfeasible, in which case more innovative solutions must be found to quantify the degree of mixing. In any case, the isotopic similarity of Earth and the Moon remains a significant constraint that must be satisfied by models of lunar origin.

\section{Preservation of ancient heterogeneities in Earth}

Early terrestrial evolution was intrinsically tied to lunar formation. The giant impact melted and vaporized large fractions of Earth, at least partially mixed the mantle and core, and set the initial conditions for Earth's subsequent evolution (Nakajima and Stevenson, 2015; Lock and Stewart, 2017, 2019; Lock et al., 2020). The processes that occurred during the formation and early evolution of Earth are recorded in ancient and modern terrestrial samples as 


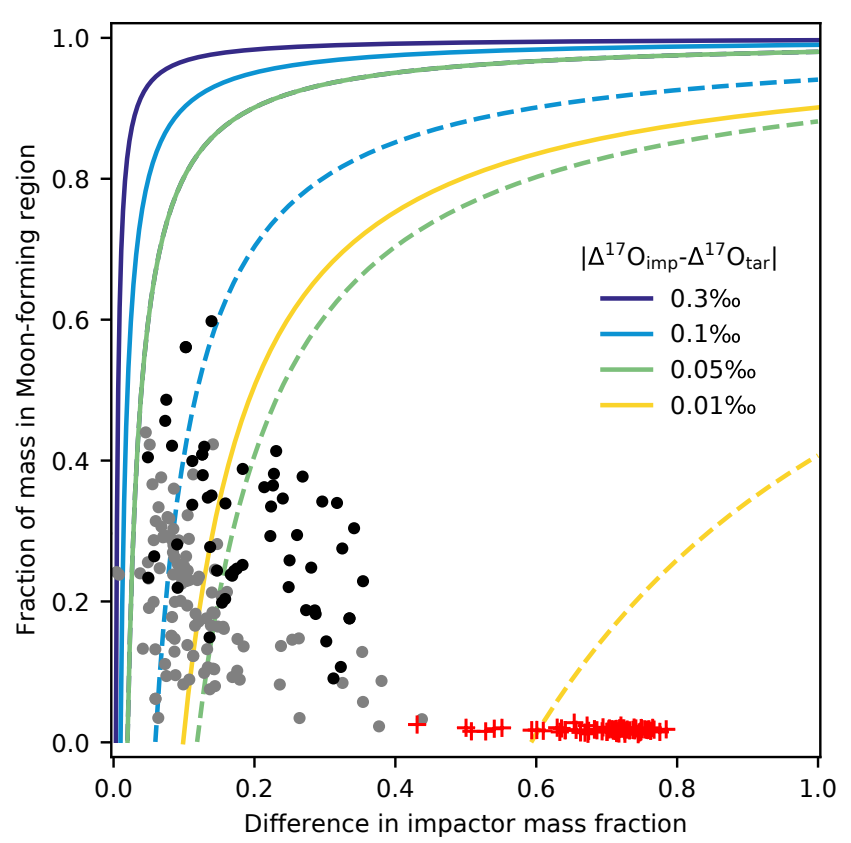

Figure 9: Producing an isotopically similar Earth and Moon requires substantial intra-impact mixing. Lines show the silicate mass fraction of the post-impact body that must be mixed (y-axis) to reproduce the $\mathrm{O}$ isotope similarity between the Earth and Moon given an initial post-impact difference in the mass fraction of impactor in the Moon-forming and isolated reservoirs (x-axis). The $\mathrm{x}$-axis is a measure of the efficiency of mixing during the impact and the $y$ axis is a measure of the efficiency of post-impact mixing. The more mixing that occurs during the impact (lower values on the $\mathrm{x}$-axis) the less post-impact mixing is required to satisfy the $\mathrm{O}$ isotope constraint. Colored lines indicate the results for different $\Delta^{17} \mathrm{O}$ offsets between the impactor and target for an Earth-Moon difference of $-1 \mathrm{ppm}$ (solid lines, as determined by Young et al., 2016) and -6 ppm (dashed lines, the most extreme value within 2 standard error from Young et al., 2016). The greater the $\Delta^{17} \mathrm{O}$ offsets between the impactor and target, or the smaller the isotopic difference between the present-day Earth and Moon, the more intra- or post-impact mixing that is required. For reference, the difference in $\Delta^{17} \mathrm{O}$ between Earth and Mars today is $0.3 \%$ (Franchi et al., 1999) and the average for enstatite chondrites calculated by Dauphas (2017) is 0.01\%. Points show the mass fraction of synestias from the simulations of Lock et al. (2018) and Lock and Stewart (2019) that could be mixed by silicate rain and the corresponding difference in impactor fraction. The gray dots are those simulations in the styles of Ćuk and Stewart (2012) and Canup (2012) that are designed to maximize mixing. The red crosses show the results of successful canonical impacts (Canup, 2004, 2008) assuming the Moon is sourced from a perfect mixture of the material implanted in the disk with no-post impact exchange between the planet and disk (c.f., Pahlevan and Stevenson, 2007). variations in isotopic ratios that are affected by short-lived radioactive decay. These variations are interpreted to reflect parent-daughter element ratio variations that existed during the lifetime of the radioactive parent isotope, i.e., a period of $\sim 5$-6 half-lives. Radioactive isotopes with relatively short half-lives (e.g., ${ }^{129} \mathrm{I},{ }^{244} \mathrm{Pu},{ }^{146} \mathrm{Sm},{ }^{182} \mathrm{Hf}$; see Table 1) trace processes that generated radiogenic isotope variations early in Earth's history. Examination of shortlived radiogenic isotope signatures in terrestrial samples can thus provide insights into the timing and mechanism of lunar formation and the Earth's subsequent evolution.

\subsection{I-Pu-Xe systematics}

Present-day mantle xenon (Xe) isotopic signatures in mid-ocean ridge basalts, plume-derived samples, and wellgases are consistent with extensive degassing of volatiles within the first $100 \mathrm{Myr}$ of Earth's history (Allègre et al., 1983; Yokochi and Marty, 2005; Mukhopadhyay, 2012). This is interpreted to reflect strong degassing either throughout accretion or during discrete loss events (e.g., only during giant impacts; Porcelli et al., 2001). A model age for the cessation of terrestrial magma ocean outgassing can be determined using I-Pu-Xe systematics in mantle-derived rocks (a mantle 'closure age'; Wetherill, 1975). However, uncertainties in initial I budgets, the partitioning behavior of I during accretion (Armytage et al., 2013; Jackson et al., 2018), and the extent of degassing before, during and after a giant impact all contribute to uncertainty in determining the timing of this last outgassing event (Mukhopadhyay and Parai, 2019). To preserve ${ }^{129} \mathrm{Xe}$ excesses from ${ }^{129} \mathrm{I}$ decay, retention of $\mathrm{Xe}$ in the mantle must have begun within the lifetime of ${ }^{129} \mathrm{I}$.

Recent studies have noted heterogeneity in radiogenic ${ }^{129} \mathrm{Xe}$ signatures between the mantle source of mid-ocean ridge basalts (MORBs) and the portion of the mantle tapped by plume-related volcanism (Mukhopadhyay, 2012). While both MORB and plume Xe isotopic signatures indicate extensive early degassing, ${ }^{129} \mathrm{I}-{ }^{129} \mathrm{Xe}$ signatures are distinct among MORB and plume-derived samples and cannot be related to one another by recent processes. Rather, the plume source must have differentiated from the upper mantle within the lifetime of ${ }^{129} \mathrm{I}$, and the chemical signature of this separation was not erased by 4.45 Gyr of mantle convection (Mukhopadhyay, 2012; Tucker et al., 2012; Parai et al., 2012; Pető et al., 2013; Parai and Mukhopadhyay, 2015; Mukhopadhyay and Parai, 2019; Parai et al., 2019). The preservation of earlyformed I-Xe heterogeneity means that Earth's mantle was never mixed to the point of homogenization after ${ }^{129} \mathrm{I}$ became extinct at $\sim 100$ Myr after the start of the Solar System.

\subsection{Sm-Nd systematics}

Early-formed chemical heterogeneities in the terrestrial silicate reservoir are evident in the short-lived ${ }^{146} \mathrm{Sm}^{-1}{ }^{142} \mathrm{Nd}$ system $\left(t_{1 / 2}=103 \mathrm{Myr}\right)$. Variations in ${ }^{142} \mathrm{Nd} /{ }^{144} \mathrm{Nd}$ are 
Table 1: The most frequently utilized short-lived radioactive isotope systems for constraining the early evolution of the Earth-Moon system in order of half-life.

\begin{tabular}{l|l}
$\begin{array}{l}\text { Short-lived radioactive parent } \\
\text { nuclides and daughter nuclides }\end{array}$ & Half-life $\left(t_{1 / 2}\right)$ \\
\hline${ }^{182} \mathrm{Hf} \rightarrow{ }^{182} \mathrm{~W}$ & $8.9 \mathrm{Myr}$ (Vockenhuber et al., 2004) \\
${ }^{129} \mathrm{I} \rightarrow{ }^{129} \mathrm{Xe}$ & $15.7 \mathrm{Myr}$ (Eckerman et al., 1993) \\
${ }^{244} \mathrm{Pu} \rightarrow{ }^{131-136} \mathrm{Xe}$ & $80 \mathrm{Myr}$ (Akovali, 2003) \\
${ }^{146} \mathrm{Sm} \rightarrow{ }^{142} \mathrm{Nd}$ & $103 \mathrm{Myr}$ (Friedman et al., 1966; Meissner et al., 1987)
\end{tabular}

commonly expressed as $\mu^{142} \mathrm{Nd}$, which refers to deviations in parts per million from a terrestrial standard. The first anomalies in $\mu^{142} \mathrm{Nd}$ were measured in $3.8 \mathrm{Gyr}$ old Archean samples coming from the Isua Supracrustal Belt in SW Greenland (Harper and Jacobsen, 1992; Boyet et al., 2003; Caro et al., 2003). These samples showed ${ }^{142} \mathrm{Nd}$ excesses that reflect a $\mathrm{Sm} / \mathrm{Nd}$ fractionation produced during the first $500 \mathrm{Ma}$ of Earth's history while ${ }^{146} \mathrm{Sm}$ was alive. Both parent and daughter elements are refractory and lithophile, but are fractionated by partial melting and crystallization (e.g., during magma ocean crystallization and crust formation) as Nd is more incompatible than Sm. Reservoirs characterized by high $\mathrm{Sm} / \mathrm{Nd}$ ratios (i.e., those that preferentially derive from the residue of partial melts) over time evolve excesses in ${ }^{142} \mathrm{Nd}$, whereas those characterized by low $\mathrm{Sm} / \mathrm{Nd}$ ratios (i.e., those that preferentially derive from melt) develop deficits in ${ }^{142} \mathrm{Nd}$ relative to an unfractionated reservoir. The timing of this fractionation can be constrained by combining short-lived and longlived Sm-Nd systematics $\left({ }^{146} \mathrm{Sm}-{ }^{142} \mathrm{Nd}\right.$ and ${ }^{147} \mathrm{Sm}-{ }^{143} \mathrm{Nd}$, respectively). Models predict that chemical fractionation associated with the crystallization of the magma ocean would have occurred around 100-150 Myr after the beginning of solar system accretion to explain observed shortand long-lived Sm-Nd signatures (e.g., Caro et al., 2003; Rizo et al., 2011).

Both excesses and deficits in ${ }^{142} \mathrm{Nd}$ relative to the average modern mantle have now been measured in samples coming from the oldest known terranes on Earth: the Kaapvaal craton in South Africa, Canada (Superior Province, Labrador, Northwest Territories), the Yilgarn craton in Western Australia and in the Napier complex in East Antarctica (see the recent reviews in Carlson et al., 2019; Guitreau et al., 2019). Very small variations of ${ }^{142} \mathrm{Nd}$ were also reported in modern samples from the Réunion hotspot, and these variations may correlate with helium isotope ratios (Peters et al., 2018). Samples from the Samoa and Hawaii hotspots which have anomalies in ${ }^{182} \mathrm{~W} /{ }^{184} \mathrm{~W}$ have been measured for ${ }^{146} \mathrm{Sm}_{-}{ }^{142} \mathrm{Nd}$ systematics Horan et al. (2018). Measured deviations are very small and remain poorly resolved with respect to ana- lytical precisions $\left(\mu^{142} \mathrm{Nd}<3 \mathrm{ppm}\right)$ even if these samples have high ${ }^{3} \mathrm{He} /{ }^{4} \mathrm{He}$ ratios ( $\mathrm{R} / \mathrm{Ra}$ up to 34 ). Thus, ${ }^{142} \mathrm{Nd}$ variations in terrestrial samples indicate that early-formed chemical reservoirs may have been preserved in the deep mantle despite 4.5 Gyr of mantle convection.

\section{3. ${ }^{182} H_{-}-^{182} W$ systematics}

Parts per million scale heterogeneity is also observed in ${ }^{182} \mathrm{~W} /{ }^{184} \mathrm{~W}$ signatures among terrestrial rocks ranging in age from $\sim 4$ Ga to modern day (for recent reviews, see Rizo et al., 2019; Carlson et al., 2019). In terrestrial studies, because variations in ${ }^{182} \mathrm{~W} /{ }^{184} \mathrm{~W}$ are small they are commonly expressed as $\mu^{182} \mathrm{~W}$, which refers to deviation in parts per million of the ${ }^{182} \mathrm{~W} /{ }^{184} \mathrm{~W}$ ratio from a high purity $\mathrm{W}$ standard. The composition of the $\mathrm{W}$ standard is commonly taken to be the composition of the BSE. For reference, chondrites have $\mu^{182} \mathrm{~W} \sim-190 \pm 10$ (Kleine et al., 2009) and mid-ocean ridge basalts have $\mu^{182} \mathrm{~W} \sim 0$ (e.g., Rizo et al., 2016b). The different geochemical behavior of the parent $\left({ }^{182} \mathrm{Hf}\right.$; lithophile) and daughter $\left({ }^{182} \mathrm{~W}\right.$; moderately siderophile) nuclides coupled with the short half-life of ${ }^{182} \mathrm{Hf}\left(t_{1 / 2}=8.9 \mathrm{Ma}\right.$, Vockenhuber et al., 2004) makes the ${ }^{182} \mathrm{Hf}-{ }^{182} \mathrm{~W}$ system an effective tracer of metal-silicate differentiation events (e.g., core formation) that occurred during the first $\sim 60 \mathrm{Myr}$ of solar system history (Touboul et al., 2012). Early differentiation events can also be traced using the Hf-W system because $\mathrm{W}$ is more incompatible than Hf which leads to fractionation in the Hf/W ratio during silicate differentiation (Shearer and Righter, 2003). If any parent-daughter $(\mathrm{Hf} / \mathrm{W})$ fractionation occurs during the lifetime of ${ }^{182} \mathrm{Hf}$, excesses or depletions in ${ }^{182} \mathrm{~W} /{ }^{184} \mathrm{~W}$ can develop in mantle or crustal reservoirs (Touboul et al., 2012).

Most mantle-derived rocks from $\sim 4$ to $\sim 2.7$ Ga are characterized by excesses in $\mu^{182} \mathrm{~W}(+5$ to +20 , with the majority between +10 and +15$)$. Samples defining this compositional range include $\sim 4$ Ga supracrustal rocks from Acasta (Willbold et al., 2015; Reimink et al., 2018), $\geq 3.8 \mathrm{Ga}$ supracrustal rocks from Nuvvuagittuq (Touboul et al., 2014), 3.8 Ga supracrustal rocks from Saglek (Liu et al., 2016), 3.8-3.3 Ga supracrustal rocks from Isua (Will- 
bold et al., 2011; Rizo et al., 2016a; Dale et al., 2017), 3.5 Ga basalts from the Pilbara Craton (Rizo et al., 2019), and 2.8-2.7 Ga komatiites from Kostomuksha (Touboul et al., 2012) and Boston Creek (Puchtel et al., 2018). Exceptions to the general enrichment in $\mu^{182} \mathrm{~W}$ in ancient materials are $3.5 \mathrm{Ga}$ Komati komatiites $\left(\mu^{182} \mathrm{~W} 0\right.$ to +5 , unresolved from the $\mathrm{W}$ standard composition; Touboul et al., 2012), 3.55 Ga komatiites from Schapenburg $\left(\mu^{182} \mathrm{~W}-6\right.$ to -12; Puchtel et al., 2016), and $>2.3$ Ga South African glacial diamictites ( $\mu^{182} \mathrm{~W} 0$ to -15 ; Mundl et al., 2018).

In modern samples, heterogeneity in $\mu^{182} \mathrm{~W}$ is also observed. Phanerozoic flood basalts that record positive $\mu^{182} \mathrm{~W}(+10$ to $+48 \mathrm{ppm})$ compositions were reported by Rizo et al. (2016b). Kruijer and Kleine (2018), however, proposed a revision to some of these data suggesting that there were no ${ }^{182} \mathrm{~W}$ isotope excesses in Phanerozoic rocks from the Ontong Java Plateau. Further investigation is required to resolve this debate. Non-anomalous $\mu^{182} \mathrm{~W}$ compositions and depletions in $\mu^{182} \mathrm{~W}$ are also manifest in the modern rock record ( +5 to -20 ; Willbold et al., 2011; Touboul et al., 2012; Liu et al., 2016; Rizo et al., 2016a; Mundl et al., 2017; Rizo et al., 2019). Samples defining the depleted ${ }^{182} \mathrm{~W}$ signature are primarily ocean island basalts (OIBs), some of which display a relationship with depletions in ${ }^{182} \mathrm{~W}$ being associated with high ${ }^{3} \mathrm{He} /{ }^{4} \mathrm{He}$ (Mundl et al., 2017). Samples with high ${ }^{3} \mathrm{He} /{ }^{4} \mathrm{He}$ are commonly interpreted to represent tapping of a region of the manthe that is less degassed relative to regions of the modern mantle (e.g., mid ocean ridge basalts; Kurz et al., 1982). The general relationship between $\mu^{182} \mathrm{~W}$ and ${ }^{3} \mathrm{He} /{ }^{4} \mathrm{He}$ in some OIBs suggests that high ${ }^{3} \mathrm{He} /{ }^{4} \mathrm{He}$ plumes either sample reservoirs in the deep mantle that were formed prior to $\sim 60 \mathrm{Ma}$ or sample reservoirs that record core-mantle interaction (Mundl et al., 2017; Rizo et al., 2019; MundlPetermeier et al., 2020).

From the current rock record, it is clear that the terrestrial mantle is defined by $\mu^{182} \mathrm{~W}$ heterogeneity that persisted from the Hadean-Archean to the present day. How the magnitude and variability in ${ }^{182} \mathrm{~W}$ developed and why modern samples tend to exhibit normal or depleted ${ }^{182} \mathrm{~W}$ signatures compared to Hadean and Archean-derived samples remain a matter of debate. Processes proposed to explain ${ }^{182} \mathrm{~W}$ heterogeneity can be divided into three general scenarios: (1) disproportional late accretion, (2) early metal-silicate or silicate-silicate fractionation, or (3) coremantle interaction, each of which are discussed below.

Disproportional late accretion requires that mantlederived samples showing excesses in $\mu^{182} \mathrm{~W}$ be derived from mantle domains which did not receive the full complement of late-accreted material (Willbold et al., 2011; Touboul et al., 2014; Rizo et al., 2016a; Puchtel et al., 2018). Late-accreted material refers to the final $\sim 0.5$ to $2 \mathrm{wt} \%$ added to Earth after final core segregation (Kimura et al., 1974; Chou, 1978; Walker, 2009; Morbidelli and Wood, 2014; Marchi et al., 2018). This material is considered to be chondritic in composition and, as such, would have been depleted in $\mu^{182} \mathrm{~W}$ relative to the present-day mantle (chondritic $\mu^{182} \mathrm{~W}=-190 \pm 10$; Kleine et al., 2009) and relatively enriched in W and HSEs compared to the pre-late veneer mantle (Morgan, 1985; Becker et al., 2006; Walker, 2009). Addition of late-accreted material into the mantle would have led to a decrease in $\mu^{182} \mathrm{~W}$ coupled with an enrichment in HSE abundance (Willbold et al., 2011). Consequently, regions isolated from the addition of late accreted material would be comparatively enriched in $\mu^{182} \mathrm{~W}$ and depleted in HSE. Coupled $\mu^{182} \mathrm{~W}-\mathrm{HSE}$ concentration estimates of primordial source regions, however, do not consistently exhibit the predicted relationship between $\mu^{182} \mathrm{~W}$ and HSE abundance. This may be due to the difficulties in accurately determining the HSE source composition (e.g., supracrustal materials are the product of multi-phase magmatic and metamorphic processes; Willbold et al., 2011). HSE abundances in the mantle can only be confidently determined using mantle peridotites and komatiites and there are few examples of Archean mantle peridotites. The complex $\mu^{182} \mathrm{~W}$-HSE relationship may also indicate that disproportional late accretion is not the sole mechanism producing $\mu^{182} \mathrm{~W}$ heterogeneity in the mantle (see Carlson et al., 2019, and references therein).

Early silicate differentiation following crystallization of a magma ocean or partial melting during the lifetime of ${ }^{182} \mathrm{Hf}$ would result in $\mu^{182} \mathrm{~W}$ heterogeneity (Touboul et al., 2012). Alternatively, early metal-silicate fractionation followed by the removal of metal from an isolated mantle domain (e.g., a basal magma ocean), may have produced variable $\mu^{182} \mathrm{~W}$ (Touboul et al., 2012) (see summary by Puchtel et al., 2018). These scenarios can be assessed by combining Hf-W systematics with the short-lived ${ }^{146} \mathrm{Sm}^{1}{ }^{142} \mathrm{Nd}$ system. The ${ }^{146} \mathrm{Sm}_{-}{ }^{142} \mathrm{Nd}$ system comprises lithophile elements, where the daughter is more incompatible than the parent in mantle melting (see Section 7.2). As such, this radiometric system is sensitive to silicate-liquid fractionation, and insensitive to metal-silicate fractionation. If silicate differentiation processes were responsible for producing variations in $\mu^{182} \mathrm{~W}$, these anomalies would be coupled with variations in ${ }^{142} \mathrm{Nd}$ so long as the fractionation event occurred within the lifetimes of both parent species (e.g., Rizo et al., 2019; Carlson et al., 2019). There are, however, limited datasets that report ${ }^{142} \mathrm{Nd}-$ ${ }^{182} \mathrm{~W}$ data obtained from the same sample (Touboul et al., 2014; Puchtel et al., 2016; Rizo et al., 2016a; Horan et al., 2018). From these coupled datasets, correlated behavior between ${ }^{142} \mathrm{Nd}-{ }^{182} \mathrm{~W}$ is generally not observed, except in Schapenburg komatiites which are linked to silicatesilicate differentiation (Puchtel et al., 2016; Rizo et al., 2019; Carlson et al., 2019). This general lack of correlation indicates that early silicate differentiation was likely not solely responsible for production of anomalies in $\mu^{182} \mathrm{~W}$ and $\mu^{142} \mathrm{Nd}$ (e.g., Touboul et al., 2014; Rizo et al., 2016a; Horan et al., 2018; Carlson et al., 2019). Given the very limited number of coupled $\mu^{142} \mathrm{Nd}-\mu^{182} \mathrm{~W}$ data obtained from the same samples, however, future work combining these systems on the same samples is required to assess the robustness of this interpretation. A few martian mete- 
orites were measured for ${ }^{182} \mathrm{Hf}$ and ${ }^{142} \mathrm{Nd}$ isotopes and even if the martian mantle differentiated during the lifetime of these systematics, no correlation has been identified (Foley et al., 2005).

Core-mantle interaction has recently been reemphasized as a viable process through which $\mu^{182} \mathrm{~W}$ heterogeneity may have formed (Mundl et al., 2017; Rizo et al., 2019; Mundl-Petermeier et al., 2020). Rizo et al. (2019) proposed that the change in $\mu^{182} \mathrm{~W}$ mantle signatures (from excess to normal or depleted) after $2.7 \mathrm{Ga}$ was due to a change in mantle dynamics occurring after the Archean or the onset of inner core crystallization. This model is based on new OIB data interpreted in the context of a compilation of the past near-decade of high precession ${ }^{182} \mathrm{~W}$ analysis. Either mechanism proposed by Rizo et al. (2019) could produce deep mantle reservoirs characterized by $\mu^{182} \mathrm{~W}$ depletions that could subsequently be entrained in mantle plumes. Notably, as the core is predicted to be highly enriched in HSEs, the deep mantle reservoirs housing $\mu^{182} \mathrm{~W}$ depletions are expected to be enriched in HSEs. There is, however, no correlation between depleted $\mu^{182} \mathrm{~W}$ and enriched HSE concentrations in studied OIBs, suggesting that there was insignificant siderophile element exchange between the core and the deep mantle reservoir despite pervasive diffusive isotope exchange (Rizo et al., 2019; Mundl-Petermeier et al., 2020). Following Puchtel and Humayun (2000) and Humayun (2011), MundlPetermeier et al. (2020) suggested core-mantle interaction via isotopic equilibration as a process by which modification of ${ }^{182} \mathrm{~W}$ isotope compositions could occur without modification of HSE abundances in the lowermost mantle. Alternatively, the HSE concentration in deep mantle source regions may not faithfully be recorded in the HSE complement of OIBs due to the complexities in estimating HSE concentrations from the basaltic rock record. It has also been suggested that HSE abundances may become decoupled from $\mathrm{W}$ during the low degrees of partial melting involved in the formation of OIBs (Jones et al., 2019). Future work further developing the accuracy of HSE concentration estimates in source regions and experimentally determining the mechanism and efficiency of chemical and isotopic exchange across the core-mantle boundary will aid in determining the role that core-mantle interaction plays in establishing $\mu^{182} \mathrm{~W}$ mantle heterogeneity (e.g., Yoshino et al., 2020).

Because Sm and Nd are lithophile elements, processes associated with core-segregation are not anticipated to significantly affect $\mathrm{Sm} / \mathrm{Nd}$ ratios or $\mathrm{Nd}$ isotope compositions. This may account for the absence of coupled $\mu^{182} \mathrm{~W}$ and $\mu^{142} \mathrm{Nd}$ compositions in some samples (Rizo et al., 2019). Carlson et al. (2019) extended these authors' interpretation by proposing $\mu^{182} \mathrm{~W}$ variations in the mantle record a predominantly core-mantle segregation process while $\mu^{142} \mathrm{Nd}$ variations record crust-mantle differentiation events that occurred after ${ }^{182} \mathrm{Hf}$ was extinct. Carlson et al. (2019) proposed that Nd model ages calculated using Archean samples reflect the time of the giant impact, with the requirement that the impact did not homogenize $\mathrm{W}$ isotopic signatures imparted during early core segregation. Consequently, they suggest that the $\mu^{142} \mathrm{Nd}$ variations reflect differentiation of the mantle after the Moon-forming impact which were effectively homogenized by the end of the Archean. Future studies combining $\mu^{182} \mathrm{~W}-\mu^{142} \mathrm{Nd}-$ HSE concentration datasets, experimentally derived constraints on chemical and isotopic exchange under coremantle boundary conditions, and numerical models tracing mantle dynamics during different stages of Earth's history will enable these theories to be further vetted.

\subsection{Using terrestrial geochemical characteristics to con- strain the Moon forming event}

In summary, very early formed isotopic heterogeneities have been preserved in the terrestrial mantle to the present day. Generation of these heterogeneities did not necessarily post-date the Moon-forming giant impact; they could have formed earlier and survived, or could have been generated by giant impacts themselves. For example, high ${ }^{3} \mathrm{He} /{ }^{22} \mathrm{Ne}$ ratios observed in Earth's mantle compared to precursor compositions (e.g., solar, chondritic) are attributed to ingassing of solar nebular gas into a terrestrial magma ocean early in Earth's history, due to the higher solubility of $\mathrm{He}$ relative to $\mathrm{Ne}$ in silicate melts (e.g., Graham, 2002). The ${ }^{3} \mathrm{He} /{ }^{22} \mathrm{Ne}$ ratio of the MORB mantle $(\sim 10)$ is significantly higher than that observed in plume sources $(\sim 2.5)$. Tucker and Mukhopadhyay (2014) argued that at least three magma ocean events occurred to raise ${ }^{3} \mathrm{He} /{ }^{22} \mathrm{Ne}$ in the upper mantle to $\sim 10$, and that the later events did not affect the whole mantle gas budget. Therefore, there is simultaneously geochemical evidence for widespread mantle melting, outgassing, and differentiation, and evidence for inefficient mixing of the early Earth's interior during and after giant impacts. Here we will discuss the constraints the preservation of primordial reservoirs places on the formation of the Moon, and the recovery of Earth immediately after the impact.

The interpretation of the constraints imposed by each radioactive system on Moon formation is critically dependent on the lifetime of the system relative to the timing of the Moon-forming impact (Section 3). If the Moonforming giant impact occurred after a radioactive system went extinct, then variations in radiogenic isotopes produced by that system must either have been produced before the impact and preserved, record heterogeneous late addition of material to the mantle from extraplanetary bodies (such as late accretion), or record exchange between the mantle and core. If the Moon formed at $\sim 4.36 \mathrm{Ga}$ ( $\sim 200 \mathrm{Myr}$ after the start of the solar system) as argued in Section 3, this requirement would apply to both ${ }^{182} \mathrm{~W}$ and ${ }^{129} \mathrm{Xe}$ isotopic anomalies as well as ${ }^{3} \mathrm{He} /{ }^{22} \mathrm{Ne}$ ratios. If some of the observed anomalies (such as ${ }^{182} \mathrm{~W},{ }^{129} \mathrm{Xe}$ ) were formed in the proto-Earth's mantle before the Moon forming impact (as seems likely based on the arguments above) the Moon-forming impact could not have homogenized the whole mantle. As $\mathrm{W}$ and noble gases are trace 
elements (unlike e.g., O), the concentration of these elements could vary significantly between different reservoirs and pre-Moon forming impact signatures may have been preserved in relatively small volumes of the mantle. The requirement for incomplete homogenization of Earth during the impact is a powerful constraint on lunar formation, particularly given the inference that efficient intra-impact mixing of impactor and target material is required to explain the isotopic similarity between the Earth and Moon (Section 6). A successful Moon forming impact must mix the majority of the mantle but leave distinct domains, of uncertain volume, that are not homogenized with the rest of the mantle. The balance between these two requirements could dramatically reduce the number of plausible Moon-forming giant impacts. However, in order to leverage this constraint, significant improvements in giant impact models are required to accurately capture mixing and thermal equilibration (see Section 6).

The need to preserve anomalies generated before the Moon-forming giant impact would also place constraints on the recovery of Earth after the Moon-forming impact. After the impact, Earth cooled rapidly by radiation, driving condensation of the outer regions and subsequent freezing of the mantle. In order to preserve pre-impact mantle heterogeneity these processes must not have homogenized the mantle. Preservation of ${ }^{182} \mathrm{~W}$ and noble gas anomalies is particularly challenging as these elements are incompatible in solid silicates (at least at upper mantle pressures) and thus are concentrated in the liquid during fractional crystallization. The post-impact evolution is dependent on the parameters of the Moon-forming impact as they determine the initial thermal and rotational state of the planet (Nakajima and Stevenson, 2015; Lock and Stewart, 2017, 2019; Lock et al., 2020). Lock and Stewart (2019) also showed that internal pressures in the post-impact body are dependent on the parameters of the impact and could have been much lower than in present-day Earth (10s of GPa lower at the core-mantle boundary) with the lowest pressures after high-angular momentum impacts. The pressures would have subsequently increased during cooling and lunar tidal recession as the body condensed and its rotation was slowed. Varying internal pressures in the aftermath of different giant impacts would change the stability of different phases and so how the mantle freezes (Lock and Stewart, 2019; Lock et al., 2020). The rate of rotation of the post-impact body also dictates the efficiency of mixing in the magma ocean, with high rotation rates suppressing mixing (Maas and Hansen, 2019) and aiding in the preservation of primordial reservoirs. The generation of anomalies from radioactive systems that were still alive at the time of the Moon-forming impact (such as ${ }^{146} \mathrm{Sm}$ ${ }^{142} \mathrm{Nd}$ ) also depends on the evolution of the post-impact body and hence the parameters of the Moon-forming impact. Studying the geochemical consequences of different pathways of recovery (condensation, magma ocean freezing and tidal evolution) could offer new and important constraints on the initial conditions of the early Earth and hence the parameters of the Moon-forming giant impact.

\section{Conclusions and future directions}

Compositional and isotopic measurements of both lunar, terrestrial, and meteoritic samples have given valuable insights into the formation of the Moon and the early evolution of Earth. Constraints from various radioactive systems suggest that the Moon formed between about 50 and 200 Myrs after the start of the solar system, with several systems favoring younger ages. Comparison between the bulk composition of the Earth and Moon has revealed that the Moon likely formed in a high temperature, modest pressure environment from an iron-depleted disk or synestia. We also argue that the isotopic similarity between the Earth and Moon requires that either the proto-Earth and impactor had very similar isotopic compositions, or that the efficiency of mixing during the collision had to have been high. However, simultaneously the impact could not have homogenized the whole mantle as isotopic signatures of pre-impact heterogeneity are preserved. Mantle heterogeneities must also be preserved during the recovery of Earth after the impact and survived 4.5 Gyr of mantle convection, providing an important test of mantle evolution models. Together, these observations provide strong constraints with which to test different models of the formation of the Moon and early evolution of Earth.

Our understanding of planet formation and the early Earth is rapidly developing with increasingly sophisticated measurements of lunar, meteoritic and terrestrial samples. Particularly important for elucidating this critical time in Earth's history are studies that combine measurements of the abundances and isotopic ratios for multiple elements from the same samples. For example, to test mechanisms for producing the MVE depletion and isotopic fractionation in the Moon relative to Earth it is important to observe if and how the different elements are coupled. Combining $\mu^{182} \mathrm{~W}-\mu^{142} \mathrm{Nd}-$ noble gas-HSE concentration measurements of terrestrial samples would also help distinguish the relationship between these different systems, would allow for identification of later-stage alteration, and would provide tests of different models for the origins of chemical and isotopic heterogeneities.

In order to be able to interpret the plethora of geochemical constraints, there is a need for models that couple the physical and geochemical processes that occurred during lunar formation and the early evolution of Earth. In this paper, we have highlighted the importance of developing new techniques to capture mixing and thermal equilibration in giant impact simulations to be able to use the efficiency of mixing to both explain the isotopic similarity between the Earth and Moon and the survival of primordial reservoirs as constraints on lunar origin. In addition, to fully utilize the survival of primordial reservoirs as a constraint on Earth's history, coupled dynamic and chemical models that track the recovery and long-term evolution of 
Earth are required. To make the connection between processes in the lunar disk or terrestrial synestia and observations, we must also develop more sophisticated models that account for the small-scale multiphase and multicomponent dynamics of these substantially vaporized structures.

Producing accurate models requires laboratory experiments to constrain the properties of materials and behavior of different elements at the extreme conditions of lunar formation and mantle evolution. Developing advanced equations of state for silicates and metals, in particular EOS that include phase transitions, at very high pressures and temperatures are fundamental to improving the accuracy of giant impact and mantle evolution models. Thermodynamic data on how materials behave at high temperatures and modest pressures in the lunar disk and terrestrial synestia are also required to accurately predict the MVE depletion and isotopic fractionation produced by different lunar formation models.

We are in a new age of lunar exploration. Several nations and private companies are planning missions to the Moon, including crewed missions. Most imminently, the China National Space Administration is planning sample return missions from the near (Chang'e 5) and potentially also the far (Chang'e 6) sides of the Moon. Acquisition of high precision measurements from different regions of the lunar surface would allow for more accurate determinations of the Moon's age, composition, and thermal history. In addition, the lunar far side may host samples from the lunar mantle (Li et al., 2019) providing a more complete view of lunar chemistry. These new data, and further studies of existing samples, will continue to elucidate the coupled early history of Earth and its Moon.

\section{A1. Data sources for Figures 5 and 6}

Data for Figures 5 and 6 were taken from a compilation by Dauphas (2017) with the exception that the lunar value for $\epsilon^{54} \mathrm{Cr}$ was taken from Mougel et al. (2018). Below, we give the original data sources for this compilation.

\section{A1.1. $\Delta^{17} O$}

$\Delta^{17} \mathrm{O}$ data was compiled by Dauphas (2017) with the aid of MetBase (Meteorite Information Database, http: // www. metbase.org/). $\Delta^{17} \mathrm{O}$ data were taken from Bischoff et al. (1991, 1993, 1998); Bischoff (1994); Bridges et al. (1997, 1999); Brearley et al. (1989); Burkhardt et al. (2017); Buchanan et al. (1993); Clayton and Mayeda (1978, 1981, 1984, 1985, 1989, 1990, 1996); Clayton et al. (1976, 1977, 1983, 1984a,b, 1991, 1997a,b); Connolly et al. (2007); Franchi et al. (1992, 1999); Grossman and Zipfel (2001); Grossman et al. (1987); Grossman (1999); Grady et al. (1987); Gooding et al. (1983); Goodrich et al. (1987); Halbout et al. (1984, 1986); Ivanov et al. (1987); Jabeen et al. (1998); Jackel et al. (1996); Kallemeyn et al. (1996); Keller et al. (1994); McCoy et al. (1995, 1996, 1997);
Mayeda and Clayton (1980, 1983, 1989a,b); Mayeda et al. (1987, 1995); Moroz et al. (1988); Nehru et al. (1996); Olsen et al. (1987, 1994); Onuma et al. (1978, 1983); Petaev et al. (1988); Prinz et al. (1991); Pun et al. (1991); Romanek et al. (1998); Rowe et al. (1994); Russell et al. (1998, 2005); Ruzicka et al. (1995); Recca et al. (1986); Sears et al. (1990); Simon et al. (1995); Schulze et al. (1994); Stepniewski et al. (1998); Weber et al. (1996, 1997); Weisberg et al. (1991, 1993, 1995, 1996, 1997); Zolensky et al. (1989, 1997); and Young et al. (2016).

\section{A1.2. $\epsilon^{50} \mathrm{Ti}$}

$\epsilon^{50} \mathrm{Ti}$ data were taken from Zhang et al. (2011, 2012); Trinquier et al. (2009); and Burkhardt et al. (2017).

\section{A1.3. $\epsilon^{54} \mathrm{Cr}$}

$\epsilon^{54} \mathrm{Cr}$ data were taken from Trinquier et al. (2007); Qin et al. (2010a,b); Shukolyukov and Lugmair (2006a,b); Shukolyukov et al. (2009); Schiller et al. (2014); Yamashita et al. (2005, 2010); Yamakawa et al. (2010); Larsen et al. (2011); Göpel and Birck (2010); Burkhardt et al. (2017); and Mougel et al. (2018).

\section{A2. Details of mixing model}

In Section 6 we present the results of a mixing model to investigate the requirements for mixing during and after the Moon-forming giant impact imposed by the isotopic similarity between the Earth and Moon. Here we provide the details of that model.

We divide the post-impact body into two regions: the Moon-forming region and an isolate region that does not communicate with the Moon forming region during the period of Moon formation. The mass of these two regions are $M_{1}$ and $M_{2}$ respectively, where 1 denotes the Moonforming region and 2 the isolated region (Figure 8 ). The masses of the two regions are such that

$$
M_{1}+M_{2}=M_{\text {Earth }}+M_{\text {Moon }},
$$

where $M_{\text {Moon }}$ and $M_{\text {Earth }}$ are the mass of the present-day Moon and Earth respectively.

The two regions are made up of a different mass fraction of impactor material, $f_{\mathrm{imp}}^{i}$, and so have different average $\Delta^{17} \mathrm{O}$ isotopic compositions, $c_{i}$. Note that both these regions can be internally heterogeneous and the only requirement is that the Moon inherits the average composition of the Moon-forming region. For simplicity, we assume that the majority of Earth mixes after the impact and that the present-day observable mantle is a mixture of the isolated region and the fraction of the Moon-forming region that was not incorporated into the Moon such that

$$
\left(M_{1}-M_{\text {Moon }}\right) c_{1}+M_{2} c_{2}=M_{\text {Earth }} c_{\text {Earth }}=0
$$

where $c_{\text {Earth }}$ is the composition of the present-day Earth's mantle which is zero by definition. The composition of 
each region is related to the composition of the target and impactor by

$$
c_{i}=f_{\mathrm{imp}}^{i} c_{\mathrm{imp}}+\left(1-f_{\mathrm{imp}}^{i}\right) c_{\mathrm{tar}},
$$

where $c_{\mathrm{imp}}$ and $c_{\mathrm{tar}}$ are the $\Delta^{17} \mathrm{O}$ isotopic composition of the impactor and target respectively.

We can determine an expression for the mass fraction of the post-impact structure that must be mixed in to the Moon-forming region $\left(F_{\text {mix }}=M_{1} /\left(M_{1}+M_{2}\right)=\right.$ $\left.M_{1} /\left(M_{\text {Earth }}+M_{\text {Moon }}\right)\right)$ given a present-day difference in $\Delta^{17} \mathrm{O}$ between the Moon and Earth $\left(\Delta c_{\mathrm{M}-\mathrm{E}}=c_{1}\right.$ by definition), a specified $\Delta^{17} \mathrm{O}$ offset between the impactor and target $\left(\Delta c_{\mathrm{imp}-\mathrm{tar}}=c_{\mathrm{imp}}-c_{\mathrm{tar}}\right)$, and a difference in the mass fraction of impactor in the two regions $\left(\Delta f_{\mathrm{imp}}=\right.$ $f_{\mathrm{imp}}^{1}-f_{\mathrm{imp}}^{2}$ ). By substituting for $M_{2}$ in equation 2 using equation 1 we can find an expression for $M_{1}$ as a function of the composition of the two regions:

$$
M_{1}=\frac{M_{\mathrm{Moon}} c_{1}-\left(M_{\mathrm{Earth}}+M_{\mathrm{Moon}}\right) c_{2}}{\left(c_{1}-c_{2}\right)}
$$

Independently we can re-express equation 2 for the isolated region $(i=2)$ to give an expression for $c_{2}$ in terms of the composition of the impactor and target:

$$
c_{2}=c_{\mathrm{imp}}-\left(1-f_{\mathrm{imp}}^{2}\right) \Delta c_{\mathrm{imp}-\mathrm{tar}} .
$$

Similarly, rearranging equation 2 for the Moon-forming region $(i=1)$ we obtain an expression for $c_{i m p}$ :

$$
c_{\mathrm{imp}}=\Delta c_{M-E}+\left(1-f_{\mathrm{imp}}^{1}\right) \Delta c_{\mathrm{imp}-\mathrm{tar}} .
$$

Substituting for $c_{\mathrm{imp}}$ in equation 5 using equation 6 we obtain

$$
c_{2}=\Delta c_{M-E}-\Delta f_{\mathrm{imp}} \Delta c_{\mathrm{imp}-\mathrm{tar}} .
$$

Substituting for $c_{2}$ in equation 4 using equation 7 and rearranging we find that

$$
\begin{aligned}
& F_{\text {mix }}= \\
& \frac{\Delta f_{\text {imp }} \Delta c_{\text {imp-tar }}\left(M_{\text {Earth }}-M_{\text {Moon }}\right)-\Delta c_{\mathrm{M}-\mathrm{E}} M_{\text {Earth }}}{\Delta f_{\text {imp }} \Delta c_{\text {imp-tar }}\left(M_{\text {Earth }}+M_{\text {Moon }}\right)},
\end{aligned}
$$

or alternatively:

$$
F_{\text {mix }}=1-\frac{\Delta c_{\mathrm{M}-\mathrm{E}} M_{\text {Earth }}}{\Delta f_{\mathrm{imp}} \Delta c_{\mathrm{imp}-\operatorname{tar}}\left(M_{\text {Earth }}+M_{\mathrm{Moon}}\right)} .
$$

The expression given in equation 9 is significant as it relates the degree of post-impact mixing that is required to explain the Earth-Moon isotopic similarity for a given degree of intra-impact mixing and compositional difference between impactor and target. We can therefore use it to understand the trade offs between mixing during and after the impact (Section 6).

\section{Acknowledgments}

This paper was instigated at the International Space Science Institute (ISSI) workshop 'Reading Terrestrial Planet Evolution in Isotopes and Element Measurements' and the authors would like to thank ISSI and Europlanet for their support. We would also like to thank Paolo Sossi and an anonymous reviewer for comments that helped improve the clarity and completeness of the manuscript, and Helmut Lammer for editorial handling. We thank Jessica Barnes for providing their $\mathrm{Cl}$ isotope database. SJL acknowledges funding from NSF (awards EAR-1947614 and EAR-1725349) and the Division of Geological and Planetary Sciences at the California Institute of Technology. KRB acknowledges funding from NASA Emerging Worlds grants 80NSSC18K0496 and NNX16AN07G, NASA SSERVI grant NNA14AB07A, and support from the Department of Earth and Planetary Sciences, Rutgers University. RP acknowledges support from Washington University. MB received funding from the European Research Council (ERC Grant agreement No 682778 - ISOREE).

\section{Copyright notice}

This is a post-peer-review, pre-copyedit version of an article published in Space Science Reviews. The final authenticated version is available online at: http://dx. doi. org/10.1007/s11214-020-00729-z

\section{References}

Agnor, C., Canup, R. M., Levison, H. F., 1999. On the character and consequences of large impacts in the late stage of terrestrial planet formation. Icarus 142 (1), 219-237.

Akovali, Y. A., 2003. Nuclear data sheets for A = 244. Nuclear Data Sheets 99 (1), 197-273.

Albarède, F., Albalat, E., Lee, C. T. A., 2015. An intrinsic volatility scale relevant to the Earth and Moon and the status of water in the Moon. Meteoritics and Planetary Science 50 (4), 568-577.

Allègre, C. J., Staudacher, T., Sarda, P., Kurz, M., 1983. Constraints on evolution of Earth's mantle from rare gas systematics. Nature 303 (5920), 762-766.

Antonangeli, D., Morard, G., Schmerr, N. C., Komabayashi, T., Krisch, M., Fiquet, G., Fei, Y., Mao, H. K., 2015. Toward a mineral physics reference model for the Moon's core. Proceedings of the National Academy of Sciences of the United States of America 112 (13), 3916-3919.

Armytage, R., Georg, R., Williams, H., Halliday, A., 2012. Silicon isotopes in lunar rocks: Implications for the Moon's formation and the early history of the Earth. Geochimica et Cosmochimica Acta 77, 504-514.

Armytage, R. M., Jephcoat, A. P., Bouhifd, M. A., Porcelli, D., 2013. Metal-silicate partitioning of iodine at high pressures and temperatures: Implications for the Earth's core and ${ }^{129 *} \mathrm{Xe}$ budgets. Earth and Planetary Science Letters 373, 140-149.

Asphaug, E., 2014. Impact origin of the Moon? Annual Review of Earth and Planetary Sciences 42 (1), 551-578.

Barboni, M., Boehnke, P., Keller, B., Kohl, I. E., Schoene, B., Young, E. D., McKeegan, K. D., 2017. Early formation of the Moon 4.51 billion years ago. Science Advances 3 (1), e1602365. 
Barnes, J. J., Franchi, I. A., McCubbin, F. M., Anand, M., 2019. Multiple reservoirs of volatiles in the Moon revealed by the isotopic composition of chlorine in lunar basalts. Geochimica et Cosmochimica Acta 266, 144-162.

Barnes, J. J., Tartèse, R., Anand, M., McCubbin, F. M., Neal, C. R., Franchi, I. A., 2016. Early degassing of lunar urKREEP by crustbreaching impact(s). Earth and Planetary Science Letters 447, $84-94$.

Barr, A. C., 2016. On the origin of Earth's Moon. Journal of Geophysical Research: Planets 121 (9), 1573-1601.

Becker, H., Horan, M. F., Walker, R. J., Gao, S., Lorand, J. P., Rudnick, R. L., 2006. Highly siderophile element composition of the Earth's primitive upper mantle: Constraints from new data on peridotite massifs and xenoliths. Geochimica et Cosmochimica Acta 70 (17), 4528-4550.

Bischoff, A., 1994. Acfer 217 - A new member of the Rumuruti chondrite group (R). Meteoritics 29 (2), 264-274.

Bischoff, A., Palme, H., Ash, R. D., Clayton, R. N., Schultz, L., Herpers, U., Stöffler, D., Grady, M. M., Pillinger, C. T., Spettel, B., Weber, H., Grund, T., Endreß, M., Weber, D., 1993. Paired Renazzo-type (CR) carbonaceous chondrites from the Sahara. Geochimica et Cosmochimica Acta 57 (7), 1587-1603.

Bischoff, A., Palme, H., Clayton, R. N., Mayeda, T. K., Grund, T., Spettel, B., Geiger, T., Endreß, M., Beckerling, W., Metzler, K., 1991. New carbonaceous and type 3 ordinary chondrites from the Sahara Desert. Meteoritics 26, 318.

Bischoff, A., Weber, D., Bartoschewitz, R., Clayton, R. N., Mayeda, T. K., Schultz, L., Spettel, B., Weber, H. W., Bischoff, A., Weber, D., Bartoschewitz, R., Clayton, R. N., Mayeda, T. K., Schultz, L., Spettel, B., Weber, H. W., 1998. Characterization of the Rumuruti chondrite regolith breccia Hughes 030 (R3-6) and implications for the occurrence of unequilibrated lithologies on the R-chondrite parent body. Meteoritics \& Planetary Science 33, A15.

Bonnand, P., Parkinson, I. J., Anand, M., 2016. Mass dependent fractionation of stable chromium isotopes in mare basalts: Implications for the formation and the differentiation of the Moon. Geochimica et Cosmochimica Acta 175, 208-221.

Borg, L. E., Connelly, J. N., Boyet, M., Carlson, R. W., 2011. Chronological evidence that the Moon is either young or did not have a global magma ocean. Nature 477 (7362), 70-73.

Borg, L. E., Gaffney, A. M., Kruijer, T. S., Marks, N. A., Sio, C. K., Wimpenny, J., 2019. Isotopic evidence for a young lunar magma ocean. Earth and Planetary Science Letters 523, 115706.

Boyce, J. W., Kanee, S. A., McCubbin, F. M., Barnes, J. J., Bricker, H., Treiman, A. H., 2018. Early loss, fractionation, and redistribution of chlorine in the Moon as revealed by the low-Ti lunar mare basalt suite. Earth and Planetary Science Letters 500, 205-214.

Boyce, J. W., Treiman, A. H., Guan, Y., Ma, C., Eiler, J. M., Gross, J., Greenwood, J. P., Stolper, E. M., 2015. The chlorine isotope fingerprint of the lunar magma ocean. Science Advances 1 (8), e1500380-e1500380.

Boyet, M., Blichert-Toft, J., Rosing, M., Storey, M., Télouk, P., Albarède, F., 2003. ${ }^{142} \mathrm{Nd}$ evidence for early Earth differentiation. Earth and Planetary Science Letters 214 (3-4), 427-442.

Boyet, M., Bouvier, A., Frossard, P., Hammouda, T., Garçon, M., Gannoun, A., 2018. Enstatite chondrites EL3 as building blocks for the Earth: The debate over the ${ }^{146} \mathrm{Sm}^{142} \mathrm{Nd}$ systematics. Earth and Planetary Science Letters 488, 68-78.

Boyet, M., Carlson, R. W., 2007. A highly depleted moon or a nonmagma ocean origin for the lunar crust? Earth and Planetary Science Letters 262 (3-4), 505-516.

Brandon, A. D., Lapen, T. J., Debaille, V., Beard, B. L., Rankenburg, K., Neal, C., 2009. Re-evaluating ${ }^{142} \mathrm{Nd} /{ }^{144} \mathrm{Nd}$ in lunar mare basalts with implications for the early evolution and bulk $\mathrm{Sm} / \mathrm{Nd}$ of the Moon. Geochimica et Cosmochimica Acta 73 (20), 6421-6445.

Brearley, A. J., Scott, E. R., Keil, K., Clayton, R. N., Mayeda, T. K., Boynton, W. V., Hill, D. H., 1989. Chemical, isotopic and mineralogical evidence for the origin of matrix in ordinary chondrites. Geochimica et Cosmochimica Acta 53 (8), 2081-2093.

Bridges, J. C., Franchi, I. A., Grady, M. M., Sexton, A. S., Pillinger,
C. T., 1997. The $\delta^{18} \mathrm{O}$ composition of Feldspar and other minerals in Lafayette. Meteoritics \& Planetary Science 32 (4), A21-A22.

Bridges, J. C., Franchi, I. A., Sexton, A. S., Pillinger, C. T., 1999. Mineralogical controls on the oxygen isotopic compositions of UOCs. Geochimica et Cosmochimica Acta 63 (6), 945-951.

Buchanan, P. C., Zolensky, M. E., Reid, A. M., 1993. Carbonaceous chondrite clasts in the howardites Bholghati and EET87513. Meteoritics 28 (5), 659-682.

Burkhardt, C., Dauphas, N., Tang, H., Fischer-Gödde, M., Qin, L., Chen, J. H., Rout, S. S., Pack, A., Heck, P. R., Papanastassiou, D. A., 2017. In search of the Earth-forming reservoir: Mineralogical, chemical, and isotopic characterizations of the ungrouped achondrite NWA 5363/NWA 5400 and selected chondrites. Meteoritics and Planetary Science 52 (5), 807-826.

Cameron, A. G. W., Ward, W. R., 1976. The origin of the Moon. In: Lunar and Planetary Science Conference Abstracts. Vol. 7. p. 120.

Canup, R. M., 2004. Simulations of a late lunar-forming impact. Icarus 168 (2), 433-456.

Canup, R. M., 2008. Lunar-forming collisions with pre-impact rotation. Icarus 196 (2), 518-538.

Canup, R. M., 2012. Forming a Moon with an Earth-like composition via a giant impact. Science 338 (6110), 1052-1055.

Canup, R. M., Asphaug, E., 2001. Origin of the Moon in a giant impact near the end of the Earth's formation. Nature 412 (6848), 708-12.

Canup, R. M., Visscher, C., Salmon, J., Fegley Jr, B., 2015. Lunar volatile depletion due to incomplete accretion within an impactgenerated disk. Nature Geoscience 8 (12), 918-921.

Carlson, R. W., Borg, L. E., Gaffney, A. M., Boyet, M., 2014. Rb-Sr, $\mathrm{Sm}-\mathrm{Nd}$ and $\mathrm{Lu}-\mathrm{Hf}$ isotope systematics of the lunar Mg-suite: The age of the lunar crust and its relation to the time of Moon formation. Philosophical transactions. Series A, Mathematical, physical, and engineering sciences 372 (2024), 20130246.

Carlson, R. W., Garçon, M., O’Neil, J., Reimink, J., Rizo, H., 2019. The nature of Earth's first crust. Chemical Geology 530, 119321.

Caro, G., Bourdon, B., Birck, J. L., Moorbath, S., 2003. ${ }^{146} \mathrm{Sm}-$ ${ }^{142} \mathrm{Nd}$ evidence from Isua metamorphosed sediments for early differentiation of the Earth's mantle. Nature 423 (6938), 428-432.

Caro, G., Morino, P., Mojzsis, S. J., Cates, N. L., Bleeker, W., 2017. Sluggish Hadean geodynamics: Evidence from coupled $146,147 \mathrm{Sm}-{ }^{142,143} \mathrm{Nd}$ systematics in Eoarchean supracrustal rocks of the Inukjuak domain (Québec). Earth and Planetary Science Letters 457, 23-37.

Carter, P. J., Lock, S. J., Stewart, S. T., 2020. The Energy Budgets of Giant Impacts. Journal of Geophysical Research: Planets 125 (1).

Charnoz, S., Lee, Y., Sossi, P., Allibert, L., Siebert, J., Hyodo, R., Genda, H., Moynier, F., 2019. Efficient early Moon devolatilisation just after its formation, through tidally assisted hydrodynamic escape. In: Lunar and Planetary Science Conference Abstracts. Vol. 50. p. 2395.

Charnoz, S., Michaut, C., 2015. Evolution of the protolunar disk: Dynamics, cooling timescale and implantation of volatiles onto the Earth. Icarus 260, 440-463.

Chen, H., Savage, P. S., Teng, F.-Z., Helz, R. T., Moynier, F., 2013. Zinc isotope fractionation during magmatic differentiation and the isotopic composition of the bulk Earth. Earth and Planetary Science Letters 369-370, 34-42.

Chou, C. L., 1978. Fractionation of siderophile elements in the Earth's upper mantle. In: Lunar and Planetary Science Conference Abstracts. Vol. 9. pp. 219-230.

Citron, R. I., Perets, H. B., Aharonson, O., 2018. The role of multiple giant impacts in the formation of the Earth-Moon system. The Astrophysical Journal 862 (1), 5.

Clayton, R., Mayeda, T., Yanai, K., 1984a. Oxygen isotopic compositions of some Yamato meteorites. Memoirs of National Institute of Polar Research. Special Issue 35, 267-271.

Clayton, R. N., Mayeda, T. K., 1978. Multiple parent bodies of polymict brecciated meteorites. Geochimica et Cosmochimica Acta 42 (3), 325-327.

Clayton, R. N., Mayeda, T. K., 1981. Redox processes in chondrules 
and chondrites. In: Lunar and Planetary Science Conference Abstracts. Vol. 12. pp. 154-156.

Clayton, R. N., Mayeda, T. K., 1984. The oxygen isotope record in Murchison and other carbonaceous chondrites. Earth and Planetary Science Letters 67 (2), 151-161.

Clayton, R. N., Mayeda, T. K., 1985. Oxygen isotopes in Shergotty. In: Lunar and Planetary Science Conference Abstracts. Vol. 16. p. 11.

Clayton, R. N., Mayeda, T. K., 1989. Oxygen isotopic composition of LEW 86010. Meteoritics 24, 259.

Clayton, R. N., Mayeda, T. K., 1990. Oxygen isotopic composition of Antarctic meteorites. In: Workshop on Differences between Antarctic and non-Antarctic meteorites. Vol. 90-01. pp. 30-31.

Clayton, R. N., Mayeda, T. K., 1996. Oxygen isotope studies of achondrites. Geochimica et Cosmochimica Acta 60 (11), 19992017.

Clayton, R. N., Mayeda, T. K., Goswami, J. N., Olsen, E. J., 1991. Oxygen isotope studies of ordinary chondrites. Geochimica et Cosmochimica Acta 55 (8), 2317-2337.

Clayton, R. N., Mayeda, T. K., Hiroi, T., Zolensky, M., Lipschutz, M. E., 1997a. Oxygen isotopes in laboratory-heated CI and CM chondrites. In: Annual Meteoritical Society Meeting. Vol. 60. p. 5255 .

Clayton, R. N., Mayeda, T. K., Kojima, H., Weisberg, M. K., Prinz, M., 1997b. Hydration and dehydration in carbonaceous chondrites. In: Lunar and Planetary Science Conference Abstracts. Vol. 28. p. 239.

Clayton, R. N., Mayeda, T. K., Olsen, E. J., Prinz, M., 1983. Oxygen isotope relationships in iron meteorites. Earth and Planetary Science Letters 65 (2), 229-232.

Clayton, R. N., Mayeda, T. K., Rubin, A. E., 1984b. Oxygen isotopic compositions of enstatite chondrites and aubrites. Journal of Geophysical Research 89 (S01), C245.

Clayton, R. N., Onuma, N., Grossman, L., Mayeda, T. K., 1977. Distribution of the pre-solar component in Allende and other carbonaceous chondrites. Earth and Planetary Science Letters 34 (2), 209-224.

Clayton, R. N., Onuma, N., Mayeda, T. K., 1976. A classification of meteorites based on oxygen isotopes. Earth and Planetary Science Letters 30 (1), 10-18.

Connelly, J. N., Bizzarro, M., Krot, A. N., Nordlund, Å., Wielandt, D., Ivanova, M. A., 2012. The absolute chronology and thermal processing of solids in the solar protoplanetary disk. Science 338 (6107), 651-5.

Connolly, H. C., Zipfel, J., Folco, L., Smith, C., Jones, R. H., Benedix, G., Righter, K., Yamaguchi, A., Aoudjehane, H. C., Grossman, J. N., 2007. The Meteoritical Bulletin, No. 91, 2007 March. Meteoritics \& Planetary Science 42 (3), 413-466.

Ćuk, M., Hamilton, D. P., Lock, S. J., Stewart, S. T., 2016. Tidal evolution of the Moon from a high-obliquity, high-angular-momentum Earth. Nature 539, 402-406.

Ćuk, M., Stewart, S. T., 2012. Making the Moon from a fast-spinning Earth: A giant impact followed by resonant despinning. Science 338 (6110), 1047-52.

Dale, C. W., Kruijer, T. S., Burton, K. W., 2017. Highly siderophile element and ${ }^{182} \mathrm{~W}$ evidence for a partial late veneer in the source of 3.8 Ga rocks from Isua, Greenland. Earth and Planetary Science Letters 458, 394-404.

Dauphas, N., 2017. The isotopic nature of the Earth's accreting material through time. Nature 541 (7638), 521-524.

Dauphas, N., Burkhardt, C., Warren, P. H., Fang-Zhen, T., 2014. Geochemical arguments for an Earth-like Moon-forming impactor. Philosophical transactions. Series A, Mathematical, physical, and engineering sciences 372 (2024), 20130244.

Dauphas, N., Meheut, M., Blanchard, M., Zeng, H., Galli, G., Canup, R. N., Visscher, C., Nie, N., 2018. Can lunar formation theories be tested with $\mathrm{K}$ isotopes? In: Lunar and Planetary Science Conference Abstracts. Vol. 49. p. 2481.

Day, J. M., Moynier, F., Shearer, C. K., 2017. Late-stage magmatic outgassing from a volatile-depleted Moon. Proceedings of the National Academy of Sciences of the United States of Amer- ica 114 (36), 9547-9551.

Deng, H., Reinhardt, C., Benitez, F., Mayer, L., Stadel, J., Barr, A. C., 2019. Enhanced mixing in giant impact simulations with a new Lagrangian method. The Astrophysical Journal 870 (2), 127.

Desch, S. J., Taylor, G. J., 2013. Isotopic mixing due to the interaction between the protolunar disk and the Earth's atmosphere. In: Lunar and Planetary Science Conference Abstracts. Vol. 44. p. 2566.

Dhaliwal, J. K., Day, J. M., Moynier, F., 2018. Volatile element loss during planetary magma ocean phases. Icarus 300, 249-260.

Dickinson, J. E., Hess, P. C., 1982. Zircon saturation in lunar basalts and granites. Earth and Planetary Science Letters 57 (2), 336-344.

Dowty, E., Prinz, M., Keil, K., 1974. Ferroan anorthosite: A widespread and distinctive lunar rock type. Earth and Planetary Science Letters 24 (1), 15-25.

Drake, M. J., Newsom, H. E., Capobianco, C. J., 1989. V, Cr, and $\mathrm{Mn}$ in the Earth, Moon, EPB, and SPB and the origin of the Moon: Experimental studies. Geochimica et Cosmochimica Acta 53 (8), 2101-2111.

Eckerman, K. F., Westfall, R. J., Ryman, J. C., Cristy, M., 1993. Nuclear decay data files of the dosimetry research group No. ORNL/TM-12350. Tech. rep., Oak Ridge National Laboratory (ORNL), Oak Ridge, TN

Elkins-Tanton, L. T., Burgess, S., Yin, Q.-Z., 2011. The lunar magma ocean: Reconciling the solidification process with lunar petrology and geochronology. Earth and Planetary Science Letters 304 (3-4), 326-336.

Foley, C. N., Wadhwa, M., Borg, L. E., Janney, P. E., Hines, R., Grove, T. L., 2005. The early differentiation history of Mars from ${ }^{182} \mathrm{~W}-{ }^{142} \mathrm{Nd}$ isotope systematics in the SNC meteorites. Geochimica et Cosmochimica Acta 69 (18), 4557-4571.

Franchi, I. A., Akagi, T., Pillinger, C. T., 1992. Laser fluorination of meteorites - Small sample analysis of $\delta^{17} \mathrm{O}$ and $\delta^{18} \mathrm{O}$. Meteoritics $27,222$.

Franchi, I. A., Wright, I. P., Sexton, A. S., Pillinger, C. T., 1999. The oxygen-isotopic composition of Earth and Mars. Meteoritics \& Planetary Science 34 (4), 657-661.

Friedman, A. M., Milsted, J., Metta, D., Henderson, D., Lerner, J., Harkness, A. L., Rokop, D. J., 1966. Alpha decay half lives of ${ }^{148} \mathrm{Gd}{ }^{150} \mathrm{Gd}$, and ${ }^{146} \mathrm{Sm}$. Radiochimica Acta $5(4), 192-194$.

Gaffney, A. M., Borg, L. E., 2014. A young solidification age for the lunar magma ocean. Geochimica et Cosmochimica Acta 140, 227-240.

Garcia, R. F., Gagnepain-Beyneix, J., Chevrot, S., Lognonné, P., 2011. Very preliminary reference Moon model. Physics of the Earth and Planetary Interiors 188 (1-2), 96-113.

Gooding, J. L., Mayeda, T. K., Clayton, R. N., Fukuoka, T., 1983. Oxygen isotopic heterogeneities, their petrological correlations, and implications for melt origins of chondrules in unequilibrated ordinary chondrites. Earth and Planetary Science Letters 65 (2), 209-224.

Goodrich, C. A., Keil, K., Berkley, J. L., Laul, J., Smith, M., Wacker, J. F., Clayton, R. N., Mayeda, T. K., 1987. Roosevelt County 027: A low-shock Ureilite with interstitial silicates and high noble gas concentrations. Meteoritics 22 (3), 191-218.

Göpel, C., Birck, J., 2010. Mn/Cr systematics: A tool to discriminate the origin of primitive meteorites? In: Goldschmidt Conference Abstracts. p. A348.

Grady, M., Aylmer, D., Kurat, G., Ntaflos, T., Ott, U., Palme, H., Spettel, B., 1987. Yamato-82042: An unusual carbonaceous chondrite with $\mathrm{CM}$ affinities. Memoirs of National Institute of Polar Research. Special Issue 46 (46), 162-178.

Graham, D. W., 2002. Noble gas isotope geochemistry of mid-ocean ridge and ocean island basalts: Characterization of mantle source reservoirs. Reviews in Mineralogy and Geochemistry 47 (1), 247317.

Grange, M. L., Pidgeon, R. T., Nemchin, A. A., Timms, N. E., Meyer, C., 2013. Interpreting U-Pb data from primary and secondary features in lunar zircon. Geochimica et Cosmochimica Acta 101, 112-132.

Greenwood, R. C., Barrat, J.-A., Miller, M. F., Anand, M., Dauphas, 
N., Franchi, I. A., Sillard, P., Starkey, N. A., 2018. Oxygen isotopic evidence for accretion of Earth's water before a high-energy Moonforming giant impact. Science Advances 4 (3), eaao5928.

Gross, J., Treiman, A. H., Mercer, C. N., 2014. Lunar feldspathic meteorites: Constraints on the geology of the lunar highlands, and the origin of the lunar crust. Earth and Planetary Science Letters 388, 318-328.

Grossman, J. N., 1999. The Meteoritical Bulletin, No. 83, 1999 July. Meteoritics \& Planetary Science 34 (S4), A169-A186.

Grossman, J. N., Clayton, R. N., Mayeda, T. K., 1987. Oxygen isotopes in the matrix of the Semarkona (LL3.0) chondrite. Meteoritics 22,395 .

Grossman, J. N., Zipfel, J., 2001. The Meteoritical Bulletin, No. 85, 2001 September. Meteoritics \& Planetary Science 36 (S9), A293A322.

Guitreau, M., Boyet, M., Paquette, J.-L., Gannoun, A., Konc, Z., Benbakkar, M., Suchorski, K., Hénot, J.-M., 2019. Hadean protocrust reworking at the origin of the Archean Napier Complex (Antarctica). Geochemical Perspectives Letters 12, 7-11.

Halbout, J., Javoy, M., Robert, F., 1984. Oxygen isotopes in type 3 ordinary chondrites. In: Lunar and Planetary Science Conference Abstracts. Vol. 15. pp. 339-340.

Halbout, J., Robert, F., Javoy, M., 1986. Oxygen and hydrogen isotope relations in water and acid residues of carbonaceous chondrites. Geochimica et Cosmochimica Acta 50 (8), 1599-1609.

Harper, C. L., Jacobsen, S. B., 1992. Evidence from coupled ${ }^{147} \mathrm{Sm}-$ ${ }^{143} \mathrm{Nd}$ and ${ }^{146} \mathrm{Sm}^{-142} \mathrm{Nd}$ systematics for very early $(4.5 \mathrm{Gyr})$ differentiation of the Earth's mantle. Nature 360 (6406), 728-732.

Hartmann, W. K., Davis, D. R., 1975. Satellite-sized planetesimals and lunar origin. Icarus $24(4), 504-515$.

Hauri, E. H., Saal, A. E., Rutherford, M. J., Van Orman, J. A., 2015. Water in the Moon's interior: Truth and consequences. Earth and Planetary Science Letters 409, 252-264.

Herzog, G. F., Moynier, F., Albarède, F., Berezhnoy, A. A., 2009. Isotopic and elemental abundances of copper and zinc in lunar samples, Zagami, Pele's hairs, and a terrestrial basalt. Geochimica et Cosmochimica Acta 73 (19), 5884-5904.

Horan, M. F., Carlson, R. W., Walker, R. J., Jackson, M., Garçon, M., Norman, M., 2018. Tracking Hadean processes in modern basalts with 142-Neodymium. Earth and Planetary Science Letters 484, 184-191.

Hosono, N., Karato, S.-i., Makino, J., Saitoh, T. R., 2019. Terrestrial magma ocean origin of the Moon. Nature Geoscience 12 (6), 418423.

Humayun, M., 2011. A model for osmium isotopic evolution of metallic solids at the core-mantle boundary. Geochemistry, Geophysics, Geosystems 12 (3), Q03007.

Ida, S., Canup, R. M., Stewart, G. R., 1997. Lunar accretion from an impact-generated disk. Nature 389 (6649), 353-357.

Ivanov, A. V., Ulyanov, A. A., Ustinov, V. I., Shukolyukov, Y. A., 1987. The Kaidun meteorite: Oxygen isotopic composition. In: Lunar and Planetary Science Conference Abstracts. Vol. 18. p. 453.

Jabeen, I., Kusakabe, M., Nagao, K., Nakamura, T., 1998. Oxygen isotope study of Tsukuba chondrite, some HED meteorites and Allende chondrules. Antarctic Meteorite Research 11, 122-135.

Jackel, A., Bischoff, A., Clayton, R. N., Mayeda, T. K., 1996. Dar AL Gani 013-A new Saharan Rumuruti-chondrite (R3-6) with highly unequilibrated (type 3 ) fragments. In: Lunar and Planetary Science Conference Abstracts. Vol. 27. p. 595.

Jackson, C. R., Bennett, N. R., Du, Z., Cottrell, E., Fei, Y., 2018. Early episodes of high-pressure core formation preserved in plume mantle. Nature 553 (7689), 491-495.

Jacobsen, S. B., Petaev, M. I., Huang, S., Sasselov, D. D., 2013. An isotopically homogeneous region of the inner terrestrial planet region (Mercury to Earth): Evidence from E chondrites and implications for giant Moon-forming impact scenarios. In: Lunar and Planetary Science Conference Abstracts. Vol. 44. p. 2344.

Jacobson, S. A., Morbidelli, A., Raymond, S. N., O'Brien, D. P., Walsh, K. J., Rubie, D. C., 2014. Highly siderophile elements in Earth's mantle as a clock for the Moon-forming impact. Nature
508 (1), 84-87.

Jing, Z., Wang, Y., Kono, Y., Yu, T., Sakamaki, T., Park, C., Rivers, M. L., Sutton, S. R., Shen, G., 2014. Sound velocity of Fe-S liquids at high pressure: Implications for the Moon's molten outer core. Earth and Planetary Science Letters 396, 78-87.

Jones, T. D., Davies, D. R., Sossi, P. A., 2019. Tungsten isotopes in mantle plumes: Heads it's positive, tails it's negative. Earth and Planetary Science Letters 506, 255-267.

Kallemeyn, G. W., Rubin, A. E., Wasson, J. T., 1996. The compositional classification of chondrites: VII. The $\mathrm{R}$ chondrite group. Geochimica et Cosmochimica Acta 60 (12), 2243-2256.

Kaspi, Y., Flierl, G. R., Showman, A. P., 2009. The deep wind structure of the giant planets: Results from an anelastic general circulation model. Icarus 202 (2), 525-542.

Kato, C., Moynier, F., 2017. Gallium isotopic evidence for extensive volatile loss from the Moon during its formation. Science Advances 3 (7), e1700571.

Kato, C., Moynier, F., Valdes, M. C., Dhaliwal, J. K., Day, J. M. D., 2015. Extensive volatile loss during formation and differentiation of the Moon. Nature communications 6 (1), 7617.

Keller, L. P., Thomas, K. L., Clayton, R. N., Mayeda, T. K., DeHart, J. M., McKay, D. S., 1994. Aqueous alteration of the Bali CV3 chondrite: Evidence from mineralogy, mineral chemistry, and oxygen isotopic compositions. Geochimica et Cosmochimica Acta 58 (24), 5589-5598.

Kimura, K., Lewis, R. S., Anders, E., 1974. Distribution of gold and rhenium between nickel-iron and silicate melts: Implications for the abundance of siderophile elements on the Earth and Moon. Geochimica et Cosmochimica Acta 38 (5), 683-701.

Kleine, T., Touboul, M., Bourdon, B., Nimmo, F., Mezger, K., Palme, H., Jacobsen, S. B., Yin, Q.-Z., Halliday, A. N., 2009. Hf-W chronology of the accretion and early evolution of asteroids and terrestrial planets. Geochimica et Cosmochimica Acta 73 (17), 5150-5188.

Kleine, T., Walker, R. J., 2017. Tungsten isotopes in planets. Annual Review of Earth and Planetary Sciences 45 (1), 389-417.

Kokubo, E., Genda, H., 2010. Formation of terrestrial planets from protoplanets under a realistic accretion condition. The Astrophysical Journal 714 (1), L21-L25.

Kokubo, E., Ida, S., Makino, J., 2000. Evolution of a circumterrestrial disk and formation of a single moon. Icarus 148 (2), 419-436.

Kruijer, T. S., Kleine, T., 2017. Tungsten isotopes and the origin of the Moon. Earth and Planetary Science Letters 475, 15-24.

Kruijer, T. S., Kleine, T., 2018. No ${ }^{182} \mathrm{~W}$ excess in the Ontong Java Plateau source. Chemical Geology 485, 24-31.

Kruijer, T. S., Kleine, T., Fischer-Gödde, M., Sprung, P., 2015. Lunar tungsten isotopic evidence for the late veneer. Nature 520, $534-537$.

Kurz, M. D., Jenkins, W. J., Hart, S. R., 1982. Helium isotopic systematics of oceanic islands and mantle heterogeneity. Nature 297 (5861), 43-47.

Larsen, K. K., Trinquier, A., Paton, C., Schiller, M., Wielandt, D., Ivanova, M. A., Connelly, J. N., Nordlund, A., Krot, A. N., Bizzarro, M., 2011. Evidence for magnesium isotope heterogeneity in the solar protoplanetary disk. Astrophysical Journal Letters 735 (2), L37.

Li, C., Liu, D., Liu, B., Ren, X., Liu, J., He, Z., Zuo, W., Zeng, X., Xu, R., Tan, X., Zhang, X., Chen, W., Shu, R., Wen, W., Su, Y., Zhang, H., Ouyang, Z., 2019. Chang'E-4 initial spectroscopic identification of lunar far-side mantle-derived materials.

Liu, J., Touboul, M., Ishikawa, A., Walker, R. J., Graham Pearson, D., 2016. Widespread tungsten isotope anomalies and W mobility in crustal and mantle rocks of the Eoarchean Saglek Block, northern Labrador, Canada: Implications for early Earth processes and W recycling. Earth and Planetary Science Letters 448, 13-23.

Lock, S. J., Stewart, S. T., 2017. The structure of terrestrial bodies: Impact heating, corotation limits, and synestias. Journal of Geophysical Research: Planets 122 (5), 950-982.

Lock, S. J., Stewart, S. T., 2019. Giant impacts stochastically change the internal pressures of terrestrial planets. Science Advances 5 (9), eaav3746. 
Lock, S. J., Stewart, S. T., Ćuk, M., 2020. The energy budget and figure of Earth during recovery from the Moon-forming giant impact. Earth and Planetary Science Letters 530, 115885.

Lock, S. J., Stewart, S. T., Petaev, M. I., Leinhardt, Z., Mace, M. T., Jacobsen, S. B., Cuk, M., 2018. The origin of the moon within a terrestrial synestia. Journal of Geophysical Research: Planets 123 (4), 910-951.

Longhi, J., 2006. Petrogenesis of picritic mare magmas: Constraints on the extent of early lunar differentiation. Geochimica et Cosmochimica Acta 70 (24), 5919-5934.

Lugmair, G., Shukolyukov, A., 1998. Early solar system timescales according to ${ }^{53} \mathrm{Mn}-{ }^{53} \mathrm{Cr}$ systematics. Geochimica et Cosmochimica Acta 62 (16), 2863-2886.

Lugmair, G. W., Carlson, R. W., 1978. The Sm-Nd history of KREEP. In: Lunar and Planetary Science Conference Abstracts. Vol. 9. pp. 689-704.

Maas, C., Hansen, U., 2019. Dynamics of a terrestrial magma ocean under planetary rotation: A study in spherical geometry. Earth and Planetary Science Letters 513, 81-94.

Marchi, S., Canup, R. M., Walker, R. J., 2018. Heterogeneous delivery of silicate and metal to the Earth by large planetesimals. Nature Geoscience 11 (1), 77-81.

Marks, N. E., Borg, L. E., Shearer, C. K., Cassata, W. S., 2019. Geochronology of an Apollo 16 clast provides evidence for a basinforming impact 4.3 billion years ago. Journal of Geophysical Research: Planets 124 (10), 2465-2481.

Mayeda, K. T., Clayton, N. R., 1989a. Oxygen isotopic compositions of unique Antarctic meteorites. NIPR Symposium on Antarctic Meteorites 14, 172.

Mayeda, T., Clayton, R., Yanai, K., 1987. Oxygen isotopic compositions of several Antarctic meteorites. Memoirs of National Institute of Polar Research. Special Issue 46, 144-150.

Mayeda, T. K., Clayton, R. N., 1980. Oxygen isotopic compositions of Aubrites and some unique meteorites. Geochimica et Cosmochimica Acta 14 (2), 1145-1151.

Mayeda, T. K., Clayton, R. N., 1983. Oxygen isotopic composition of ALHA 81005. In: Lunar and Planetary Science Conference Abstracts. Vol. 14. p. 472.

Mayeda, T. K., Clayton, R. N., 1989b. Oxygen isotopes in the Bholghati Howardite. In: Lunar and Planetary Science Conference Abstracts. Vol. 20. p. 648.

Mayeda, T. K., Yanai, K., Clayton, R. N., 1995. Another martian meteorite. In: Lunar and Planetary Science Conference Abstracts. Vol. 26. pp. 917-918.

McCoy, T. J., Keil, K., Bogard, D. D., Garrison, D. H., Casanova, I., Lindstrom, M. M., Brearley, A. J., Kehm, K., Nichols, R. H., Hohenberg, C. M., 1995. Origin and history of impact-melt rocks of enstatite chondrite parentage. Geochimica et Cosmochimica Acta 59 (1), 161-175.

McCoy, T. J., Keil, K., Clayton, R. N., Mayeda, T. K., Bogard, D. D., Garrison, D. H., Huss, G. R., Hutcheon, I. D., Wieler, R., 1996. A petrologic, chemical, and isotopic study of Monument Draw and comparison with other acapulcoites: Evidence for formation by incipient partial melting. Geochimica et Cosmochimica Acta 60 (14), 2681-2708.

McCoy, T. J., Keil, K., Clayton, R. N., Mayeda, T. K., Bogard, D. D., Garrison, D. H., Wieler, R., 1997. A petrologic and isotopic study of lodranites: Evidence for early formation as partial melt residues from heterogeneous precursors. Geochimica et Cosmochimica Acta 61 (3), 623-637.

McDonough, W., Sun, S., 1995. The composition of the Earth. Chemical Geology 120 (3-4), 223-253.

McLeod, C. L., Brandon, A. D., Armytage, R. M. G., 2014. Constraints on the formation age and evolution of the Moon from ${ }^{142} \mathrm{Nd}^{-}{ }^{143} \mathrm{Nd}$ systematics of Apollo 12 basalts. Earth and Planetary Science Letters 396, 179-189.

Meissner, F., Schmidt-Ott, W. D., Ziegeler, L., 1987. Half-life and $\alpha$-ray energy of ${ }^{146} \mathrm{Sm}$. Zeitschrift für Physik A Atomic Nuclei 327 (2), 171-174.

Melosh, H. J., 2014. New approaches to the Moon's isotopic crisis. Philosophical transactions. Series A, Mathematical, physical, and engineering sciences 372 (2024), 20130168.

Miyazaki, Y., Korenaga, J., 2019. On the timescale of magma ocean solidification and its chemical consequences: 2. Compositional differentiation under crystal accumulation and matrix compaction. Journal of Geophysical Research: Solid Earth 124 (4), 3399-3419.

Morbidelli, A., Wood, B., 2014. Late accretion and the late veneer. In: Badro, J., Walter, M. (Eds.), The early Earth: Accretion and differentiation. John Wiley \& Sons, Inc, Ch. 4.

Morgan, J. W., 1985. Osmium isotope constraints on Earth's late accretionary history. Nature 317 (6039), 703-705.

Morgan, J. W., Hertogen, J., Anders, E., 1978. The Moon: Composition determined by nebular processes. The Moon and the Planets 18 (4), 465-478.

Moroz, L. V., Ustinov, V. I., Kononkova, N. N., Zaslavskaya, N. I., Shukolyukov, Y. A., 1988. Oxygen isotopes of chromite and chemical composition of the minerals from polymineral nodules in Sikhote-Alin meteorite. In: Lunar and Planetary Science Conference Abstracts. Vol. 19. pp. 809-810.

Mougel, B., Moynier, F., Göpel, C., 2018. Chromium isotopic homogeneity between the Moon, the Earth, and enstatite chondrites. Earth and Planetary Science Letters 481, 1-8.

Mukhopadhyay, S., 2012. Early differentiation and volatile accretion recorded in deep-mantle neon and xenon. Nature 486 (7401), 1014.

Mukhopadhyay, S., Parai, R., 2019. Noble gases: A record of Earth's evolution and mantle dynamics. Annual Review of Earth and Planetary Sciences 47 (1), 389-419.

Mundl, A., Touboul, M., Jackson, M. G., Day, J. M. D., Kurz, M. D., Lekic, V., Helz, R. T., Walker, R. J., 2017. Tungsten-182 heterogeneity in modern ocean island basalts. Science 356 (6333), 66-69.

Mundl, A., Walker, R. J., Reimink, J. R., Rudnick, R. L., Gaschnig, R. M., 2018. Tungsten-182 in the upper continental crust: Evidence from glacial diamictites. Chemical Geology 494, 144-152.

Mundl-Petermeier, A., Walker, R. J., Fischer, R. A., Lekic, V., Jackson, M. G., Kurz, M. D., 2020. Anomalous ${ }^{182} \mathrm{~W}$ in high ${ }^{3} \mathrm{He} /{ }^{4} \mathrm{He}$ ocean island basalts: Fingerprints of Earth's core? Geochimica et Cosmochimica Acta 271, 194-211.

Nakajima, M., Stevenson, D. J., 2014. Investigation of the initial state of the Moon-forming disk: Bridging SPH simulations and hydrostatic models. Icarus 233, 259-267.

Nakajima, M., Stevenson, D. J., 2015. Melting and mixing states of the Earth's mantle after the Moon-forming impact. Earth and Planetary Science Letters 427, 286-295.

Nehru, C. E., Prinz, M., Weisberg, M. K., Ebihara, M. E., Clayton, R. N., Mayeda, T. K., 1996. A new Brachinite and petrogenesis of the group. In: Lunar and Planetary Science Conference Abstracts. Vol. 27. pp. 943-944.

Nemchin, A., Timms, N., Pidgeon, R., Geisler, T., Reddy, S., Meyer, C., 2009. Timing of crystallization of the lunar magma ocean constrained by the oldest zircon. Nature Geoscience 2 (2), 133-136.

Ni, P., Zhang, Y., Chen, S., Gagnon, J., 2019. A melt inclusion study on volatile abundances in the lunar mantle. Geochimica et Cosmochimica Acta 249, 17-41.

Nie, N. X., Dauphas, N., 2019. Vapor drainage in the protolunar disk as the cause for the depletion in volatile elements of the Moon. The Astrophysical Journal 884 (2), L48.

Norman, M. D., Borg, L. E., Nyquist, L. E., Bogard, D. D., 2003. Chronology, geochemistry, and petrology of a ferroan noritic anorthosite clast from Descartes breccia 67215: Clues to the age, origin, structure, and impact history of the lunar crust. Meteoritics and Planetary Science 38 (4), 645-661.

Nyquist, L. E., Shih, C. Y., Reese, Y. D., Park, J., Bogard, D. D., Garrison, D. H., Yamaguchi, A., 2010. Lunar crustal history recorded in lunar anorthosites. In: Lunar and Planetary Science Conference. Vol. 41. p. 1383.

Nyquist, L. E., Wiesmann, H., Bansal, B., Shih, C. Y., Keith, J. E., Harper, C. L., 1995. ${ }^{146} \mathrm{Sm}^{142} \mathrm{Nd}$ formation interval for the lunar mantle. Geochimica et Cosmochimica Acta 59 (13), 2817-2837.

Olsen, E., Davis, A., Clarke, R. S., Schultz, L., Weber, H. W., Clayton, R., Mayeda, T., Jarosewich, E., Sylvester, P., Grossman, L., Wang, M.-S., Lipschutz, M. E., Steele, I. M., Schwade, J., 1994. 
Watson: A new link in the HE iron chain. Meteoritics 29 (2), 200-213.

Olsen, E. J., Dod, B. D., Schmitt, R. A., Sipiera, P. P., 1987. Monticello: A class-rich Howardite. Meteoritics 22 (1), 81-96.

O'Neil, J., Carlson, R. W., Francis, D., Stevenson, R. K., Deibel, C. M., DiGiovine, B., Greene, J. P., Henderson, D. J., Jiang, C. L., Marley, S. T., Nakanishi, T., Pardo, R. C., Rehm, K. E., Robertson, D., Scott, R., Schmitt, C., Tang, X. D., Vondrasek, R., Yokoyama, A., 2008. Neodymium-142 evidence for Hadean mafic crust. Science 321 (5897), $1828-1831$.

Onuma, N., Clayton, R., Mayeda, T., Yanai, K., 1978. Oxygen isotopes in several Yamato meteorites. Memoirs of National Institute of Polar Research. Special Issue 8, 220-224.

Onuma, N., Ikeda, Y., Mayeda, T. K., Clayton, R. N., Yanai, K., 1983. Oxygen isotopic composition of photographically described inclusions from Antarctic unequilibrated ordinary chondrites. In: Memoirs of National Institute of Polar Research. Special Issue. Vol. 30. pp. 306-314.

Pahlevan, K., Stevenson, D. J., 2007. Equilibration in the aftermath of the lunar-forming giant impact. Earth and Planetary Science Letters 262 (3-4), 438-449.

Paniello, R. C., Day, J. M. D., Moynier, F., 2012. Zinc isotopic evidence for the origin of the Moon. Nature 490 (7420), 376-9.

Parai, R., Mukhopadhyay, S., 2015. The evolution of MORB and plume mantle volatile budgets: Constraints from fission $\mathrm{Xe}$ isotopes in Southwest Indian Ridge basalts. Geochemistry, Geophysics, Geosystems 16 (3), 719-735.

Parai, R., Mukhopadhyay, S., Standish, J., 2012. Heterogeneous upper mantle $\mathrm{Ne}, \mathrm{Ar}$ and Xe isotopic compositions and a possible Dupal noble gas signature recorded in basalts from the Southwest Indian Ridge. Earth and Planetary Science Letters 359-360, $227-239$.

Parai, R., Mukhopadhyay, S., Tucker, J. M., Peto, M. K., 2019. The emerging portrait of an ancient, heterogeneous and continuously evolving mantle plume source. Lithos 346-347, 105153.

Petaev, M. I., Ustinov, V. I., Zaslavkaya, N. I., Gavrilov, E. Y., Shukolyukov, A., 1988. Oxygen isotopes in Pomozdino meteorite. In: Lunar and Planetary Science Conference Abstracts. Vol. 19. p. 917.

Peters, B. J., Carlson, R. W., Day, J. M., Horan, M. F., 2018. Hadean silicate differentiation preserved by anomalous ${ }^{142} \mathrm{Nd} /{ }^{144} \mathrm{Nd}$ ratios in the Réunion hotspot source. Nature 555 (7694), 89-93.

Pető, M. K., Mukhopadhyay, S., Kelley, K. A., 2013. Heterogeneities from the first 100 million years recorded in deep mantle noble gases from the Northern Lau Back-arc Basin. Earth and Planetary Science Letters 369-370, 13-23.

Porcelli, D., Woolum, D., Cassen, P., 2001. Deep Earth rare gases: Initial inventories, capture from the solar nebula, and losses during moon formation. Earth and Planetary Science Letters 193 (1-2), $237-251$

Potts, N. J., Barnes, J. J., Tartèse, R., Franchi, I. A., Anand, M., 2018. Chlorine isotopic compositions of apatite in Apollo 14 rocks: Evidence for widespread vapor-phase metasomatism on the lunar nearside $\sim 4$ billion years ago. Geochimica et Cosmochimica Acta 230, 46-59.

Pringle, E. A., Moynier, F., 2017. Rubidium isotopic composition of the Earth, meteorites, and the Moon: Evidence for the origin of volatile loss during planetary accretion. Earth and Planetary Science Letters 473, 62-70.

Prinz, M., Chatterjee, N., Weisberg, M. K., Clayton, R. N., Mayeda, T. K., 1991. MAC88177: A new type of achondrite? In: Lunar and Planetary Science Conference Abstracts. Vol. 22. p. 1099.

Puchtel, I., Humayun, M., 2000. Platinum group elements in Kostomuksha komatiites and basalts: Implications for oceanic crust recycling and core-mantle interaction. Geochimica et Cosmochimica Acta 64 (24), 4227-4242.

Puchtel, I. S., Blichert-Toft, J., Touboul, M., Horan, M. F., Walker, R. J., 2016. The coupled ${ }^{182} \mathrm{~W}-{ }^{142} \mathrm{Nd}$ record of early terrestrial mantle differentiation. Geochemistry, Geophysics, Geosystems 17 (6), 2168-2193.

Puchtel, I. S., Blichert-Toft, J., Touboul, M., Walker, R. J., 2018.
${ }^{182} \mathrm{~W}$ and HSE constraints from $2.7 \mathrm{Ga}$ komatiites on the heterogeneous nature of the Archean mantle. Geochimica et Cosmochimica Acta 228, 1-26.

Pun, A., Keil, K., Taylor, G. J., King, E., 1991. A unique Eucrite clast from the Kapoeta Howardite. In: Lunar and Planetary Science Conference Abstracts. Vol. 22. p. 1105.

Qin, L., Alexander, C. M., Carlson, R. W., Horan, M. F., Yokoyama, T., 2010a. Contributors to chromium isotope variation of meteorites. Geochimica et Cosmochimica Acta 74 (3), 1122-1145.

Qin, L., Rumble, D., Alexander, C. M., Carlson, R. W., Jenniskens, P., Shaddad, M. H., 2010b. The chromium isotopic composition of Almahata Sitta. Meteoritics and Planetary Science 45 (10-11), 1771-1777.

Quintana, E. V., Barclay, T., Borucki, W. J., Rowe, J. F., Chambers, J. E., 2016. The frequency of giant impacts on Earth-like worlds. The Astrophysical Journal 821 (2), 126.

Recca, S., Scott, E., Keil, K., Clayton, R., Mayeda, T., Huss, G., Jarosewich, E., Weeks, K., Hasan, F., Sears, D., Wieler, R., Signer, P., 1986. Ragland, an LL3.4 chondrite find from New Mexico. Meteoritics 21 (2), 217-229.

Reimink, J. R., Chacko, T., Carlson, R. W., Shirey, S. B., Liu, J., Stern, R. A., Bauer, A. M., Pearson, D. G., Heaman, L. M., 2018. Petrogenesis and tectonics of the Acasta Gneiss Complex derived from integrated petrology and ${ }^{142} \mathrm{Nd}$ and ${ }^{182} \mathrm{~W}$ extinct nuclidegeochemistry. Earth and Planetary Science Letters 494, 12-22.

Reufer, A., Meier, M. M., Benz, W., Wieler, R., 2012. A hit-and-run giant impact scenario. Icarus 221 (1), 296-299.

Ringwood, A., Seifert, S., Wänke, H., 1987. A komatiite component in Apollo 16 highland breccias: Implications for the nickel-cobalt systematics and bulk composition of the moon. Earth and Planetary Science Letters 81 (2-3), 105-117.

Ringwood, A. E., 1979. Origin of the Earth and Moon. SpringerVerlag New York Inc.

Ringwood, A. E., 1986. Terrestrial origin of the Moon. Nature 322 (6077), 323-328.

Ringwood, A. E., Kesson, S. E., 1977. Basaltic magmatism and the bulk composition of the Moon. The Moon 16 (4), 425-464.

Rizo, H., Andrault, D., Bennett, N. R., Humayun, M., Brandon, A., Vlastelic, I., Moine, B., Poirier, A., Bouhifd, M. A., Murphy, D. T., 2019. ${ }^{182} \mathrm{~W}$ evidence for core-mantle interaction in the source of mantle plumes. Geochemical Perspectives Letters $11,6-11$.

Rizo, H., Boyet, M., Blichert-Toft, J., Rosing, M., 2011. Combined $\mathrm{Nd}$ and $\mathrm{Hf}$ isotope evidence for deep-seated source of Isua lavas. Earth and Planetary Science Letters 312 (3-4), 267-279.

Rizo, H., Walker, R., Carlson, R., Touboul, M., Horan, M., Puchtel, I., Boyet, M., Rosing, M., 2016a. Early Earth differentiation investigated through ${ }^{142} \mathrm{Nd},{ }^{182} \mathrm{~W}$, and highly siderophile element abundances in samples from Isua, Greenland. Geochimica et Cosmochimica Acta 175, 319-336.

Rizo, H., Walker, R. J., Carlson, R. W., Horan, M. F., Mukhopadhyay, S., Manthos, V., Francis, D., Jackson, M. G., 2016b. Preservation of Earth-forming events in the tungsten isotopic composition of modern flood basalts. Science 352 (6287), 809-812.

Romanek, C. S., Perry, E. C., Treiman, A. H., Socki, R. A., Jones, J. H., Gibson, E. K., 1998. Oxygen isotopic record of silicate alteration in the Shergotty-Nakhla-Chassigny meteorite Lafayette. Meteoritics and Planetary Science 33 (4), 775-784.

Rowe, M. W., Clayton, R. N., Mayeda, T. K., 1994. Oxygen isotopes in separated components of CI and CM meteorites. Geochimica et Cosmochimica Acta 58 (23), 5341-5347.

Rufu, R., Aharonson, O., 2019. Impact dynamics of moons within a planetary potential. Journal of Geophysical Research: Planets 124 (4), 1008-1019.

Rufu, R., Aharonson, O., Perets, H. B., 2017. A multiple-impact origin for the Moon. Nature Geoscience 10, 89-94.

Russell, S. S., McCoy, T. J., Jarosewich, E., Ash, R. D., 1998. The Burnwell, Kentucky, low iron oxide chondrite fall: Description, classification and origin. Meteoritics and Planetary Science 33 (4), 853-856.

Russell, S. S., Zolensky, M. E., Righter, K., Folco, L., Jones, R. H., 
Connolly, H. C., Grady, M. M., Grossman, J. N., 2005. The Meteoritical Bulletin, No. 89, 2005 September. Meteoritics \& Planetary Science 40 (S9), A201-A263.

Ruzicka, A., Kring, D. A., Hill, D. H., Boynton, W. V., Clayton, R. N., Mayeda, T. K., 1995. Silica-rich orthopyroxenite in the Bovedy chondrite. Meteoritics 30 (1), 57-70.

Salmon, J., Canup, R. M., 2012. Lunar accretion from a Rocheinterior fluid disk. The Astrophysical Journal 760 (1), 83.

Salmon, J., Canup, R. M., 2014. Accretion of the Moon from noncanonical discs. Philosophical transactions. Series A, Mathematical, physical, and engineering sciences 372 (2024), 20130256.

Saxena, P., Elkins-Tanton, L., Petro, N., Mandell, A., 2017. A model of the primordial lunar atmosphere. Earth and Planetary Science Letters 474, 198-205.

Schiller, M., Van Kooten, E., Holst, J. C., Olsen, M. B., Bizzarro, M., 2014. Precise measurement of chromium isotopes by MC-ICPMS. Journal of Analytical Atomic Spectrometry 29 (8), 1406-1416.

Schoenberg, R., Zink, S., Staubwasser, M., von Blanckenburg, F., 2008. The stable Cr isotope inventory of solid Earth reservoirs determined by double spike MC-ICP-MS. Chemical Geology 249 (34), 294-306.

Schulze, H., Bischoff, A., Palme, H., Spettel, B., Dreibus, G., Otto, J., 1994. Mineralogy and chemistry of Rumuruti: The first meteorite fall of the new $\mathrm{R}$ chondrite group. Meteoritics 29 (2), 275286.

Sears, D. W. G., Batchelor, J. D., Mason, B., Scott, E. R. D., Clayton, R. N., Mayeda, T. K., 1990. South Australian type 3 chondrites. Meteoritics 25 (4), 407-408.

Seifert, S., Ringwood, A. E., 1988. The lunar geochemistry of chromium and vanadium. Earth, Moon and Planets 40 (1), 45-70.

Shariff, K., 2009. Fluid mechanics in disks around young stars. Annual Review of Fluid Mechanics 41 (1), 283-315.

Sharp, Z. D., Mercer, J. A., Jones, R. H., Brearley, A. J., Selverstone, J., Bekker, A., Stachel, T., 2013. The chlorine isotope composition of chondrites and Earth. Geochimica et Cosmochimica Acta 107, 189-204.

Sharp, Z. D., Shearer, C. K., McKeegan, K. D., Barnes, J. D., Wang, Y. Q., 2010. The chlorine isotope composition of the Moon and implications for an anhydrous mantle. Science 329 (5995), 1050-3.

Shearer, C. K., Righter, K., 2003. Behavior of tungsten and hafnium in silicates: A crystal chemical basis for understanding the early evolution of the terrestrial planets. Geophysical Research Letters 30 (1), 7-1-7-4.

Shukolyukov, A., Lugmair, G., 2006a. Manganese-chromium isotope systematics of carbonaceous chondrites. Earth and Planetary Science Letters 250 (1-2), 200-213.

Shukolyukov, A., Lugmair, G. W., 2006b. The Mn-Cr isotope systematics in the ureilites Kenna and LEW85440. In: Lunar and Planetary Science Conference Abstracts. Vol. 37. p. 1478.

Shukolyukov, A., Lugmair, G. W., Irving, A. J., 2009. Mn-Cr isotope systematics of angrite Northwest Africa 4801. In: Lunar and Planetary Science Conference Abstracts. Vol. 40. p. 1381.

Simon, S. B., Grossman, L., Casanova, I., Symes, S., Benoit, P., Sears, D. W. G., Wacker, J. F., 1995. Axtell, a new CV3 chondrite find from Texas. Meteoritics 30 (1), 42-46.

Sio, C. K., Borg, L. E., Cassata, W. S., 2020. The timing of lunar solidification and mantle overturn recorded in ferroan anorthosite 62237. Earth and Planetary Science Letters 538, 116219.

Snyder, G. A., Neal, C. R., Taylor, L. A., Halliday, A. N., 1995. Processes involved in the formation of magnesian-suite plutonic rocks from the highlands of the Earth's Moon. Journal of Geophysical Research 100 (E5), 9365-9388.

Solomatov, V. S., Stevenson, D. J., 1993a. Kinetics of crystal growth in a terrestrial magma ocean. Journal of Geophysical Research 98 (E3), 5407.

Solomatov, V. S., Stevenson, D. J., 1993b. Nonfractional crystallization of a terrestrial magma ocean. Journal of Geophysical Research 98 (E3), 5391-5406.

Solomatov, V. S., Stevenson, D. J., 1993c. Suspension in convective layers and style of differentiation of a terrestrial magma ocean. Journal of Geophysical Research 98 (E3), 5375.
Sossi, P. A., Klemme, S., O'Neill, H. S. C., Berndt, J., Moynier, F., 2019. Evaporation of moderately volatile elements from silicate melts: Experiments and theory. Geochimica et Cosmochimica Acta 260, 204-231.

Sossi, P. A., Moynier, F., 2017. Chemical and isotopic kinship of iron in the Earth and Moon deduced from the lunar Mg-Suite. Earth and Planetary Science Letters 471, 125-135.

Sossi, P. A., Moynier, F., van Zuilen, K., 2018. Volatile loss following cooling and accretion of the Moon revealed by chromium isotopes. Proceedings of the National Academy of Sciences 115 (43), 1092010925.

Sprung, P., Kleine, T., Scherer, E. E., 2013. Isotopic evidence for chondritic $\mathrm{Lu} / \mathrm{Hf}$ and $\mathrm{Sm} / \mathrm{Nd}$ of the Moon. Earth and Planetary Science Letters 380, 77-87.

Steenstra, E. S., Berndt, J., Klemme, S., Fei, Y., van Westrenen, W., 2020. A possible high-temperature origin of the Moon and its geochemical consequences. Earth and Planetary Science Letters 538,116222 .

Steenstra, E. S., Lin, Y., Dankers, D., Rai, N., Berndt, J., Matveev, S., van Westrenen, W., 2017. The lunar core can be a major reservoir for volatile elements S, Se, Te and Sb. Scientific Reports 7 (1), 14552 .

Steenstra, E. S., Rai, N., Knibbe, J. S., Lin, Y. H., van Westrenen, W., 2016. New geochemical models of core formation in the Moon from metal-silicate partitioning of 15 siderophile elements. Earth and Planetary Science Letters 441, 1-9.

Stephant, A., Anand, M., Zhao, X., Chan, Q. H., Bonifacie, M., Franchi, I. A., 2019. The chlorine isotopic composition of the Moon: Insights from melt inclusions. Earth and Planetary Science Letters 523, 115715.

Stepniewski, M., Borucki, J., Siemiatkowski, J., 1998. New data on the L5(S1) chondrite Baszkowka (Poland). Meteoritics \& Planetary Science 33, A150-A151.

Tartèse, R., Anand, M., Joy, K. H., Franchi, I. A., 2014. H and $\mathrm{Cl}$ isotope systematics of apatite in brecciated lunar meteorites Northwest Africa 4472, Northwest Africa 773, Sayh al Uhaymir 169, and Kalahari 009. Meteoritics and Planetary Science 49 (12), 2266-2289.

Taylor, D. J., McKeegan, K. D., Harrison, T. M., 2009. Lu-Hf zircon evidence for rapid lunar differentiation. Earth and Planetary Science Letters 279 (3-4), 157-164.

Taylor, G. J., Wieczorek, M. A., 2014. Lunar bulk chemical composition: A post-Gravity Recovery and Interior Laboratory reassessment. Philosophical Transactions of the Royal Society A: Mathematical, Physical and Engineering Sciences 372 (2024), 20130242.

Taylor, S. R., 1982. Planetary science: A lunar perspective. Lunar and Planetary Institute.

Taylor, S. R., 2014. The Moon re-examined. Geochimica et Cosmochimica Acta 141, 670-676.

Taylor, S. R., McLennan, S., 2009. Planetary crusts: Their composition, origin and evolution. Cambridge University Press.

Thiemens, M. M., Sprung, P., Fonseca, R. O., Leitzke, F. P., Münker, C., 2019. Early Moon formation inferred from hafnium-tungsten systematics. Nature Geoscience 12 (9), 696-700.

Thompson, C., Stevenson, D. J., 1988. Gravitational instability in two-phase disks and the origin of the Moon. The Astrophysical Journal 333, 452.

Tian, Z., Wisdom, J., Elkins-Tanton, L., 2017. Coupled orbitalthermal evolution of the early Earth-Moon system with a fastspinning Earth. Icarus 281, 90-102.

Touboul, M., Liu, J., O'Neil, J., Puchtel, I. S., Walker, R. J., 2014. New insights into the Hadean mantle revealed by ${ }^{182} \mathrm{~W}$ and highly siderophile element abundances of supracrustal rocks from the Nuvvuagittuq Greenstone Belt, Quebec, Canada. Chemical Geology $383,63-75$.

Touboul, M., Puchtel, I. S., Walker, R. J., 2012. ${ }^{182}$ W evidence for long-term preservation of early mantle differentiation products. Science 335 (6072), 1065-9.

Touboul, M., Puchtel, I. S., Walker, R. J., 2015. Tungsten isotopic evidence for disproportional late accretion to the Earth and Moon. Nature 520, 530-533. 
Treiman, A. H., Boyce, J. W., Gross, J., Guan, Y., Eiler, J. M., Stolper, E. M., 2014. Phosphate-halogen metasomatism of lunar granulite 79215: Impact-induced fractionation of volatiles and incompatible elements. American Mineralogist 99 (10), 1860-1870.

Trinquier, A., Birck, J., Allegre, C. J., 2007. Widespread ${ }^{54} \mathrm{Cr}$ heterogeneity in the inner solar system. The Astrophysical Journal 655 (2), 1179-1185.

Trinquier, A., Elliott, T., Ulfbeck, D., Coath, C., Krot, A. N., Bizzarro, M., 2009. Origin of nucleosynthetic isotope heterogeneity in the solar protoplanetary disk. Science 324 (5925), 374-376.

Tucker, J. M., Mukhopadhyay, S., 2014. Evidence for multiple magma ocean outgassing and atmospheric loss episodes from mantle noble gases. Earth and Planetary Science Letters 393, 254-265.

Tucker, J. M., Mukhopadhyay, S., Schilling, J.-G., 2012. The heavy noble gas composition of the depleted MORB mantle (DMM) and its implications for the preservation of heterogeneities in the mantle. Earth and Planetary Science Letters 355-356, 244-254.

Valley, J. W., Cavosie, A. J., Ushikubo, T., Reinhard, D. A., Lawrence, D. F., Larson, D. J., Clifton, P. H., Kelly, T. F., Wilde, S. A., Moser, D. E., Spicuzza, M. J., 2014. Hadean age for a post-magma-ocean zircon confirmed by atom-probe tomography. Nature Geoscience 7 (3), 219-223.

Vockenhuber, C., Oberli, F., Bichler, M., Ahmad, I., Quitté, G., Meier, M., Halliday, A. N., Lee, D. C., Kutschera, W., Steier, P., Gehrke, R. J., Helmer, R. G., 2004. New half-life measurement of ${ }^{182}$ Hf: Improved chronometer for the early solar system. Physical Review Letters 93 (17), 172501.

Walker, R. J., 2009. Highly siderophile elements in the Earth, Moon and Mars: Update and implications for planetary accretion and differentiation. Chemie der Erde - Geochemistry 69 (2), 101-125.

Wang, K., Jacobsen, S. B., 2016. Potassium isotopic evidence for a high-energy giant impact origin of the Moon. Nature 538 (7626), 487-490.

Wang, X., Amet, Q., Fitoussi, C., Bourdon, B., 2018. Tin isotope fractionation during magmatic processes and the isotope composition of the bulk silicate Earth. Geochimica et Cosmochimica Acta $228,320-335$.

Wang, X., Fitoussi, C., Bourdon, B., Fegley, B., Charnoz, S., 2019a. Tin isotopes indicative of liquid-vapour equilibration and separation in the Moon-forming disk. Nature Geoscience 12 (9), 707-711.

Wang, Y., Hsu, W., Guan, Y., 2019b. An extremely heavy chlorine reservoir in the Moon: Insights from the apatite in lunar meteorites. Scientific Reports 9 (1), 5727.

Wänke, H., Baddenhausen, H., Blum, K., Cendales, M., Dreibus, G., Hofmeister, H., Kruse, H., Jagoutz, E., Palme, C., Spettel, B., 1977. On the chemistry of lunar samples and achondrites - Primary matter in the lunar highlands: A re-evaluation. In: Lunar and Planetary Science Conference Abstracts. Vol. 2. pp. 2191-2213.

Wänke, H., Dreibus, G., 1982. Chemical composition and isotopic evidence for the early history of the Earth-Moon system. In: Brosche, P., Sündermann, J. (Eds.), Tidal friction and the Earth's rotation II. Springer-Verlag, pp. 322-344.

Wanke, H., Palme, H., Baddenhausen, H., Dreibus, G., Kruse, H., Spettel, B., 1977. Element correlations and the bulk composition of the Moon. Philosophical Transactions of the Royal Society A: Mathematical, Physical and Engineering Sciences 285 (1327), 4148.

Ward, W. R., 2017. Evolution of a protolunar disk in vapor/melt equilibrium. Journal of Geophysical Research: Planets 122 (2), 342-357.

Warren, P. H., 1985. The magma ocean concept and lunar evolution. Annual Review of Earth and Planetary Sciences 13 (1), 201-240.

Warren, P. H., 2005. "New" lunar meteorites: Implications for composition of the global lunar surface, lunar crust, and the bulk Moon. Meteoritics \& Planetary Science 40 (3), 477-506.

Weber, D., Clayton, R. N., Mayeda, T. K., Bischoff, A., 1996. Unusual equilibrated carbonaceous chondrites and CO3 meteorites from the Sahara. In: Lunar and Planetary Science Conference Abstracts. Vol. 27. p. 1395.

Weber, D., Schultz, L., Weber, H. W., Clayton, R. N., Mayeda, T. K., Bischoff, A., 1997. Hammadah AL Hamra 119 - A new, un- brecciated Saharan Rumuruti chondrite. In: Lunar and Planetary Science Conference Abstracts. Vol. 28. p. 1511.

Weber, R. C., Lin, P.-Y., Garnero, E. J., Williams, Q., Lognonné, P., 2011. Seismic detection of the lunar core. Science 331 (6015), 309-12.

Weisberg, M., Prinz, M., Clayton, R., Mayeda, T., Grady, M., Pillinger, C., 1995. The CR chondrite clan. Proceedings of the NIPR Symposium on Antarctic Meteorites 8, 11-32.

Weisberg, M. K., Prinz, M., Clayton, R. N., Mayeda, T. K., 1993. The CR (Renazzo-type) carbonaceous chondrite group and its implications. Geochimica et Cosmochimica Acta 57 (7), 1567-1586.

Weisberg, M. K., Prinz, M., Clayton, R. N., Mayeda, T. K., 1997. CV3 chondrites: Three subgroups, not two. Meteoritics \& Planetary Science 32, A138-A139.

Weisberg, M. K., Prinz, M., Clayton, R. N., Mayeda, T. K., Grady, M. M., Franchi, I., Pillinger, C. T., Kallemeyn, G. W., 1996. The $\mathrm{K}$ (Kakangari) chondrite grouplet. Geochimica et Cosmochimica Acta 60 (21), 4253-4263.

Weisberg, M. K., Prinz, M., Kojima, H., Yanai, K., Clayton, R. N., Mayeda, T. K., 1991. The Carlisle Lakes-type chondrites: A new grouplet with high $\Delta^{17} \mathrm{O}$ and evidence for nebular oxidation. Geochimica et Cosmochimica Acta 55 (9), 2657-2669.

Wetherill, G. W., 1975. Radiometric chronology of early SolarSystem. Annual Review of Nuclear Science 25 (1), 283-328.

Wiechert, U., Halliday, A. N., Lee, D. C., Snyder, G. A., Taylor, L. A., Rumble, D., 2001. Oxygen isotopes and the Moon-forming giant impact. Science 294 (5541), 345-8.

Wilde, S. A., Valley, J. W., Peck, W. H., Graham, C. M., 2001. Evidence from detrital zircons for the existence of continental crust and oceans on the Earth 4.4 Gyr ago. Nature 409 (6817), 175-178.

Willbold, M., Elliott, T., Moorbath, S., 2011. The tungsten isotopic composition of the Earth's mantle before the terminal bombardment. Nature 477 (7363), 195-198.

Willbold, M., Mojzsis, S. J., Chen, H. W., Elliott, T., 2015. Tungsten isotope composition of the Acasta Gneiss Complex. Earth and Planetary Science Letters 419, 168-177.

Williams, J. G., Konopliv, A. S., Boggs, D. H., Park, R. S., Yuan, D.-N., Lemoine, F. G., Goossens, S., Mazarico, E., Nimmo, F., Weber, R. C., Asmar, S. W., Melosh, H. J., Neumann, G. A., Phillips, R. J., Smith, D. E., Solomon, S. C., Watkins, M. M., Wieczorek, M. A., Andrews-Hanna, J. C., Head, J. W., Kiefer, W. S., Matsuyama, I., McGovern, P. J., Taylor, G. J., Zuber, M. T., 2014. Lunar interior properties from the GRAIL mission. Journal of Geophysical Research: Planets 119 (7), 1546-1578.

Wimpenny, J., Marks, N., Knight, K., Rolison, J. M., Borg, L., Eppich, G., Badro, J., Ryerson, F. J., Sanborn, M., Huyskens, M. H., Yin, Q.-z., 2019. Experimental determination of Zn isotope fractionation during evaporative loss at extreme temperatures. Geochimica et Cosmochimica Acta 259, 391-411.

Wisdom, J., Tian, Z., 2015. Early evolution of the Earth-Moon system with a fast-spinning Earth. Icarus 256, 138-146.

Yamakawa, A., Yamashita, K., Makishima, A., Nakamura, E., 2010. Chromium isotope systematics of achondrites: Chronology and isotopic heterogeneity of the inner solar system bodies. Astrophysical Journal 720 (1), 150-154.

Yamashita, K., Maruyama, S., Yamakawa, A., Nakamura, E., 2010. ${ }^{53} \mathrm{Mn}-{ }^{53} \mathrm{Cr}$ chronometry of $\mathrm{CB}$ chondrite: Evidence for uniform distribution of ${ }^{53} \mathrm{Mn}$ in the early solar system. Astrophysical Journal 723 (1), 20-24.

Yamashita, K., Ueda, T., Najamura, N., Kita, N., Heaman, L. M., 2005. Chromium isotopic study of Mesosiderite and Ureilite: Evidence for $\epsilon^{54} \mathrm{Cr}$ deficit in differentiated meteorites. In: NIPR Symposium on Antarctic Meteorites. Vol. 29. pp. 100-101.

Yin, Q., Jacobsen, S. B., Yamashita, K., 2002. Diverse supernova sources of pre-solar material inferred from molybdenum isotopes in meteorites. Nature 415 (6874), 881-883.

Yokochi, R., Marty, B., 2005. Geochemical constraints on mantle dynamics in the Hadean. Earth and Planetary Science Letters $238(1-2), 17-30$.

Yoshino, T., Makino, Y., Suzuki, T., Hirata, T., 2020. Grain boundary diffusion of $\mathrm{W}$ in lower mantle phase with implications for 
isotopic heterogeneity in oceanic island basalts by core-mantle interactions. Earth and Planetary Science Letters 530, 115887.

Young, E. D., Kohl, I. E., Warren, P. H., Rubie, D. C., Jacobson, S. A., Morbidelli, A., 2016. Oxygen isotopic evidence for vigorous mixing during the Moon-forming giant impact. Science 351 (6272), 493-496.

Young, E. D., Tang, H., 2019. Isotopic fractionation of moderately volatile elements during Moon formation. In: Lunar and Planetary Science Conference Abstracts. Vol. 50. p. 1941.

Zhang, J., Dauphas, N., Davis, A. M., Leya, I., Fedkin, A., 2012. The proto-Earth as a significant source of lunar material. Nature Geoscience 5 (4), 251-255.

Zhang, J., Dauphas, N., Davis, A. M., Pourmand, A., 2011. A new method for MC-ICPMS measurement of titanium isotopic composition: Identification of correlated isotope anomalies in meteorites. Journal of Analytical Atomic Spectrometry 26 (11), 2197-2205.

Zolensky, M. E., Mittlefehldt, D. W., Lipschutz, M. E., Wang, M.S., Clayton, R. N., Mayeda, T. K., Grady, M. M., Pillinger, C., Barber, D., 1997. CM chondrites exhibit the complete petrologic range from type 2 to 1 . Geochimica et Cosmochimica Acta 61 (23), 5099-5115.

Zolensky, M. E., Mittlefehldt, D. W., Lipschutz, M. E., Xiao, X., Clayton, R. N., Mayeda, T. K., Barrett, R. A., Grady, M. M., 1989. The composition and mineralogy of EET 83334. Meteoritics 24,345 . 